\title{
The building blocks of workplace inclusion
}

Citation for published version (APA):

Nelissen, P. T. J. H. (2017). The building blocks of workplace inclusion. [Doctoral Thesis, Maastricht University]. Maastricht University. https://doi.org/10.26481/dis.20170512pn

Document status and date:

Published: 01/01/2017

DOI:

10.26481/dis.20170512pn

Document Version:

Publisher's PDF, also known as Version of record

\section{Please check the document version of this publication:}

- A submitted manuscript is the version of the article upon submission and before peer-review. There can be important differences between the submitted version and the official published version of record.

People interested in the research are advised to contact the author for the final version of the publication, or visit the DOI to the publisher's website.

- The final author version and the galley proof are versions of the publication after peer review.

- The final published version features the final layout of the paper including the volume, issue and page numbers.

Link to publication

\footnotetext{
General rights rights.

- You may freely distribute the URL identifying the publication in the public portal. please follow below link for the End User Agreement:

www.umlib.nl/taverne-license

Take down policy

If you believe that this document breaches copyright please contact us at:

repository@maastrichtuniversity.nl

providing details and we will investigate your claim.
}

Copyright and moral rights for the publications made accessible in the public portal are retained by the authors and/or other copyright owners and it is a condition of accessing publications that users recognise and abide by the legal requirements associated with these

- Users may download and print one copy of any publication from the public portal for the purpose of private study or research.

- You may not further distribute the material or use it for any profit-making activity or commercial gain

If the publication is distributed under the terms of Article $25 \mathrm{fa}$ of the Dutch Copyright Act, indicated by the "Taverne" license above, 


\section{THE BUILDING BLOCKS OF WORKPLACE INCLUSION}

Philippe T.J.H. Nelissen 

THE BUILDING BLOCKS

OF WORKPLACE INCLUSION 


\section{Colophon}

Cover design by Marleen Kurvers - www.oode.nl

Creative editor Francien Hazen - www.fraz.nl

Cover illustration of the Diffuser Cabinet by Dirk Vander Kooij - www.dirkvanderkooij.com Layout and printed by: Gildeprint - www.gildeprint.nl

ISBN 978-94-6233-589-9

(c) Philippe T.J.H. Nelissen, Maastricht 2017

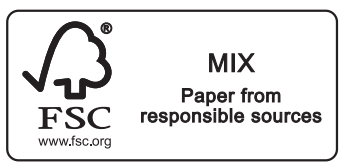

All rights reserved. No parts of this book may be reproduced or transmitted in any form or by any means, without permission from the author or, when appropriate, the publisher of the article. 


\section{THE BUILDING BLOCKS OF WORKPLACE INCLUSION}

\section{PROEFSCHRIFT}

ter verkrijging van de graad van doctor aan de Universiteit Maastricht, op gezag van de Rector Magnificus, Prof. dr. Rianne Letschert

volgens het besluit van het College van Decanen,

in het openbaar te verdedigen

op vrijdag 12 mei 2017 om 14 uur

door

Philippe Theodoor Julien Hendrik Nelissen 
Promotor

Prof. dr. F.R.H. Zijlstra

\section{Copromotor}

Dr. U.R. Hülsheger

\section{Beoordelingscommissie}

Prof. dr. R.A.C. Ruiter (voorzitter)

Prof. dr. S. Brouwer (Rijksuniversiteit Groningen)

Prof. dr. P.A.E.G. Delespaul

Prof. dr. C.M. van Heugten

Prof. dr. G. Kok
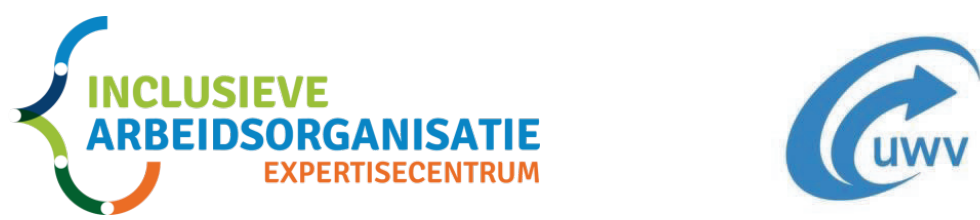

This work was supported by the Dutch Employee Insurance Agency UWV. 


It's not that easy being green

Having to spend each day the color of the leaves

When I think it could be... nicer

Being red or yellow or gold or something much more colorful like that

It's not easy being green

It seems your blending with so many other ordinary things

And people tend to pass you over

Cause you're not standing out like fleece sparkles in the water or stars in the sky

But green's the color of spring

And green can be cool and friendly like

And green can be big like an ocean

Or important like a mountain

Or tall like a tree

When green is all there is to be

It could make you wonder why

But why wonder why wonder

I'm green and it'll do fine

It's beautiful

And I think it's what I wanna be

- Kermit the Frog, the Muppet Show (1977) 



\section{Table of contents}

Chapter $1 \quad$ Introduction 11

Chapter 2 How and When Stereotypes Relate to Helping

Behavior toward People with Disabilities

Chapter 3 Lending a Helping Hand at Work:

A Multilevel Investigation of Prosocial Motivation, Inclusive Climate and Inclusive Behavior

Chapter 4 With a Little Help from my Team:

Well-Being of People with Disabilities at Work

Chapter 5 Disclosure or non-disclosure - is this the question?

Chapter 6 General Discussion

References

Appendix

Valorization

Summary

Samenvatting

Dankwoord

Curriculum Vitae

Publications 


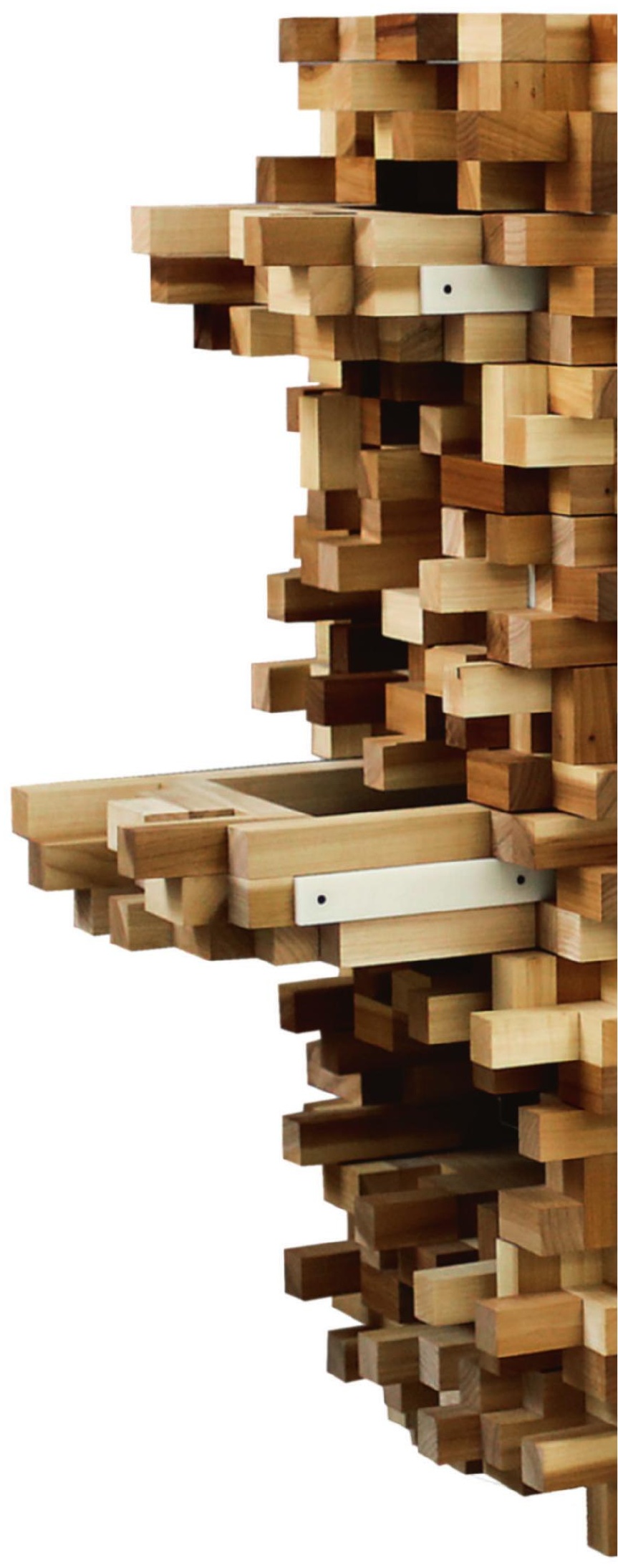


CHAPTER 1

Introduction 
Chapter 1 


\title{
Introduction
}

\begin{abstract}
"In het Nederland waar ik wil wonen, doet iedereen mee. Man en vrouw, jong en oud, hier geboren en van ver, mensen met en zonder arbeidsbeperking. ledereen die kan werken, moet de kans krijgen dat ook te doen. Daarom ben ik supergemotiveerd om er voor te zorgen dat zoveel mogelijk mensen aan de slag gaan" Jetta Klijnsma, Staatssecretaris van Social zaken en Werkgelegenheid, Nederland (Rijksoverheid, 2015)

"In the Netherlands, the country where I want to live, everyone participates. Man and woman, young and old, indigenous or immigrant, people with and without a work disability. Anyone who is able to work should have the opportunity to do so. That is why I am extremely motivated to make sure that as many people as possible get to work." Jetta Klijnsma, Dutch State Secretary Social Affairs and Employment Opportunities (translated by author) (Rijksoverheid, 2015).
\end{abstract}

Workplace inclusion, particularly for people with disabilities, is the main goal that Jetta Klijnsma, the Dutch State Secretary of Social Affairs and Employment Opportunities, wants to accomplish when she addressed the Dutch Parliament and its constituents with this message. In the implementation of her vision on workplace inclusion for people with disabilities, there is a strong focus on "yes we can!", rather than "no we cannot" participate. Having access to work is vital as it allows individuals to become part of a community (Jahoda, 1981). Therefore, to achieve workplace inclusion for people with disabilities, every person with the ability to work should be facilitated to do so, instead of pushing them to the outskirts of society as has often been the case throughout history. To achieve this workplace inclusion in the Netherlands, Klijnsma recently introduced the Participation Act (2015), which aims to facilitate the employment of 125.000 people with disabilities in regular organizations over the next decade.

Creating employment opportunities for people with disabilities is not a sole Dutch matter; the European Commission advocates for a voluntary intake of the norms and values that go along with the view on Corporate Social Responsibility (European Commission, 2011). European organizations are invited to go beyond legal regulations and integrate social and environmental concerns to create sustainable employment. With regard to the employment of people with a large distance to the labor market, organizations are encouraged to facilitate their intake and integration in the global workforce. Similarly, 
in 1990 the US passed the Americans with Disabilities Act (ADA), which was more recently fortified into the ADA Amendments Act (ADAAA, 2008). These Acts are designed to prevent people with disabilities to be discriminated based on their disability in all aspects of life, and particularly for employment related issues. In all, whether it concerns guidelines or enforceable Acts, policymakers are aware that employment difficulties for people with disabilities need to be remedied.

It seems clear that as far as legislation is concerned, some of the obstacles towards employment for people with disabilities appear to have been removed. Nevertheless, although attaining work is a prerequisite, there is a need to ensure the sustainable employment of people with disabilities. Creating employment opportunities alone does not suffice, building tenure is essential, especially considering the high turnover rates for people with disabilities (Bosch, Overmars-Marx, Ooms, \& Zwinkels, 2009). Making sure that not only obstacles to obtain work are dealt with, but also those obstacles that become extant once work has commenced should therefore not escape our attention. The conditions at the workplace such as accommodations, guidance, supervisors, teams and colleagues might have a large influence on the level of workplace inclusion. It is with these thoughts in mind that the main research question of this dissertation has arisen: What are the building blocks of workplace inclusion for people with disabilities? As such, this is a problem driven research, and therefore I will use psychological theories and perspectives to advance the issues concerning workplace inclusion for people with disabilities (Ruiter, Massar, van Vugt, \& Kok, 2013). In this way I aim to generate knowledge on workplace inclusion which might be used as guidelines for organizations that wish to employ people with disabilities. Additionally, my goal is to make a scientific contribution to the literature on employment for people with disabilities, to identify factors that contribute to workplace inclusion, as well as to further knowledge on what happens to people with disabilities once they enter the workplace. More specifically, this dissertation offers three main contributions to theory and scientific research literature, in the domain of research on people with disabilities at work, within the literature on Organizational Citizenship Behavior, and by adopting a multilevel approach in team climate research.

Firstly, in the domain of research on people with disabilities at work, I aim to extend knowledge on the work situation of people with disabilities. While research on people with disabilities has often revolved around the legal protection with regard to equal employment opportunities (Kruse \& Schur, 2003), or on the perspective of the employer with regard to accommodation costs (Peck \& Kirkbride, 2001), as well as their (negatively) biased employment perspectives (Hunt \& Hunt, 2004), this dissertation will address the scarcity of research on the workplace inclusion of people with disabilities who passed the first hurdles towards employment and are currently working. This scarcity of research on the work situation of people with disabilities is surprising as theories and knowledge within the field 
of Industrial an Organizational Psychology are readily applicable to this demographic group. Therefore, rather than focusing on the enabling characteristics of people with disabilities themselves, such as proactive or impression management behavior (Colella, DeNisi, \& Varma, 1997) or whether disability disclosure is a reasonable course of action (Santuzzi, Waltz, Finkelstein, \& Rupp, 2014), an encompassing 360 degree approach is proposed in which the employee (colleagues), job, as well as organizational characteristics are taken into consideration. To be more specific, in the articles presented in this dissertation it will be illustrated how prosocial motivation, stereotypes towards people with disabilities, attitudes towards the employment of people with disabilities, work pressure, (team) inclusive behavior, inclusive climate, and well-being of people with disabilities constitute the primary building blocks of workplace inclusion for people with disabilities.

Secondly, this dissertation adds to the theory and research literature on organizational citizenship behavior $(O C B)$ by applying this established construct in the domain of employment for people with disabilities. A new and tailored version of helping behavior specifically toward people with disabilities, labeled 'inclusive behavior', is introduced. Inclusive behavior is an extra-role behavior directed at facilitating and benefiting one's colleague with a disability in the work team. The studies presented in this dissertation utilize inclusive behavior as a central factor; as an independent and dependent variable, as well as at both the individual and the team level of analysis. Additionally, a research gap in potential beneficial outcomes of citizenship behavior is addressed. Although OCB is a widely and extensively studied concept (Podsakoff, Whiting, Podsakoff, \& Blume, 2009; Podsakoff, MacKenzie, Paine, \& Bachrach, 2000), outcomes of citizenship behavior have mostly dealt with performance related outcomes such as performance ratings and reward allocation, as well as absenteeism and turnover intentions (Podsakoff et al., 2009). Yet, well-being related outcomes for the recipients of such acts of citizenship are scarce, which is surprising given the fact that (specifically for OCB-I (Williams \& Anderson, 1991)) these are intended to benefit others. Especially with sustainable employment in mind, the positive effects of citizenship behavior on employee well-being may develop into an exciting new research area.

Thirdly, this dissertation on workplace inclusion aims to complement the climate research literature. Climate represents the perceptions of a team on the daily policies, practices and procedures, and refers to a specific topic (Schneider, 2000; Schneider \& Reichers, 1983). Thus to gauge a climate for workplace inclusion, the novel concept of 'inclusive climate' is introduced to represent team members' norms and perceptions of the way people with disabilities are accepted, helped, and treated in their team. The effects of inclusive climate, especially as a team level boundary condition on individual level relationships, may add supplementary insight on the occurrence of workplace inclusion. In addition, in accordance with the research trend of using the unit level of analysis of citizenship behaviors (Ehrhart, 
Bliese, \& Thomas, 2006; Ehrhart \& Naumann, 2004; Podsakoff, Podsakoff, Mackenzie, Maynes, \& Spoelma, 2014), and in continuation of individual level inclusive behavior, team inclusive behavior is introduced. Because of the premise that "it is only in the aggregate and over time" (p.91) that these behaviors have beneficial consequences for the recipient and therefore the organization itself (Podsakoff et al., 2014), the effects of team inclusive behavior on the well-being of people with disabilities will be examined. By utilizing a multilevel model, it is shown that factors at both the individual and team level play a role in the display of inclusive behavior, and may consequently relate to the well-being of people with disabilities.

As it is essential to grasp the background that describes the employment issues of people with disabilities in detail which lead to the genesis of my research questions, this introduction will proceed as follows: I first provide information on our target group within the Netherlands, then I explain why the work participation of people with disabilities is low, to continue with insight on why society needs to take action (now). Additionally, to create the foundation to pursue my research goals, I will provide an overview of current literature on the field of sustainable employment for people with disabilities.

\section{People with Disabilities in the Netherlands}

In this dissertation I discuss the boundary conditions concerning the sustainable employment of people with disabilities. It is therefore necessary to first take a closer look at the target group of this research to present a more precise image of people with disabilities. Consequently, by providing more information I aim to adjust the common stereotypical view on the prevalence and functioning of people with disabilities.

In this research I focused on a specific Dutch group with disabilities, which are labeled as the "Wajong". The term Wajong originates from the Dutch Act "Wet Werk en Arbeidsondersteuning Jonggehandicapten (1998)". Before the introduction of the Participation Act in 2015, all Dutch people that suffered from a disability before the age of 18 , that prevented them to work, were guaranteed to be included by this Act for the duration of their disability. Currently more than 250.000 people make use of this social safety net (CBS, 2015) ${ }^{1}$. In the Wajong, only $14 \%$ has a somatic clinical picture, whereas $39 \%$ has an intellectual disability, $19 \%$ were identified with a psychiatric syndrome, $16 \%$ is diagnosed with autism, $7 \%$ suffers from attention deficit disorders, and $5 \%$ has other developmental disorders. Striking is that over $50 \%$ of this group is diagnosed with more than 1 disorder. In total, $86 \%$ of people with disabilities have some sort of mental disorder.

\footnotetext{
${ }^{1}$ As of the $1^{\text {st }}$ of January 2015, the Participation Act has gone into effect. Consequently the label of Wajong will disappear and evolve to a label that indicates the fitness to work for people with disabilities. Those who are able to work will be supported by the government (UWV) or the municipalities in search for work. Evidently, the population which has a large distance to labor market will not change and the outcomes of our research will still relate to their workplace inclusion.
} 


\section{Disability Diagnosis}

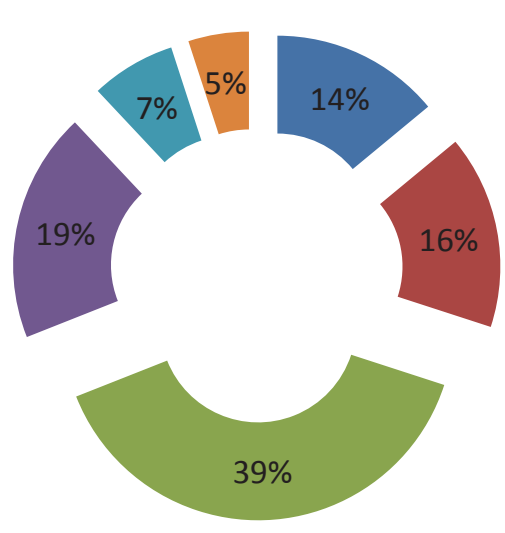

- Somatic Disability

autism

- Intellectual Disability

- Psychiatric Syndrome Attention Deficit
Disorder

- Developmental Disorder

Figure 1. Disability prevalence by diagnosis.

Considering the educational level of people in the Wajong, it becomes apparent that only a minority of $15 \%$ graduated from university or college, whereas $35 \%$ obtained an intermediate vocational education degree, and $50 \%$ had a practical training in high school. Partly related to the educational level of people with disabilities, some qualitative research findings have led to the division of five categories of people with disabilities (Van der Pijl, Waasdorp, \& Oonk, 2014). The severity of disability increases from 1 to 5 , therefore making those in category 1 the most attractive for potential employers as they require fewer employer and employee investment. Most people with disabilities ranked within the first type will have a physical disability, a higher degree of education, a low need for support, and have the capability to develop themselves. Those who are ranked in type 2 and 3 will have an educational degree and the ability to work, albeit with the correct guidance. People with disabilities ranked in type 2 are characterized as mostly having a developmental disability, in type 3 people with disabilities mostly have a mild intellectual disability. Whereas people with disabilities in type 4 and 5 will most likely not be eligible for work as their disability is too severe (Van der Pijl et al., 2014). 


\section{Disability Type}

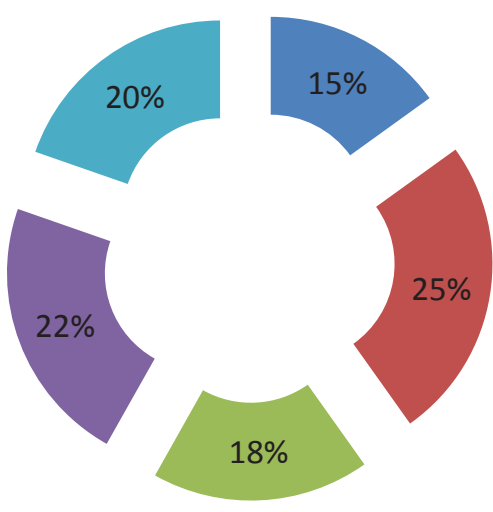

type 1

type2

type 3

type 4

type 5

Figure 2. Disability prevalence by type.

Taking the numbers of these categories into account, it becomes apparent that, regardless of the severity of their limitations, $58 \%$ of people with disabilities in the Netherlands are eligible to perform work. However, only about 23\% of Dutch people with disabilities (Wajong) are currently employed (Paling, 2013; UWV, 2015), and even when people with disabilities acquire work, there appears to be a high degree of turnover (Bosch et al., 2009). Half of the working people with disabilities work for a regular employer, the other half is employed in government sponsored social employment facilities (UWV, 2013). Of those that are employed by a regular employer, $58 \%$ uses some form of governmentally organized support at the workplace. It is obvious that these employment numbers do not yet meet the intentions stated by the European Commission. In the next paragraphs reasons will be put forward in an effort to explain the current low number of work participation for people with disabilities.

\section{The Low Work Participation of People with Disabilities}

Creating sustainable work opportunities for people with disabilities is a universal challenge. In the Netherlands, the employment rate of 23\% for people with disabilities (Paling, 2013; UWV, 2015), is in high contrast with the 70\% (aged 15-75) of the Dutch general labor force that is employed (CBS, 2015). In Europe only $24 \%$ of people with disabilities is employed, versus $64 \%$ of people without disabilities (aged 15-64) (Eurostat, 2001), in the US less than $18 \%$ of people with disabilities is active, versus $64 \%$ of people without disabilities (18-65) (Bureau of Labor Statistics, 2015). Overall it appears that there is a high similarity in the difference between the employment rate of people with disabilities and those without 
disabilities in the western world. These statistics therefore show that there is definitely room for improvement to tighten the gap between the employment rates of both groups.

There are various reasons as to why people with disabilities have lower work participation. First, people with a low education level, such as the majority of people with disabilities, generally have a higher distance to the labor market (Zijlstra, Mulders, \& Nijhuis, 2012). This distance has arisen because work has evolved from simple assembly-line production work, to complex jack of all trades professions. In the aftermath of World War 2, manual labor was necessary to rebuild the economy as well as the society. Gradually, technology made its entry in organizational functioning to facilitate automation, computerization and robotization processes, thereby diminishing the amount of low-skilled work. Moreover, most manual production work has shifted from western-European countries to "low-wage countries". Therefore, the shift towards a tertiary and quaternary economy (service industry) has caused a further diminishment of jobs entailing simpler work activities (Zijlstra, 2009; Zijlstra et al., 2012). Consequently, work has become more complex because educational demands for jobs are set at an all-time high and employees are expected to function optimally in teams. That is, to function well in a team, team members should possess social skills, certain personality facets such as high conscientiousness and teamwork knowledge (Morgeson, Reider, \& Campion, 2005), which are all difficult abilities to master. Furthermore, more complex jobs in a growing service industry have led to additional job demands that require a level in professional skills in interpersonal communication as well as a variety of knowledge on planning, problem solving, technology and flexibility (Johnson, Mermin, \& Resseger, 2007; Zijlstra, 2009). In sum, attaining and retaining work in a high demanding labor market is difficult. Especially for people with disabilities the gap between skills and demands has become too large to bridge on their own.

Second, besides work becoming increasingly complex, the low work participation of people with disabilities appears to be related to the organization's hiring intentions (Bosch et al., 2009; Kaye, Jans, \& Jones, 2011; Peck \& Kirkbride, 2001). Employers and traditional organizations are looking for the best person-organization fit, and consequently exclude people with disabilities from employment opportunities. In practice it is often up to the employers' personal opinion and goodwill to decide to hire a person with a disability (Bosch et al., 2009). Additionally, employers are concerned with extra costs that accompany contracting people with disabilities such as providing accommodations at the workplace, as well as the hassle in terms of supervision and training hours, on top of a loss of productivity (Peck \& Kirkbride, 2001). Other employers claim that a lack of knowledge on this target group prevents them to fully oversee the consequences that go along with employing people with disabilities in their organization (Kaye et al., 2011). As such research shows that the road to employment for people with disabilities is still paved with hurdles and obstacles, next I will argue why these issues need to be dealt with (now). 


\section{Why and Why Now?}

One could argue that it is quite reasonable to look for the best job applicant, or that it is better to err on the safe side in order to avoid unforeseen issues. So why should there be a focus on employing people with disabilities or even people with a large distance to the labor market in general? In short, due to the Participation Act, employers are required to employ people with disabilities. However, it is far more imperative to recognize that the circumstances in our society require us to address this issue.

To be more precise, demographic developments show that our population is ageing (United Nations, 2013). The baby-boom generation born in the period after the Second World War has begun to reach the legal age of retirement. Therefore the population pyramid is gradually turning into a mushroom; the broad base of the labor force is diminishing (CBS, 2012). As years go by more and more people will retire, and with the decline in the birthrate, not enough youngsters will enter the job market. Predictions with regard to deficits in the future Dutch labor market make note of 200.000 jobs in the year 2020, and even 600.000 jobs in the year 2030 (van Duin \& Garssen, 2010; Zijlstra et al., 2012). However, keeping in mind that the economic crisis gave rise to higher unemployment rates and increase of the retirement age from 65 to 67 , such predictions might be out of date. Still, recent financial and political statements (NOS, 2015; van der Laan, 2015) indicate that the economic crisis is behind us. Thus although there seems to be a delay in the outcome of these figures due to the economic crisis, the consequences of these demographic developments are twofold. Not only a greater labor force is required to pay for social security and pension funds, but we will also need more care for the elderly. Therefore especially the service sector, e.g. hospitals, is expected to have difficulties filling job openings. These demographic changes are pushing us to rethink our views on working society. The fact is, there are presently several groups of people who are not participating in today's labor market. Not only older employees $(+55)$, but also people with disabilities fit this criterion (Zijlstra et al., 2012). Specifically the latter group can help fill this future employment gap, especially for less demanding jobs. Furthermore, currently there are more than 250.000 people with disabilities (Wajong) in the Netherlands of which most receive welfare payments (CBS, 2015), of which a large part is able to work. Therefore, an increase of working people with disabilities can broaden the labor force to help carry the load of the social security, as well as alleviate government expenditures by lowering welfare payment costs.

Nonetheless, foremost, work is important for people with disabilities. For the same reasons that it is important for all others; it takes a central place in our lives, as people generally spend a third of their lives working. Besides working for a monetary incentive, employment fulfils certain needs such as self-realization, a relation with others, and making life meaningful (Lopes, 2011). The effects of the benefits of work usually become apparent when people are out of a job. Unemployed people are deprived of (i) a shared experience, 
(ii) a structured experience of time, (iii) collective purpose, (iv) status and identity, and (v) required regular activity (Cole, 2007; Jahoda, 1981). Job insecurity is thus generally related with the feeling of a loss of benefits such as financial and social resources (Selenko \& Batinic, 2013). Therefore, employment might lead to a better integration in society and an improvement of the physical and mental health (Schuring, Mackenbach, Voorham, \& Burdorf, 2011) as well as better self-development, even for people with disabilities (Nijhuis, 2011; Black, 2008.). Organizations that put the employment of people with disabilities central because of the reasons stated above are called inclusive organizations (Zijlstra et al., 2012).

\section{Inclusive Organizations}

In order to allow an organization's mission of corporate social responsibility to lead to sustainable employment for people with disabilities it appears that certain factors such as social support, climate, and well-being appear to be critical to the success of workplace inclusion (Hagen et al., 2008; van Ruitenbeek, Mulder, Zijlstra, Nijhuis, \& Mulders, 2013). Therefore organizations need to value a diverse workforce. Such an inclusive organization is:

"an organization that optimally uses the diversity of talents and capacities of the labor market. It is an organization that facilitates all members to contribute to set organizational goals by the force of their own means and capabilities. Inclusive organizations are therefore capable to attract and maintain employment of people with disabilities and to prevent employees from prematurely dropping out with disabilities caused by sickness or age" (translated by author) (Nijhuis, Mulders, \& Zijlstra, 2011, p1).

In this definition it becomes clear that an inclusive organization should not only attract and hire people with disabilities, but also provide all the necessary boundary conditions to facilitate sustainable employment. Consequently, employment opportunities need to be encouraged, as well as work environments that allow for long-term employment. The former will most likely be remedied by society, political actions, and corporate social responsibility. To address the latter, no technical solution will suffice. It is within this frame of mind that the theoretical perspectives to deal with this problem driven research come into play (Ruiter et al., 2013).

\section{Workplace Inclusion Factors}

In order to situate the building blocks of workplace inclusion which will be addressed in this dissertation, I will first give an overview on the literature and theoretical perspectives that have inspired researchers throughout the years when considering the employment difficulties of people with disabilities. 
Research on people with disabilities in the context of work has often focused on the legal protection of people with disabilities to provide equal employment opportunities (Kruse \& Schur, 2003). Especially in the US where the ADA (1990) and the ADAAA (2008) are in effect, discriminatory actions of employers have inspired researchers to investigate the beneficial role of legislation on the employment opportunities of people with disabilities (Bradbury \& Jacobson, 2013). Other studies have beheld the employers' perspective with regard to physical adaptations and costs that have to be made to accommodate people with physical disabilities (Peck \& Kirkbride, 2001). Employers often fear the unknown additional costs in physically adjusting the workplace (e.g. a ramp for heightened accessibility) or costs associated with extra supervision and administrative hours, all of which will hold them back in employing people with disabilities. Additionally the lack of awareness concerning disabilities and the fear of legal liability can be severe drawbacks for employers (Kaye et al., 2011). Consequently, research attention has been drawn to the employers' attitudes regarding their recruitment (Fraser, Ajzen, Johnson, Hebert, \& Chan, 2011; Hunt \& Hunt, 2004; Nota, Santilli, Ginevra, \& Soresi, 2014). These negative attitudes seem to stem from erroneous information and stereotypes, and may hinder the employability of people with disabilities throughout their careers (Hunt \& Hunt, 2004). Nevertheless, findings concerning the attitudes of employers are mixed, showing that not all attitudes are negative, as certain employers are more willing to employ people with disabilities under guidance of rehabilitation professionals (Gilbride, Stensrud, Ehlers, Evans, \& Peterson, 2000), or when employers have previous experience with employing people with disabilities (Unger, 2002).

Although gaining positive hiring intentions of employers is a first prerequisite towards sustainable employment, in this dissertation I aim to address the building blocks that contribute to the workplace inclusion as seen from the view within Industrial and Organizational psychology. I will therefore move on to research directed at people with disabilities once they are employed.

The organizational socialization of people with disabilities, the process in which they become part of a team and an organization, depends on their expectations, feedback provided by the supervisor, support from peers, and high ability expectations from the management (Colella, 1994). Therefore, to some extent, people with disabilities can have an influence on the way they are treated in the workplace. In a study on performance appraisals, it was found that proactive or impression management behavior channeled negative disability effects (Colella \& Varma, 1999), which has even lead to the statement that any behavior people with disabilities engage in might enhance their inclusion (Colella \& Bruyère, 2011). Similarly, the decision of disclosing one's disability might have a large impact on the treatment in the workplace (Santuzzi et al., 2014), regardless whether it is warranted by legal or personal means. However, as the inclusion of people with disabilities also depends upon support and feedback from supervisors (Colella, 1994), or on climate and 
culture aspects (Nelissen, Vornholt, Van Ruitenbeek, Hülsheger, \& Uitdewilligen, 2014; Schur, Kruse, \& Blanck, 2005; Schur, Kruse, Blasi, \& Blanck, 2009; van Ruitenbeek et al., 2013), there appear to be many factors beyond the control of people with disabilities. Nonetheless, research that focuses on factors that facilitate the inclusion of people with disabilities into their work teams is scarce and has been suggested as an area in need of further research (Colella \& Bruyère, 2011). Hence, in this dissertation an encompassing 360 degree approach is taken in which the employee (colleagues), job, as well as organizational characteristics are taken into consideration. With these thoughts in mind the research question that drives this dissertation has sprung: What are the factors that facilitate workplace inclusion of people with disabilities?

To identify these building blocks and the boundary conditions that influence workplace inclusion, workplace inclusion needs to be defined. It can be delineated as the degree to which "people with disabilities are accepted, helped, and treated as others by their coworkers"(Colella \& Bruyère, 2011, p. 492-493). The displayed behavior by coworkers thus seems to be pivotal to their workplace inclusion, which was also specified when the key factors in organizational socialization were discussed (Colella, 1994). Similarly, qualitative studies found that the way employees interact, and particularly whether employees are willing to offer help when necessary, are factors depicted to contribute to the workplace inclusion (Bosch et al., 2009; Lammerts \& Stavenuiter, 2010). In the field of Industrial and Organizational Psychology, such helping behavior can be termed as Organizational Citizenship Behavior (OCB) (Borman, 2004; D. Organ, 1988). Organizational Citizenship Behavior, in turn, is defined as "individual behavior that is discretionary, not directly or explicitly recognized by the formal reward system, and in the aggregate promotes the effective functioning of the organization" (Organ, 1988, p4). OCB has been found to have numerous beneficial effects for both the employee, team and organization in terms of productivity, efficiency, absenteeism, job satisfaction and turnover intentions (Podsakoff et al., 2014, 2009). Thus, as suggested by the definition of workplace inclusion, the qualitative literature findings, as well as similar to findings concerning the beneficial effects of social support during the socialization process (Colella, 1994; Fisher, 1985), it appears that providing help and support to people with disabilities is one of the building blocks that might lead to a higher degree of inclusion. Therefore, in this dissertation, citizenship behavior will be utilized as a central concept and tailored to the domain of workplace inclusion of people with disabilities.

The new and tailored version of citizenship behavior or providing help for one's colleagues with disabilities will be referred to as "inclusive behavior". More specifically, and in line with the concept of OCBI (Organizational Citizenship Behavior directed at the Individual) which was put forward by Williams and Anderson (1991), inclusive behavior is directed toward the benefit of other individuals. The individuals targeted by inclusive behavior are people with disabilities who are part of the work team or department of 
which the employees are thought of to display this behavior. I therefore defined inclusive behavior as extra role behavior that is intended to benefit people with disabilities at work. It is operationalized as the courtesy and altruism dimension of $\mathrm{OCB}$, analogous to the concept of OCBI (Lepine, Erez, \& Johnson, 2002; N. P. Podsakoff et al., 2009; P. M. Podsakoff, Mackenzie, \& Moorman, 1990; Williams \& Anderson, 1991). The goal of inclusive behavior, as it is for $\mathrm{OCBI}$, is to benefit other individuals (people with disabilities) by means of providing help with a relevant problem at the workplace (altruism) or by preventing such work-related problems (courtesy). With regard to the pivotal role inclusive behavior might play with respect to the sustainable employment of people with disabilities, its antecedents and consequences at both the individual and team level will be central to the research presented in this dissertation.

When looking at the organizational characteristics that can contribute to sustainable employment, team climate might act as a boundary condition. Team climate refers to "the (aggregated) meanings that employees impute to their jobs, co-workers, leaders, pay performance expectations, opportunities for promotion, equity of treatment and the like" (James et al., 2008, p.6). Team climate can have a specific focus of interest (Schneider, 2000), such as safety, diversity or service. With regard to the functioning of people with disabilities I developed the concept of inclusive climate; the perceptions of employees on the practices, procedures and behaviors that get rewarded, supported and expected with regard to being responsive to the needs, capabilities, and qualities of their coworkers with disabilities. A climate that fosters inclusion is likely to be related to employees' inclusive behavior. This idea is corroborated by qualitative studies that researched the functioning of people with disabilities in organizations, and concluded that inclusion is often dependent on matters such as "a working atmosphere" (Bosch et al., 2009; Lammerts \& Stavenuiter, 2010; van Ruitenbeek et al., 2013). Furthermore, research on the employment of people with disabilities has stated that a diversity-friendly climate determines their work experience (Colella \& Bruyère, 2011), and even that workplace environments which are fair and responsive, might be particularly important for people with disabilities (Schur et al., 2005, 2009). Therefore the role inclusive climate as an enabling factor to the display of inclusive behavior will be examined and argued for.

Concluding, the goal of this dissertation is to contribute to the field of employment for people with disabilities, to identify factors that contribute to workplace inclusion, as well as to further knowledge on what happens to people with disabilities at the workplace. Practically, this dissertation aims to generate knowledge on inclusion for people with disabilities as which might be used as a tool for organizations that wish to employ them. The findings of our research have the potential to foster important practical implications which might optimize the odds of successful workplace inclusion for people with disabilities. 


\section{Overview of the Dissertation}

I have discussed the problems concerning the employment of people with disabilities, why society needs to address these, as well as Acts that facilitate their intake in organizations. However, what happens when people with disabilities are employed, or what factors influence their turnover or sustainable employment is insufficiently known (Colella \& Bruyère, 2011). Our ${ }^{2}$ premise is that inclusive organizations in which employees display inclusive behavior, the inclusion of people with disabilities will be facilitated. Hence in the next chapters I will focus on the building blocks of inclusion at the workplace for people with disabilities. In doing so, I will theoretically concentrate on building blocks such as inclusive climate, inclusive behavior and their role in facilitating inclusion. Practically I aim to generate knowledge which may function as guidelines to inclusive organizations to better accommodate people with disabilities at work. Thus, the following empirical chapters respectively deal with antecedents of inclusive behavior at the individual level, antecedents of inclusive behavior at both individual and team level, to consequently look at potential consequences of team inclusive behavior at the team level.

In chapter 2 antecedents of inclusive behavior at the individual level are examined. This chapter examines how stereotypes and attitudes towards people with disabilities may influence the display of inclusive behavior. As people with disabilities are often faced with a negative stereotypes and attitudes it is crucial to see how they affect inclusion at the workplace. We utilize the Reasoned Action Approach (Fishbein \& Ajzen, 2010) to illuminate how stereotypes (basic knowledge) lead to negative or positive attitudes and ultimately guide helping behavior towards people with disabilities at work. Moreover, since the perceived amount of work might influence the opportunities people have to display inclusive behavior, we add work pressure (Roe \& Zijlstra, 2000) as a boundary condition to the equation.

In chapter 3 we provide a multilevel perspective on the antecedents of inclusive behavior. For this study we build on the functional approach to explain why prosocially motivated employees (Grant \& Berg, 2010) will be more inclined to display inclusive behavior. That is, employees who are prosocially motivated want to express their prosocial needs and values, and may do so via the display of inclusive behavior. We additionally consider team inclusive climate as a direct and indirect antecedent of inclusive behavior. Inclusive climate refers to group norms that guide behavior with regard to being inclusive. We thus examine whether employees who adhere to these norms might be more inclined to display inclusive behavior.

\footnotetext{
${ }^{2}$ Because I have worked together with a number of co-authors on the studies reported in this dissertation, I use the term 'we' to designate myself and the co-authors with whom the various studies were designed and executed.
} 
In certain situations the influence of inclusive climate might even be strong enough to restrain individual characteristics because employees will adhere to group settings when norms are perceived in collectivistic manner. ${ }^{3}$

Qualitative studies have put forward that well-being of people with disabilities at work is crucial for their inclusion. Therefore, in chapter 4, which is modelled at the team level, we aim to empirically investigate the effects of team inclusive behavior on the well-being of people with disabilities. We build upon the social support theory (Cohen \& Wills, 1985) to research whether team inclusive behavior positively affects the well-being of people with disabilities. We examine whether job resources such as social support or inclusive behavior are able to mitigate the adverse effects of a demanding work environment on the experienced strain. A positive effect on the well-being of people with disabilities would certainly be beneficial toward reaching the goal of sustainable employment.

In chapter 5 we discuss the issue of disclosure versus non-disclosure in response to an article by Santuzzi, Waltz, Finkelstein and Rupp (2014). The focus article deals with disclosure problems for people with disabilities. The authors state that revealing one's identity as an employee with a disability may have serious consequences concerning their health, social relationships and work performance. Santuzzi et al. (2014) furthermore argue that current U.S. legislation is not well enough equipped to deal with the specific situation of people with (invisible) disabilities at work, and suggest changes to legislation and workplace policies. In our commentary we concur the basic gist of Santuzzi et al. (2014), however we feel that in facilitating people with disabilities to disclose a change in legislation is insufficient. In this chapter we highlight the role of the organization at three levels, as well as a broader and international perspective on legislation and other factors that may influence the disclosure decisions of people with disabilities at work. At the individual level we suggest interventions, crafted to raise awareness and knowledge on disabilities in order to counter people negative stereotypes and attitudes. At the team level we highlight the role of the work environment and specific climates (e.g. inclusive) that will foster inclusion. Lastly, at the organizational level we highlight the role of organizational culture and the interplay between the values of the organization and their employees. We end by taking an international perspective, and therefore stress that work related issues for people with disabilities is a universal problem rather than solely situated in the US.

Finally, in chapter 6, I provide an overview of the main findings of each study. Theoretical and practical implications will be discussed, as well as suggestions for future research.

Taken together, the building blocks and relationships described above are depicted in the following overarching multilevel model.

\footnotetext{
${ }^{3}$ Notably, the studies presented in chapters 2 and 3 rely on different parts of the same dataset: While chapter 2 is based on employee - colleague dyads, chapter 3 is based on employees nested in work teams. Both chapters have one variable in common, namely inclusive behavior. More detailed information on the sample and data collection procedure can be found in the respective method sections. To provide an overview between the study variables in chapters 2 and 3, an overall correlation table is provided in the appendix. The data for the study reported in chapter 4 is based on a different data set.
} 


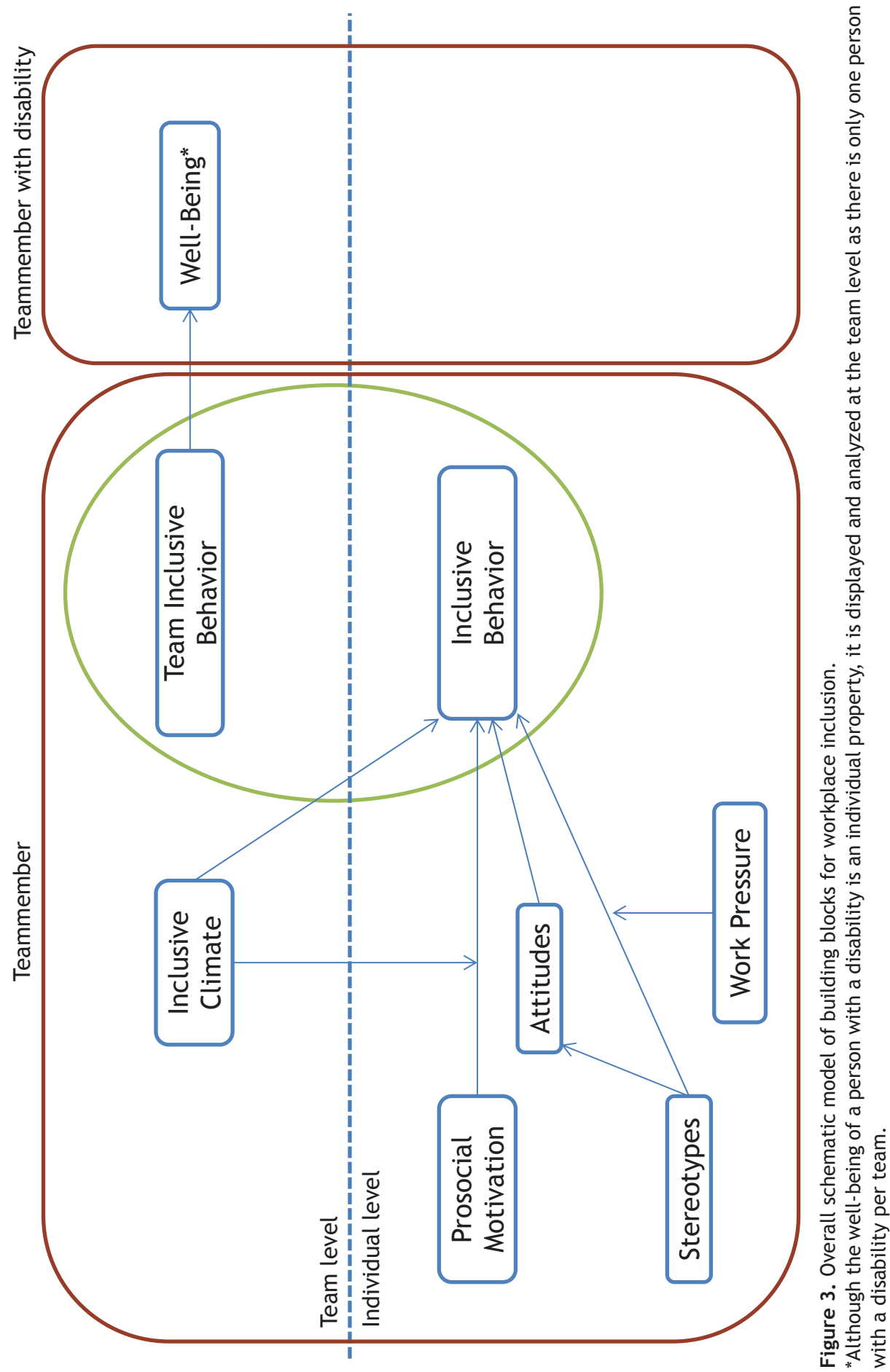




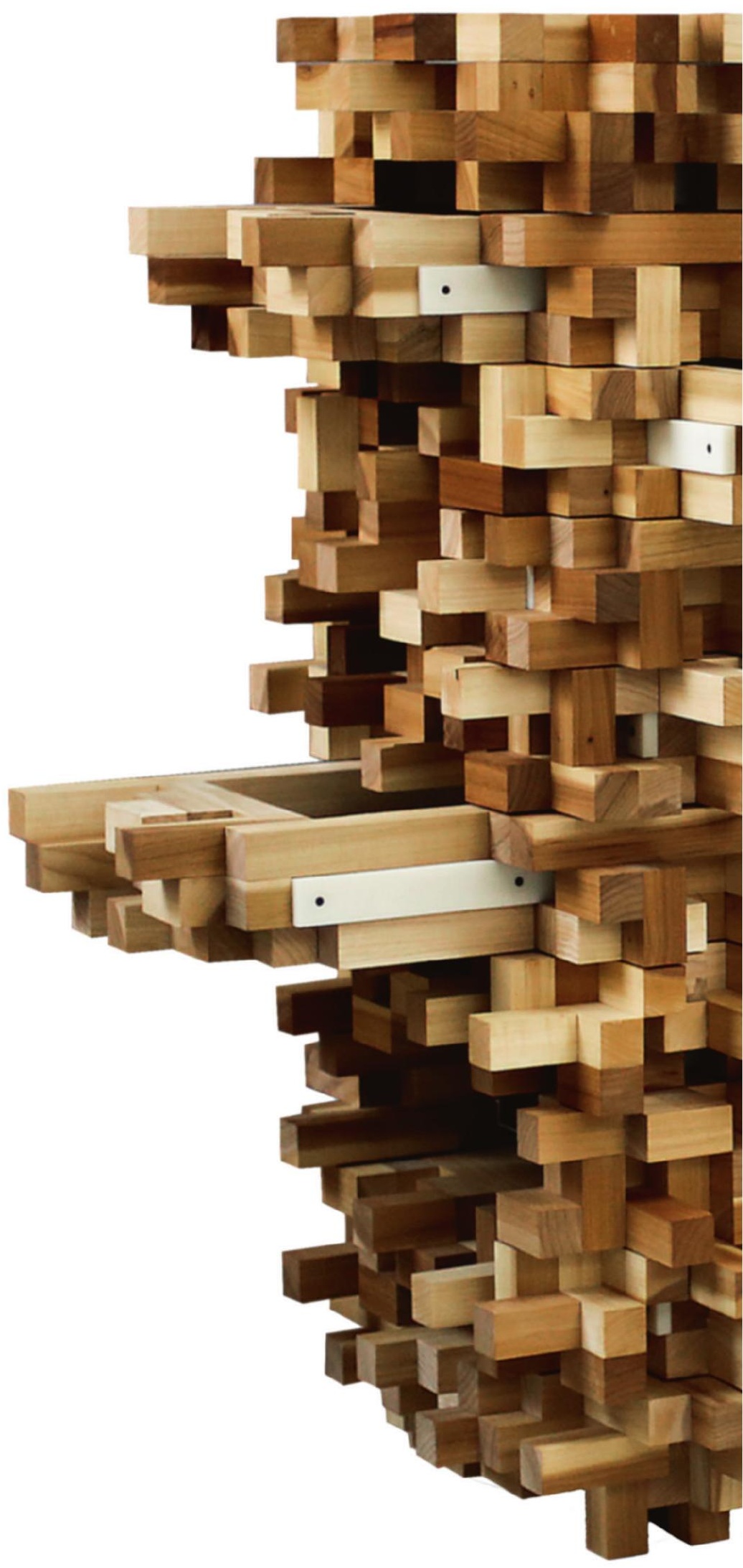




\section{CHAPTER 2}

How and When Stereotypes Relate to Helping Behavior toward People with Disabilities

Published as:

Nelissen, P. T. J. H., Hülsheger, U. R., van Ruitenbeek, G. M. C., \& Zijlstra, F. R. H. (2016).

How and when stereotypes relate to inclusive behavior toward people with disabilities. The International Journal of Human Resource Management, 27(14), 1610-1625. http: / / doi.org/10.1080/09585192.2015.1072105 


\begin{abstract}
The guidelines of the European Commission on corporate social responsibility stress the importance of sustainable employment for people with disabilities. The road to employment is however paved with obstacles, such as the often negative stereotypes and attitudes of employers and employees, which influence the treatment of people with disabilities at the work floor. In the present study, we build upon the reasoned action approach to illuminate how and when stereotypes of employees toward people with disabilities relate to helping behavior at work. In a sample of 313 employee-colleague dyads, we found that the relationship between stereotypes (rated by employees) and helping behavior (rated by colleagues) is mediated by employee attitudes toward the employment of people with disabilities (targets). Moreover, work pressure functions as a boundary condition that shapes the relationship between stereotypes and helping behavior, in such a way that the relationship is stronger when work pressure is low. Research and practical implications are discussed in conclusion.
\end{abstract}

Keywords: stereotypes; attitudes; people with disabilities; work pressure; helping (inclusive) behavior 


\section{Introduction}

In recent years, the employment of people with disabilities has become a central issue in Europe. The European Commission states that people with disabilities are to be facilitated to reach higher levels of acceptance, integration, and social inclusion in society (Coles \& Scior, 2012; European Commission, 2011; Scior, 2011). One way to achieve this goal is through gaining a higher degree of sustainable employment for people with disabilities. Since work has a central place in people's lives, being employed will therefore not only facilitate integration in society (Jahoda, 1981), but will also benefit physical and mental health (Schuring et al., 2011). In this setting, there is a need for more corporate social responsibility to constitute a new mindset on employment issues. Especially inclusive organizations, which aim to harbor a diverse work force, might provide a solution to reach higher levels of employment for people with disabilities (Zijlstra et al., 2012). However, when entering the job market, one of the boundaries that people with disabilities face are the stereotypes and attitudes of employers and employees (Bruyère, Erickson, \& Ferrentino, 2002; Hunt \& Hunt, 2004; Schur et al., 2005; Scior, 2011). This, often negative, perception (Mackelprang \& Salsgiver, 1996) is one of the reasons why people with disabilities experience a bias in the way they are treated at the work floor (Colella \& Bruyère, 2011; Hunt \& Hunt, 2004). Moreover, negative attitudes of coworkers have been shown to prevent people with disabilities from fulfilling goals, and limit them from having access to every aspect of life (Akrami, Ekehammar, Claesson, \& Sonnander, 2006). Especially in organizations aiming at becoming more inclusive, the treatment by colleagues and supervisors is important for the workplace inclusion of people with disabilities (Colella \& Bruyère, 2011), mainly because it pertains to their job success and job satisfaction (Wehman, 2003).

Whereas research on people with disabilities in the context of work has often focused on the legal protection of people with disabilities to provide equal employment opportunities (Kruse \& Schur, 2003), and on the employer perspective with regard to physical adaptations and costs that have to be made to accommodate people with physical disabilities (Peck \& Kirkbride, 2001), as well as on employers' attitudes regarding their recruitment (Hunt \& Hunt, 2004), we aim to address factors that contribute to the workplace inclusion once people with disabilities are already employed. In this frame of mind, we leave aside factors that originate from people with disabilities themselves, such as proactive or impression management behavior (Colella et al., 1997), or whether disclosing one's disability is warranted by legal or personal means (Santuzzi et al., 2014). Instead, we advocate to rather use industrial- organizational knowledge on the individual, team and organizational level, to develop interventions in order to address factors such as stereotypes, attitudes and colleague behavior, climate perceptions and organizational interventions to facilitate workplace inclusion (Nelissen et al., 2014). However, research that focuses on factors that 
facilitate the inclusion of people with disabilities into their work teams is scarce and has been suggested as an area in need of further research (Colella \& Bruyère, 2011). Therefore, with the present study we intend to advance this line of research by identifying factors that may facilitate people with disabilities from reaching their full potential in the labor market. Our ultimate goal is to identify factors at the individual level that might have an influence on inclusion at the workplace for people with disabilities.

Research on workplace inclusion has been addressed from various angles. A recent study on the attitudes of employers towards employing people with disabilities conceptualized work inclusion as the way that people with disabilities have access to employment (Nota et al., 2014). Another study described workplace inclusion as being able to interact with one's (non-disabled) colleagues (Wehman, 2003). However, inclusion as a broader concept can also be referred to as 'not being excluded', which implies that workplace inclusion is possible when "people with disabilities are accepted, helped and treated as others by their coworkers" (Colella \& Bruyère, 2011, p.492-493). As stated in this definition of workplace inclusion, and similar to the beneficial effects of social support during the socialization process (Fisher, 1985), we concur that providing help and support to people with disabilities is one of the anchors that might lead to a higher degree of inclusion. In this paper we therefore particularly address factors that might contribute to how people with disabilities are helped at the workplace by their coworkers. Hence, we focus on employees' stereotypes and attitudes towards people with disabilities and how these influence the extent to which they provide help towards colleagues with disabilities at the work floor.

Providing help for one's colleagues with disabilities will be referred to as "inclusive behavior". This new concept refers to extra-role behaviors that are not part of the formal role description, but (indirectly) support the organization, as does the concept of Organizational Citizenship Behavior (OCB) (N. P. Podsakoff et al., 2014; Williams \& Anderson, 1991). More specifically, and in line with the concept of OCBI (Organizational Citizenship Behavior directed at the Individual) which was put forward by Williams and Anderson (1991), inclusive behavior is directed toward the benefit of other individuals. The individuals targeted by inclusive behavior are people with disabilities who are part of the work team or department of which the employees are thought of to display this behavior. We therefore define inclusive behavior as extra role behavior that is intended to benefit people with disabilities at work. It is operationalized as the courtesy and altruism dimension of OCB, analogous to the concept of OCBI (Lepine, Erez, \& Johnson, 2002; M. Podsakoff, Mackenzie, \& Moorman, 1990; N. P. Podsakoff, Whiting, Podsakoff, \& Blume, 2009; Williams \& Anderson, 1991). The goal of inclusive behavior, as it is for OCBI, is to benefit other individuals (people with disabilities) by means of providing help with a relevant problem at the workplace (altruism) or by preventing such work-related problems (courtesy). In concreto, all questionnaire items concerning inclusive behavior are referenced toward a specific individual beneficiary: the colleague with a disability. 
The relationships between stereotypes, attitudes and inclusive behavior are framed within the theoretical framework of the Reasoned Action Approach This most recent approach of the Theory of Planned Behavior describes how, among others, cognitions and attitudes predict behavior. Within the limits of this study, the application of this well tested and extensive model can provide the grounds to research the link between stereotypes, attitudes and behavior towards people with disabilities. This should consequently provide more insights on employment issues of people with disabilities, which may ultimately be used to inform organizational strategies to foster workplace inclusion.

In addition to investigating relationships between stereotypes, attitudes and inclusive behavior, we aim to shed light on boundary conditions of these relationships. Exploring boundary conditions will facilitate more precise knowledge on the nature of the stereotype - inclusive behavior relationship. Employees might only be able to display inclusive behavior when the circumstances allow them to. We will therefore investigate the role of work pressure as a boundary condition. As many employees claim to experience work pressure, a subjective sensation of strain during the execution of work related tasks (Roe \& Zijlstra, 2000), it might have an impact on the opportunities that one has to display inclusive behavior. Dependent on experience of strain, employees might or might not feel the need to exceed the mandatory tasks, and thus perform inclusive behavior.

Moreover, most studies on attitudes towards people with disabilities have a qualitative nature (Scior, 2011). Therefore, the goal of the present study is to quantitatively illuminate how and when stereotypes of coworkers lead to inclusive behavior in the workplace. Figure 1 depicts the corresponding model.

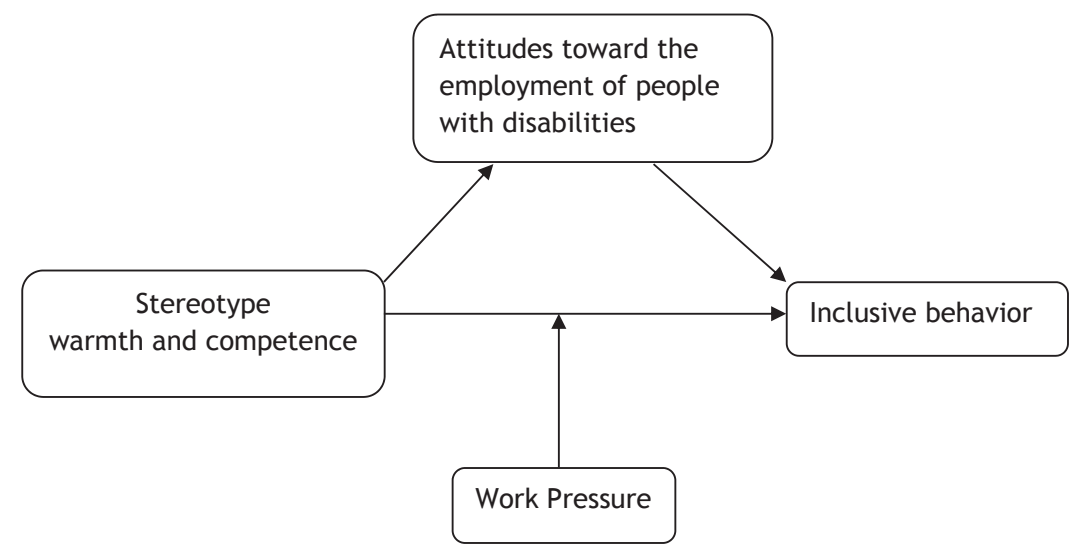

Figure 1. Mediation and moderation model of stereotypes toward people with disabilities on inclusive behavior. 


\section{Stereotypes and inclusive behavior}

Some of the important barriers that people with disabilities face, in the road to employment, are the stereotypes and attitudes of employers and their employees (Bruyère et al., 2002; Colella \& Bruyère, 2011; Stone \& Colella, 1996). Even when employed, some people with disabilities are not rated as much on their performance, but rather on the grounds of the stereotypical beliefs of their employers (Colella \& Varma, 1999). The lack of experience in working with people with disabilities, inclines employers to lean on their stereotypes to portray them as poor performers, frequently absent and as bringing along a feeling of unease to the people that surround them (Kaye et al., 2011). Especially this last example of stereotypical behavior might hinder the inclusion of people with disabilities at the workplace. To look at how stereotypes might impede inclusion, in the next section we will first clarify the concept of stereotypes and how it is different from prejudice, to consequently discuss the stereotype content model to further explain why stereotypes might have an influence on the amount of displayed inclusive behavior.

Stereotypes refer to the way a group of people is viewed by society and have been defined as 'shared beliefs about person attributes, usually personality traits, but often also behaviors, of a group of people' (Leyens, Yzerbyt, and Schadron 1994, p.11). It is a description of similar characteristics of a certain group, without passing judgment. Stereotypes need not necessarily have a negative connotation; they can be positive or negative, and can be accurate or inaccurate. In general, stereotypes allow for easier information processing by relying on previously stored heuristics instead of new information (Hilton \& von Hippel, 1996). The usage of stereotypes may yield pragmatic knowledge to swiftly assess what others' goals and intentions might be (Fiske, Cuddy, Glick, \& Xu, 2002). While this tactic may have its advantages (e.g. in threatening situations where one has to think fast), they are mostly based on oversimplified group features (Stone \& Colella, 1996). Notably, although in common language the terms stereotype and prejudice are often used interchangeably, they do not equate. Whereas stereotypes refer to cognitive ideas a person has of a group of people, prejudice is a negative affective response towards the stereotyped group (Akrami et al., 2006; Amodio \& Devine, 2006). Furthermore, people can be conscious of various stereotypes, without approving them or having feelings of prejudice (Leyens et al., 1994). For instance, to assess stereotypes towards people with disabilities, one might ask participants: 'As viewed by society, how good natured are people with disabilities?' (Fiske et al., 2002, p.884). Such a question will not lead to a cognitive evaluative response, but merely shows a positive or negative view or valence of the target group. In contrast, prejudices are typically captured with items like 'People with intellectual disabilities do not have the character strength that people without intellectual disability have' (Akrami et al. 2006, p.616). 
Fiske, Cuddy, Glick and Xu (2002) argue that stereotypes can vary over two dimensions; warmth and competence. These dimensions respectively refer to the amount of 'like' and 'respect' one has for others. The warmth-dimension can be based on an assessment of what others' goals are, and the competence-dimension refers to whether they are able to execute these goals. People that one considers to be warm and competent, have positive goals (in line with the beholders') and are able to fulfill them. While this group of people is admired, and is usually similar to the beholder of the stereotypes, people that score low on warmth and competence are perceived in a negative manner and as inadequate to pursue their goals. In general, people with disabilities, are rated to be warm but not competent (Fiske et al., 2002). The high score on warmth therefore reflects having no intent to harm one's own reference group, while the low competence catches the lack of ability to harm. This sort of paternalistic stereotype is characterized by disrespect and pity towards the stereotyped group.

It is therefore important to assess whether these stereotypes will influence employees' inclusive behavior towards people with disabilities at work. However, very few disability studies focus on the relationship between stereotypes and (positive) behavior towards another group. Stone and Colella (1996) have suggested, but not empirically tested, that stereotypes will affect employees' responses to work with people with disabilities. Accordingly, stereotypes influence employees' expectancies towards working with people with disabilities, which in turn will have an effect on how people with disabilities are treated and helped within the organization. Employees use stereotypes to evaluate others and will consequently make assumptions on how they will perform at work. This performance expectation may affect the treatment of people with disabilities, in such a way that a negative stereotype view (e.g. low warmth and low competence) will inhibit inclusive behavior at the workplace and thus inclusion (Stone \& Colella, 1996). One could also argue that pity, as a result of high warmth and low competence, would facilitate acts of kindness and consequently inclusive behavior. We state, however, that the feeling of pity might lead to a single positive action but that this behavior will not endure over a longer period of time, which is one of the assumptions of citizenship behaviors (Podsakoff, Mackenzie, Paine, \& Bachrach, 2000).

Although the research presented above did not directly test the relationship between stereotypes and behavior, it does give reason to expect that the more warmth and competent people with disabilities are rated, the more inclusive behavior will be displayed by their colleagues. In the present study we will directly test this relationship in the context of work.

Hypothesis 1a: High stereotype warmth toward people with disabilities is positively related to inclusive behavior.

Hypothesis $1 \mathrm{~b}$ : High stereotype competence toward people with disabilities is positively related to inclusive behavior. 


\section{How: attitudes as a potential underlying mechanism}

In the preceding section we proposed that stereotypes are related to inclusive behavior. In trying to illuminate the processes underlying this relationship we build upon the Reasoned Action Approach (Fishbein \& Ajzen, 2010) and argue that this relationship is mediated by coworkers' attitudes towards the employment of people with disabilities.

Attitudes, in general, can be defined as 'a latent disposition or tendency to respond with some degree of favorableness or unfavorableness to a psychological object' (Fishbein and Ajjzen 2010, p.76) and can therefore be seen as more proximal antecedent of inclusive behavior than stereotypes. According to the Reasoned Action Approach, attitudes will only be predictive of behavior if they correspond to one another (Fishbein \& Ajzen, 2010). Thus, to predict inclusive behavior, attitudes should specifically relate to the employment of people with disabilities. An example of such an attitude is: 'Everyone, regardless of the level or the type of disability, has the capability to do some job' (Schneider 2008, p.1821). Consequently, based on the Reasoned Action Approach, employees who are favorable to the notions of employment, cooperation, and inclusion of people with disabilities will be more inclined to display inclusive behavior. The amount of displayed inclusive behavior will be based on the expectations people have about performing inclusive behavior, which, in turn, will guide the valence of the attitudes (Fishbein \& Ajzen, 2010).

The idea that attitudes are proximal predictors of behavior in general has been corroborated in a plethora of individual studies and a number of meta-analyses (e.g. Kraus 1995; Glasman and Albarracín 2006). For instance, employee attitudes toward safety climate have been shown to be related to safety behavior (Fogarty \& Shaw, 2010) and workplace attitudes, such as perceived organizational support, fairness and affective commitment, have been shown to be related to interpersonal helping behavior (Choi, 2006). In general, research on attitudes towards people with disabilities and how these shape behavior towards these people is scarce and nearly non-existent in the context of work (see Fraser, Ajzen, Johnson, Hebert, and Chan 2011 for an exception). Yet, researchers have already theoretically argued that positive attitudes towards the employment of people with disabilities are important for acceptance and inclusion (Coles \& Scior, 2012).

In sum, based on the theoretical advances and empirical evidence on the Reasoned Action Approach, we expect attitudes towards the employment of people with disabilities to be proximally related to inclusive behavior at work. Furthermore, we expect these attitudes to mediate the relationship between stereotypes (warmth and competence) towards people with disabilities and inclusive behavior. This idea is grounded in research suggesting that attitudes towards people with disabilities stem from stereotypes and beliefs that are based on a lack of accurate knowledge, education level, and prior contact with persons with disabilities (Hunt and Hunt 2004; Scior 2011). Based on the beliefs employees have about people with disabilities and how it would be like to work side by side, attitudes 
are generated (Fishbein and Ajzen 2010). Attitudes will thus attribute meaning to certain beliefs in order to be interpreted (L. A. James \& James, 1989). Similarly, in a study on immigration policies, it was found that attitudes towards several immigration groups are based on stereotypes about immigrants (Reyna, Dobria, \& Wetherell, 2013).

Accordingly, by following the Reasoned Action Approach, we argue that stereotypes form the basis for attitudes, which will attribute meaning to these beliefs and will consequently lead to corresponding behavior. We therefore hypothesize that the relationship between stereotypes (warmth and competence) toward people with disabilities and inclusive behavior is mediated by the attitudes employees have about the employment of people with disabilities.

Hypothesis 2a: The relationship between stereotype warmth toward people with disabilities and inclusive behavior is mediated by attitudes toward the employment of people with disabilities.

Hypothesis 2b: The relationship between stereotype competence toward people with disabilities and inclusive behavior is mediated by attitudes toward the employment of people with disabilities.

\section{When: work pressure as potential boundary condition}

The argumentation presented above suggests that stereotype warmth and competence should, overall, be positively related to inclusive behavior. However, there may very well be boundary conditions which influence and shape this relationship. Specifically, we argue that that work pressure has a significant influence on the positive relationship between stereotypes and the occurrence of inclusive behavior. Work pressure can be defined as an enduring 'subjective state of tension associated with the current and/or anticipated execution of work tasks' (Roe and Zijlstra 2000, p. 29). Work pressure is a phenomenon to be taken into account according to a recent review of the European working conditions (Eurofound, 2012). The majority of European workers reported to experience high work pressure, as a result of high work intensity and high work demand (Eurofound, 2012; Sonnentag \& Zijlstra, 2006). Employees, who experience work pressure, feel strain while performing work tasks, conditional on the employee's assessment of the amount of future work. One of the main outcomes of work pressure is strain (Roe \& Zijlstra, 2000). Thus, as more than one in every two employees claims to be subject to work pressure, and as this consequently might lead to strain dependent upon the magnitude of upcoming work tasks, it does not seem likely that these employees are keen on taking on additional extra-role tasks such as displaying inclusive behavior. In sum, it appears that although employees with a positive view on people with disabilities are more inclined to display inclusive behavior, those who feel pressured by work, and are subjectively overloaded with work tasks, will 
not be likely to take on any extra tasks regardless of the stereotypes they hold towards people with disabilities. To avoid stress, their main focus will probably be predominantly on the mandatory job tasks, and less on discretionary and volitional ones, intended to benefit others. Under conditions of low work pressure, however, we expect that employees' stereotypes will shape behavior much more strongly. To conclude, although we expect an overall positive relationship between stereotype warmth and competence and inclusive behavior, we expect this relationship to be stronger under conditions of low work pressure, when employees have the necessary resources to be able to display inclusive behavior.

Hypothesis 3a: The relationship between stereotype warmth toward people with disabilities and inclusive behavior is moderated by work pressure; in such a way that the relationship is stronger when work pressure is low.

Hypothesis 3b: The relationship between stereotype competence toward people with disabilities and inclusive behavior is moderated by work pressure; in such a way that the relationship is stronger when work pressure is low.

\section{Method}

\section{Participants and procedure}

Respondents were 372 employees from seven organizations located throughout the Netherlands, which were selected on the basis of employing people with disabilities (response rate $=35 \%$ ). The organizations were active in e.g. the healthcare sector, retail stores or the super market industry. Employees worked in teams with a minimum of three colleagues (maximum reported of nine colleagues in one team) and were eligible for our research if one of the team-members had a disability. In the Netherlands, people with disabilities are examined and tested on their capability to work by governmental institutions and may receive wage dispensations for the work they perform. Within this regulation no distinction based on disability type is made by the Dutch government. Therefore no distinction on disability type was made or recorded; various physical, cognitive, mental, sensory, and developmental impairments (e.g. deafness, learning disability, autistic spectrum disorder) were included. Employees were aware that certain team members had a disability; however specifics on their situation were not automatically communicated to the staff by their supervisors due to privacy reasons. All team-members (except for the team member with a disability) were invited to fill in questionnaires and consequently provided self-ratings on stereotypes and attitudes towards people with disabilities and work pressure. Employee inclusive behavior was assessed by peer-ratings, provided by 313 work colleagues (response rate $29.4 \%$ ). These peers were selected by the first participant, who was instructed to choose a colleague 
with who they had regular contact, but not the coworker with a disability. Independently choosing a peer is common procedure to obtain reliable multiple source data, coworkers are very well suited to assess such behavior as they work closely together and have adequate opportunities to observer one another (Rioux \& Penner, 2001). Furthermore, as employees and their colleagues were paired, 59 employees who failed to provide a colleague report were dropped from our analyses, resulting in a final sample of 313 employees, who work together with a total of 86 people with disabilities. Jobs of employees entailed e.g. shelf re-stockers $(41 \%)$, nurses $(6 \%)$, or cashiers $(5 \%)$. Respondents were $46 \%$ male, with a total average tenure of 12.45 years $(S D=10.38)$, and 38 years of age $(S D=13.90)$.

\section{Measures}

Most measures were adopted from English and translated into Dutch with a translation and back-translation process, whilst taking into account the guidelines for test translation and adaptation (Hambleton, 2001). The work pressure scale was originally published in Dutch.

Employees provided ratings on stereotypes and attitudes towards people with disabilities, and self-rated their work pressure.

\section{Stereotypes towards people with disabilities}

Participants completed 7 out 9 items of the warmth and competence dimensions of stereotype content model measure put forward in the first study by Fiske, Cuddy, Glick, and $\mathrm{Xu}$ (2002). The scale was assessed on a 5 point Likert scale ranging from 1 (not at all) to 5 (very much). Two items (confidence and warmth) were not included in our measurement due to conceptual overlap when translated into Dutch. Participants were requested to give their opinion upon the prevailing view of society on people with disabilities. In order to reduce social desirability, respondents were asked to evaluate how people with disabilities are viewed by others, and not by their personal beliefs (L. M. Finkelstein, Ryan, \& King, 2013; Fiske et al., 2002). The items on the warmth dimension were 'As viewed by society, how tolerant/good natured/sincere are people with disabilities?', and for the competence dimension: 'As viewed by society, how competent/ independent/competitive/intelligent are people with disabilities?'. Cronbach's Alpha for the warmth dimension was $a=.67$, and .80 for the competence dimension.

\section{Attitudes towards the employment of people with disabilities}

Participants completed five items of the attitudes towards the employment of people with disabilities scale developed by Schneider (2008). The scale was assessed on a 5 point Likert scale ranging from 1 (strongly disagree) to 5 (strongly agree). The items were 'Everyone, regardless of the level or the type of disability, has the capability to do some job', 'Disabled people are more loyal employees than non-disabled employees', 'Disabled people have a 
right to work', 'Employing disabled people is good for a business's image', and 'Disabled people should earn equal wages to co-workers doing similar jobs' $(a=.61)$.

\section{Work pressure}

Participants completed the 10 items of the Tilburg Work Pressure Questionnnaire (T-WPQ) by Roe and Zijlstra (2000). The scale was assessed on a 5 point Likert scale ranging from 1 (strongly disagree) to 5 (strongly agree). Sample items were 'I have the feeling that I am under pressure at work', 'I feel the burden of responsibility at work'. Cronbach's Alpha was $a=.86$.

Peers (work colleagues) provided ratings on the target person's inclusive behavior.

\section{Inclusive behavior}

We assessed inclusive behavior with an 8-item scale adapted from the altruism and courtesy subscales as introduced for Organizational Citizenship Behavior (OCB) (P. M. Podsakoff et al., 1990). The scale was assessed on a 5 point Likert scale ranging from 1 (strongly disagree) to 5 (strongly agree). The scales were adapted to the viewpoint of the participant, peers' questionnaires referred to their colleague $(a=.89)$. The instruction stated that the questions referred to the person with a disability in their work team. The questions were; 'My colleague does not abuse the right of people with disabilities', 'My colleague tries to avoid creating problems with people with disabilities', 'My colleague considers the impact of his/her actions on people with disabilities', 'My colleague helps people with disabilities who have been absent', 'My colleague helps people with disabilities who have heavy workloads', 'My colleague helps orient new people with disabilities even though it is not required', 'My colleague willingly helps people with disabilities who have work related problems', 'My colleague is always ready to lend a helping hand to people with disabilities around him/her'.

\section{Statistical analysis}

Confirmatory factor analyses (CFA) were conducted in the $\mathrm{R}$ environment (R Core Team, 2012) by using the lavaan package (Rosseel, 2012). Mediation and moderation was analyzed using the Preacher and Hayes process plugin for SPSS version 21 (Preacher and Kelley 2011; Hayes 2013). Confidence intervals were computed using a bootstrapped standard error (SE) $(n=5000)$. Significance of the indirect effect is determined by examining the $95 \%$ confidence interval by resampling the indirect effect to represent the population (Hayes, 2009). Coefficient estimates outside the 95\% bias-corrected and accelerated (BCa) bootstrap confidence limits are considered significant mediation effects, comparable to the regular alpha cutoff of $p=.05$ (Preacher \& Kelley, 2011). We first used statistical model 4 to assess mediation, whereupon we utilized model 5 to concurrently check for mediation and moderation of the direct effect (Hayes 2013). 


\section{Results}

First, we conducted a confirmatory factor analysis (CFA) on the constructs stereotypes of people with disabilities and attitudes towards the employment of people with disabilities to assess whether they were distinct from each other (Hu and Bentler 1999, Ilies, Scott, and Judge 2006; Hoffman, Blair, Meriac, and Woehr 2007). A two-factor model fit the data very well $\left(\mathrm{x}^{2}(34, \mathrm{~N}=301)=49.11, \mathrm{RMSEA}=0.04, \mathrm{SRMR}=0.04, \mathrm{NNFI}=.96, \mathrm{CFI}=.98\right)$, particularly when compared to a one-factor model $\left(x^{2}(135, N=290)=945.13\right.$, RMSEA $=0.14$, SRMR $=0.13$, $\mathrm{NNFI}=0.45, \mathrm{CFI}=0.52$, in which both stereotypes and attitudes loaded on one factor.

Means, standard deviations, and intercorrelations between study variables of this crosssectional study are displayed in Table 1. Regression analysis did not reveal a significant direct relationship between warmth or competence and inclusive behavior (respectively $b=0.074, p=0.198 ; b=0.044, p=0.439$ ), thereby rejecting hypotheses $1 a$ and $1 b$. As there is no need for these direct effects to be significant in order to carry on with the mediation analysis (Hayes, 2009), we continued to search for the indirect effect proposed in hypotheses $2 \mathrm{a}$ and $2 \mathrm{~b}$, which are shown in Table 2 . With regard to hypothesis $2 \mathrm{a}$, results of mediation analyses indicated a significant indirect effect of stereotype warmth on inclusive behavior through attitudes towards the employment of people with disabilities $(b=0.056$, $\mathrm{BCa} 95 \% \mathrm{Cl}[0.0209 ; 0.1068], \mathrm{K}^{2}=.054 ; \mathrm{BCa} 95 \% \mathrm{Cl}$ [0.0202; 0.1028]). For hypothesis $2 \mathrm{~b}$, the indirect effect of stereotype competence on inclusive behavior via attitudes towards the employment of people with disabilities, a similar significant indirect effect was found ( $\mathrm{b}=0.043, \mathrm{BCa} 95 \% \mathrm{Cl}[0.0151 ; 0.0848], \mathrm{K}^{2}=.044 ; \mathrm{BCa} 95 \% \mathrm{Cl}[0.0157 ; 0.0865]$ ), thereby confirming both hypotheses on the indirect effect of stereotypes on inclusive behavior via attitudes towards the employment of people with disabilities. Both Kappa squared values are situated between .01 and .09 , corresponding to a small effect that reflected $4.4-5.4 \%$ of the largest possible indirect effect (Preacher \& Kelley, 2011).

Table 1. Means, standard deviations, reliability estimates and intercorrelations of study variables

\begin{tabular}{|c|c|c|c|c|c|c|c|c|c|c|}
\hline & Variable & $n$ & $M$ & SD & $a$ & 1 & 2 & 3 & 4 & 5 \\
\hline 1 & Stereotype Warmth & 309 & 3,31 & 0,63 & .67 & - & & & & \\
\hline 2 & Stereotype Competence & 309 & 2.65 & .66 & .80 & $.39^{* *}$ & - & & & \\
\hline 3 & $\begin{array}{l}\text { Attitudes toward the employment } \\
\text { of people with disabilities }\end{array}$ & 313 & 3,85 & .63 & .61 & $.32^{* *}$ & $.24^{* *}$ & - & & \\
\hline 4 & Work Pressure & 311 & 2,58 & .80 & .86 & .02 & -.06 & .02 & - & \\
\hline 5 & Inclusive Behavior & 310 & 4,09 & .62 & .89 & .07 & .04 & $.19^{* *}$ & -.01 & \\
\hline
\end{tabular}

Note: ${ }^{* *} p<.01$. 


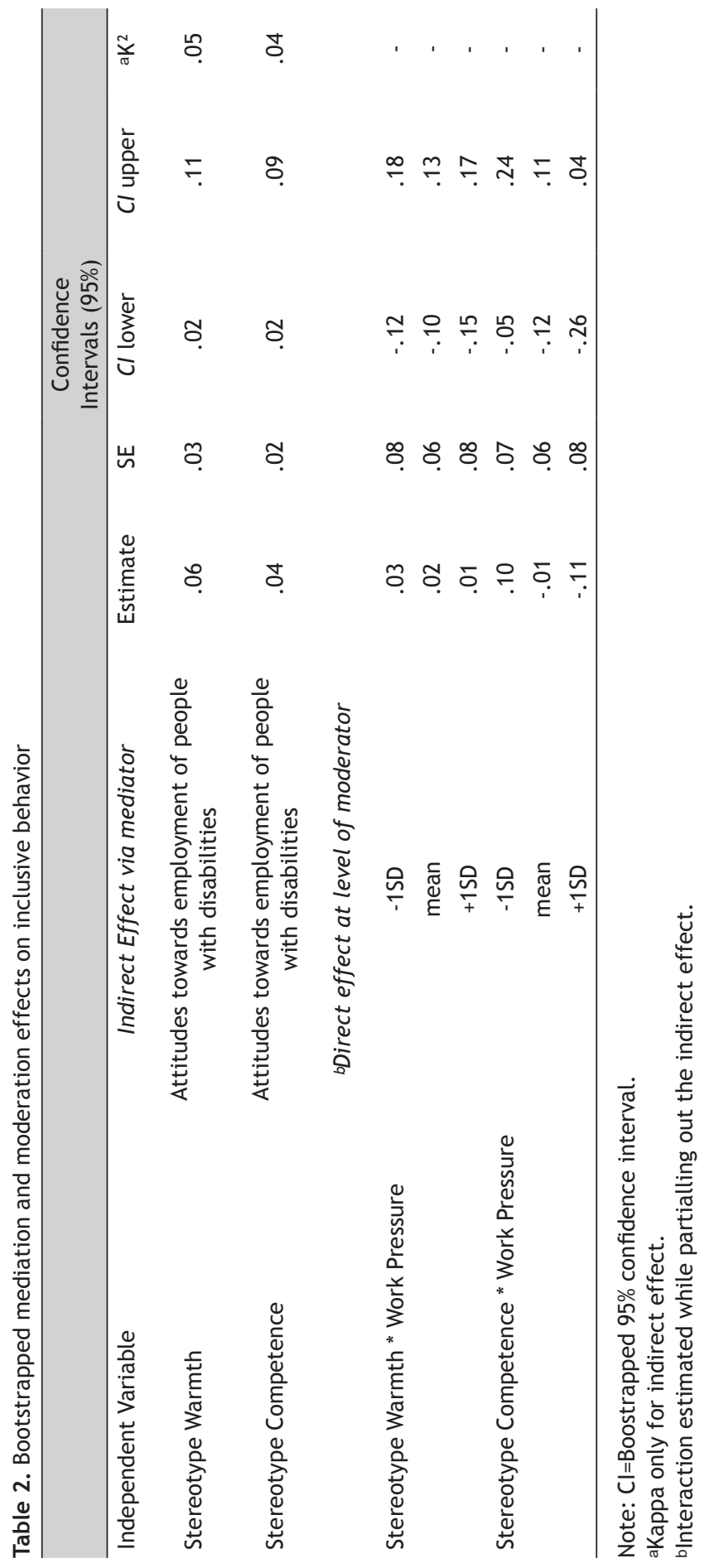


As can be seen in the lower part of Table 2, hypothesis 3a concerning the moderating effect of work pressure on the direct effect of stereotype warmth on inclusive behavior, while controlling for the indirect effect, was not significant $(b=-0.013, p=0.84)$. Hypothesis $3 \mathrm{~b}$ which tested the moderating effect of work pressure on the direct effect of stereotype competence, while controlling for the indirect effect, was significant $(b=-0.128, p=0.42)$. Results of the sample showed a clear antagonistic interaction between stereotype warmth and work pressure on inclusive behavior. The overall pattern was significant in the total interaction, although the conditional effects were not $(\mathrm{Cl}$ low [-0.0490;0.2401]; medium [-0.1163;0.1048]; high [-0.2577;0.0435]. A graphical depiction of this interaction effect is shown in Figure 2.

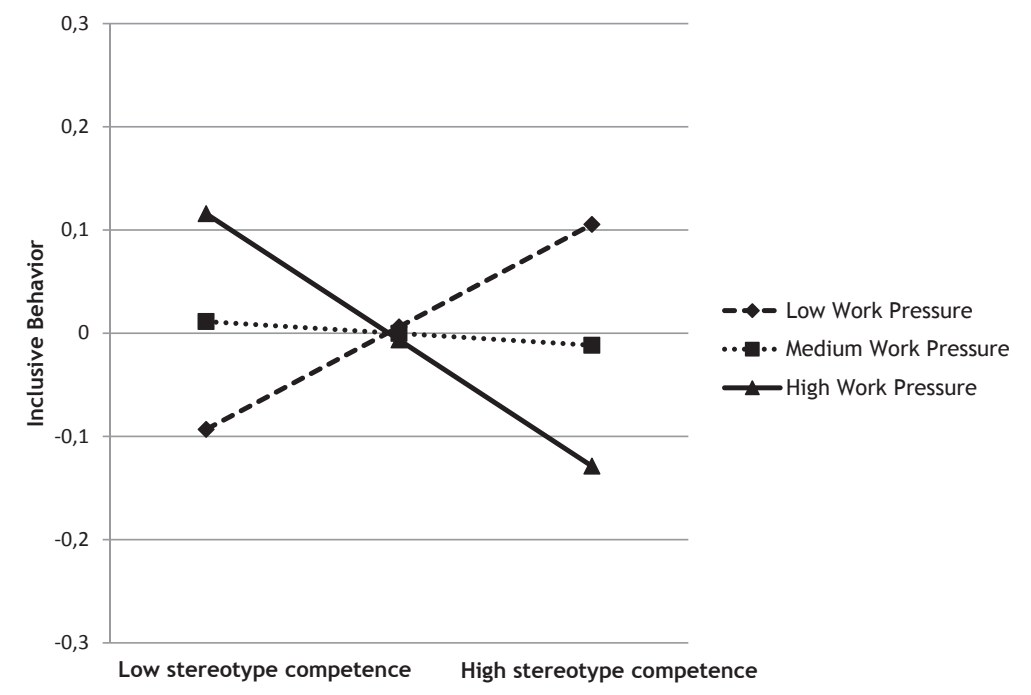

Figure 2. Interaction of inclusive climate and prosocial motivation on individual inclusive behavior.

\section{Discussion}

Work is central in peoples' lives, but for people with disabilities employment might be hindered due to stereotypes and attitudes of their coworkers. Our premise is that if inclusive behavior is displayed, people with disabilities should become better integrated into their work team and inclusion will be facilitated. Therefore this study set out to examine how and when stereotype warmth and competence towards people with disabilities relate to inclusive behavior. This way, we aim to shed light on the factors that influence the inclusion of people with disabilities at the workplace, stated to be one of the research areas in which I/O Psychology should focus on (Colella \& Bruyère, 2011). Thus, in this research we 
studied the work situation of people with disabilities who were already employed, and how the stereotypes and attitudes of their coworkers relate the amount of displayed inclusive behavior.

Our study shows that stereotypes towards people with disabilities are not directly related to inclusive behavior (hypothesis $1 \mathrm{a}$ and $1 \mathrm{~b}$ ), but by building on the Reasoned Action Approach (Fishbein \& Ajzen, 2010) we have been able to demonstrate that there is an indirect relationship of stereotypes through attitudes towards the employment of people with disabilities on inclusive behavior (hypothesis $2 a$ and $2 b$ ). The cognitive appraisal that attitudes give to the beliefs employees have, gives rise to behavior that corresponds to these attitudes. Therefore we claim that employees who have positive attitudes towards the employment of people with disabilities will be more likely to perform inclusive behavior, to allow people with disabilities to perform better, which is a prerequisite on the road to inclusion and possibly even sustainable employment.

With regard to our moderator analyses, while controlling for the indirect effect, we found mixed results. Hypothesis $3 a$, which was concerned with the moderating effect of work pressure on the relationship between stereotype warmth and inclusive behavior did not yield a significant effect. Hypothesis $3 b$, that explored the same effect for stereotype competence, on the other hand, did show a significant interaction. This would mean that employees would display inclusive behavior irrespective of the amount of work pressure they experienced if they rate their colleagues with disabilities high on stereotype warmth. Alternatively, for stereotype competence, it does depend on work pressure whether inclusive behavior will be displayed. The relationship is positive when work pressure is low, but negative when work pressure is high. From these findings, we might infer that 'liking' will more frequently lead to displaying inclusive behavior, whereas 'respect' will only do so in the right circumstances. Perhaps when a person is deemed to be competent at the workplace, there is less need to continuously display inclusive behavior, only when the opportunity presents itself. Being (perceived as) competent is an indispensable facet of work which might lead employees to believe that their colleague with a disabilities are able to fend for themselves and do not need continuous help.

Additionally, this research shows that stereotypes toward people with disabilities need not necessarily lead to prejudice, and thus have a negative connotation. Better still, it might lead to an array of positive behavior. That is, the way stereotypes are interpreted depends on the cognitive appraisal of coworkers who will check their opinion on the willingness to display the corresponding volitional inclusive behavior. To conclude, stereotype warmth and stereotype competence, via attitudes, toward people with disabilities play an important role in the amount of displayed inclusive behavior. Since inclusive behavior is thought to have positive consequences to the inclusion of people with disabilities, work in such a setting is essential for inclusive organizations. 


\section{Strengths, Limitations, and Directions for Future Research}

A notable strength of this study is the multiple source data we used (predictors assessed by team members and inclusive behavior by work colleagues) allowing for independent assessments of inclusive behavior and the reduction of common method bias.

The present study is not without its limitations, which should be considered in future research. First, our results are based on cross-sectional data. Our mediation analysis does not warrant a causal pathway. However, based on the Reasoned Action Approach, this setup of variables seems the most plausible. We therefore assume that the pathways of variables presented cannot be reversed or be seen as reciprocal. Second, as our study was framed on only a section of the Reasoned Action Approach, future research might want to study the complete theory and incorporate perceived norms and perceived control into their model. This way, the additive value of these variables can provide this line of research with a broader view on how to influence inclusive behavior.

Our study provided valuable insights into the factors that contribute to the inclusion of people with disabilities once they have entered the labor market. More empirical research is needed to address the aspects that might influence the work situation of people with disabilities. Moreover, with regard to the potential positive consequences of inclusive behavior, relationships to performance, productivity, and well-being need to be addressed in future research; in order to make sure that inclusive behavior does indeed lead to a higher degree of inclusion and ultimately more sustainable employment for people with disabilities.

\section{Practical Implications}

Inclusive organizations should keep in mind that the employment of people with disabilities will activate certain stereotypes and beliefs within their staff that have an impact on the treatment of people with disabilities at work. Attitudes toward the employment of people with disabilities and perceived work pressure play a role determining the nature of this relationship. Both can be malleable by organizational interventions, therefore inclusive organizations need to adapt their strategy to their corporate social responsibility goals. These strategies aimed at an increase inclusive behavior can be implemented on three levels; individual, team, and organizational level.

Interventions can be planned throughout entire organizations to focus on individual change. Stone and Colella (1996) have argued that organizations should develop training programs that counter the misleading information that may have been engendered by stereotypes, on norms of day to day interaction, and on decreasing feelings of anxiety while working with people with disabilities. Hunt and Hunt (2004) state that attitudes can only be changed by challenging peoples' beliefs. They therefore devised an educational intervention which increased knowledge on and yielded positive attitudes towards people 
with disabilities in the workplace. This indicates the importance of an active inclusive organization that needs to put organizational goals into practice. Secondly, also at team level there are many factors that might have an influence on the amount of displayed inclusive behavior. It has been shown that work environments that are fair and responsive are specifically beneficial for people with disabilities (Schur et al., 2009). Team leaders can thus have major influence on the daily practices and procedures that constitute a work climate and should therefore be made aware of the important role they play in the display of inclusive behavior. Lastly, inclusive organizations that wish to attain a diverse workforce are advised to incorporate corporate sustainable responsibility in their mission statements. An active implementation of the values that foster belonging is key to achieve sustainable employment for people with disabilities (Schur et al., 2009). 
How and When Stereotypes Relate to Helping Behavior toward People with Disabilities 


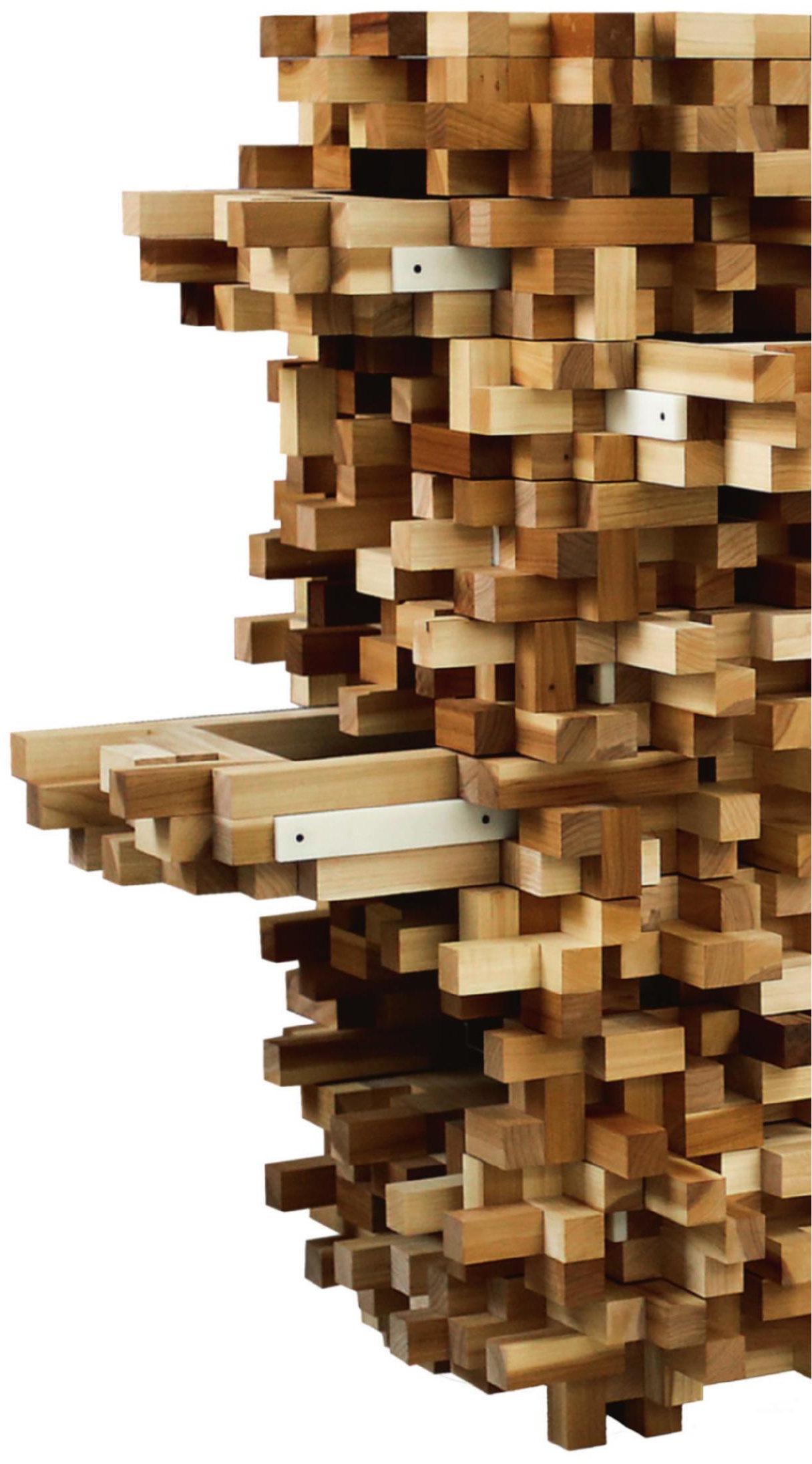




\section{CHAPTER 3}

\section{Lending a Helping Hand at Work:}

\section{A Multilevel Investigation of Prosocial Motivation, Inclusive Climate and Inclusive Behavior}

Published as:

Nelissen, P. T. J. H., Hülsheger, U. R., van Ruitenbeek, G. M. C., \& Zijlstra, F. R. H. (2016). Lending a helping hand at work: A multilevel investigation of prosocial motivation, inclusive climate and inclusive behavior. Journal of Occupational Rehabilitation, 1-10. http://doi. org/10.1007/s10926-016-9680-z 


\begin{abstract}
Purpose - People with disabilities often encounter difficulties at the workplace such as exclusion or unfair treatment. Researchers have therefore pointed to the need to focus on behavior that fosters inclusion as well as variables that are antecedents of such 'inclusive behavior'. Therefore the purpose of this study was to research the relationship between prosocial motivation, team inclusive climate and employee inclusive behavior. Method - A survey was conducted among a sample of 282 paired employees and colleagues, which were nested in 84 teams. Employees self-rated prosocial motivation and team inclusive climate, their inclusive behavior was assessed by colleagues. Hypotheses were tested using multilevel random coefficient modeling.

Results - Employees who are prosocially motivated will display more inclusive behavior towards people with disabilities, and this relationship is moderated by team inclusive climate in such a way that the relationship is stronger when the inclusive climate is high.

Conclusion - This study shows that inclusive organizations, which value a diverse workforce, need to be aware of not only individual employee characteristics, but also team level climate to ensure the smooth integrations of people with disabilities into regular work teams.
\end{abstract}

Key words: inclusive climate, inclusive (helping) behavior, prosocial motivation, people with disabilities, workplace inclusion, multilevel modeling 


\section{Introduction}

In an ever changing European society that is currently discerning both the rising number of baby-boom generation retirees and a diminishing labor force, there is a need to focus on employing disadvantaged groups, such as people with disabilities. Not only to embrace people with disabilities in working society or to counter their low employment rates, but also to allow the social security system to be upheld (European Commission, 2007; Nelissen et al., 2014). Therefore, the European Commission stimulates the participation of people with (physical and non-physical) disabilities to the labor market in their 2011-2014 strategy by stressing that corporate social responsibility is beneficial to both enterprises and the society as a whole (European Commission, 2011; Lindgreen \& Swaen, 2010). In the US, legislation such as the ADA (Americans with Disabilities Act, 1990) and the ADAAA (ADA Amendments Act, 2008) were devised to attain similar goals and protect people with disabilities from employment discrimination. However, employment issues and biases (e.g. disclosure decisions, low performance expectations, stereotyping, limited growth opportunities, or high involuntary turnover) persist for people with disabilities once they have entered the labor market (Colella \& Bruyère, 2011; Santuzzi et al., 2014). Some of these problems often originate from exclusion and unfair treatment by their work colleagues (Stone \& Colella, 1996). To address such issues there is a need to learn more about how organizations can facilitate inclusion. Yet, research on how inclusion in organizations can be fostered remains scarce, and Industrial and Organizational (IO) research is requested to focus on factors that enable the accommodation of people with disabilities at the workplace (Colella \& Bruyère, 2011; Santuzzi et al., 2014). With the present study we follow this call by studying factors that contribute to inclusion both at the individual- and the team-level of analysis. Specifically, we build upon the prosocial motivation and the team climate literatures and suggest that individual prosocial motivation and team inclusive climate both contribute to foster inclusion at work. As an outcome variable, we focus on inclusive behavior, which we conceptualize as a form of citizenship or helping behavior that is specifically directed at coworkers with disabilities (Nelissen, Hülsheger, van Ruitenbeek, \& Zijlstra, 2016). Figure 1 depicts the corresponding model. 


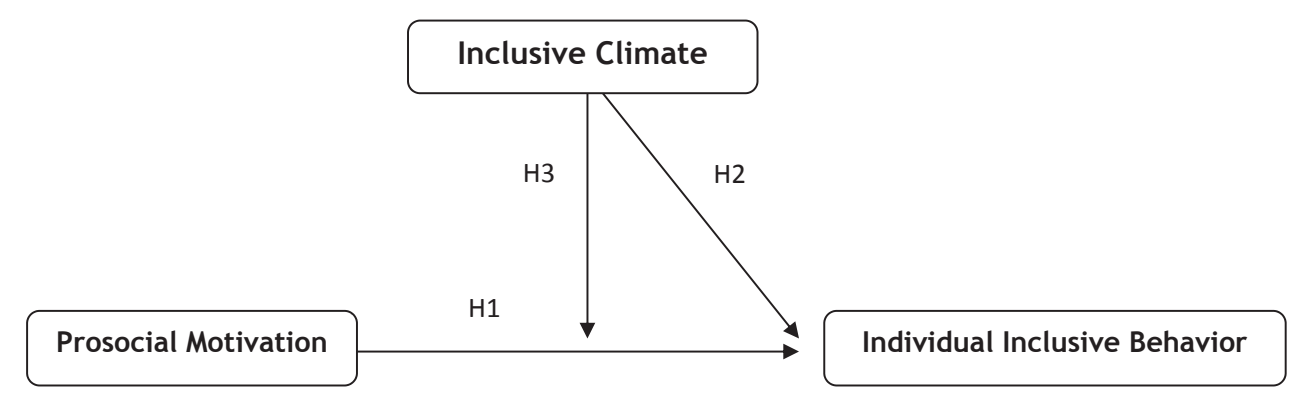

Figure 1. Multilevel and cross-level processes of inclusive behavior

\section{Inclusive Behavior}

Helping behavior at the workplace, in general, has received a lot of research attention in various forms such as (a) organizational citizenship behavior (OCB) (Penner, Midili, \& Kegelmeyer, 1997; Wright, Wright, \& Sablynski, 2008), (b) prosocial behavior (Grant \& Gino, 2010; McNeely \& Meglino, 1994; Penner, Dovidio, Piliavin, \& Schroeder, 2005), (c) citizenship performance (Borman, Penner, Allen, \& Motowidlo, 2001), and (d) volunteer activities (M. A. Finkelstein, Penner, \& Brannick, 2005; Penner \& Finkelstein, 1998). These helping behaviors are clearly related concepts that have an important conceptual overlap since all of them refer to extra role behaviors which are volitional, discretionary and intended to benefit others (Borman et al., 2001; Penner et al., 2005; Rioux \& Penner, 2001). Organizational citizenship behavior reflects behavior that goes above and beyond the job description, and can be defined as "performance that supports the social and psychological environment in which task performance takes place" [18, p.95] Most importantly, studies on helping behavior have made important contributions by revealing the beneficial consequences of helping on an individual, team, and organizational level, such as increase of employee performance and productivity (N. P. Podsakoff et al., 2009), but also employee well-being (Weinstein \& Ryan, 2010). Similarly, the present study aims at extending the line of prosocially motivated helping research by focusing on a specific kind of citizenship behavior that is tailored towards employees with disabilities, which we label inclusive behavior (Nelissen et al., 2016). We therefore define inclusive behavior as extra role behavior that is intended to benefit people with disabilities at work. Parallel to the concept of OCBI (organizational citizenship behavior which targets to benefit the individual, and therefore indirectly benefits the organization), it is set up to represent the courtesy and altruism dimension of OCB (Lepine et al., 2002; N. P. Podsakoff et al., 2009; P. M. Podsakoff et al., 1990; Williams \& Anderson, 1991). The goal of inclusive behavior is to benefit colleagues with disabilities at work by means of providing help with a relevant problem at the workplace (altruism) or by preventing such work-related problems (courtesy). 


\section{Prosocial Motivation and Inclusive Behavior}

Motivation explains why individuals initiate, direct, and prolong certain work related actions in general (Batson, 1987; Pinder, 1984). Work related actions that are specifically aimed at benefiting others, such as coworkers, are deemed to stem from prosocial motivation (Batson, 1987). Prosocial motivation, in turn, originates from the desire to meet internally set goals, and to stay true to one's identity (Grant, 2008). Moreover, prosocial motivation is argued to have its roots in people's prosocial dispositions, values, and motives (Grant \& Berg, 2010; Grant \& Mayer, 2009; Rioux \& Penner, 2001). Prosocial motives and motivation therefore bear some similarities in that both represent an active concern for the welfare of others (Schwartz \& Bilsky, 1987), a need to be helpful, as well as a desire to build helpful relationships with others (Rioux \& Penner, 2001).

In order to identify the motives or values that bring employees to engage in citizenship behaviors, researchers have used a functional approach (Penner et al., 1997; Rioux \& Penner, 2001; Snyder, 1993). The functional approach to motivation aims to clarify why people decide to perform extra-role behaviors (Arthaud-Day, Rode, \& Turnley, 2012) and suggests that people will willingly engage in helping behavior because such actions meet their own needs and it allows them to reach set goals (Rioux \& Penner, 2001). Motives and values will thus provide insight in the rationale of people's actions (Arthaud-Day et al., 2012). As prosocial values capture individuals' need to be helpful and a desire to build positive relationships with others (Rioux \& Penner, 2001), employees with prosocial values will thus be more inclined to engage in helping behavior in general, including inclusive behavior. Furthermore, employees who are prosocially motivated have the desire to perform beneficial actions for others, because they care about changing others' lives for the better (Grant, 2007), and will therefore be more inclined to display prosocial and other helping behaviors (Grant \& Berg, 2010). A number of studies have provided empirical evidence for the relationship between prosocial motivation and different kinds of helping or prosocial behavior (e.g. (Grant, 2007; Grant \& Mayer, 2009; Rioux \& Penner, 2001). Specifically, in organizations which aim and value a diverse workforce that includes people with disabilities, prosocially motivated employees will have apt opportunities to help others and display inclusive behavior.

Given the arguments presented above, we expect that prosocially motivated employees will be more inclined to go the extra mile by displaying more inclusive behavior than low prosocially motivated employees.

Hypothesis 1: There is a positive relationship between prosocial motivation and individual inclusive behavior. 


\section{The Role of Context}

Although we expect to find an overall positive relationship between employees' prosocial motivation and inclusive behavior, we expect that contextual factors influence the strength of this relationship. A number of studies have revealed a positive relationship between prosocial factors and various forms of helping behavior (Grant \& Gino, 2010; McNeely \& Meglino, 1994). Grant and Mayer (Grant \& Mayer, 2009), however, argued that future research should consider moderators in order to gain a more comprehensive understanding under which conditions prosocial motivation results in citizenship behavior. Looking into moderators at the individual level of analysis, Grant and Mayer (Grant \& Mayer, 2009) were able to show that impression management motives interact with prosocial motives in predicting citizenship behavior. Additionally, Maner and Gailliot (Maner \& Gailliot, 2007) found that kinship influences the motivation-helping dyad, in such a way that motivation predicts helping behavior more strongly if participants are related. Other research illustrates that the relationship between prosocial motivation and prosocial behavior is influenced by the way jobs are designed (Grant et al., 2007; Grant \& Berg, 2010): The prosocial motivationhelping behavior relationship was stronger when employees had the opportunity to witness the perceived beneficial consequences of their actions.

In the present study we build upon and extend these findings on individual-level moderators of the prosocial motivation - behavior link by investigating how contextual, teamlevel variables shape the prosocial motivation - inclusive behavior relationship. In recent years, researchers have increasingly started to focus on contextual variables of the work environment, investigating them not only as direct predictors of individual work behavior but also as moderators (Choi, 2006; Hirst, Van Knippenberg, \& Zhou, 2009; L. James et al., 2008; Johns, 2006). Since organizations are multilevel entities, it is important to take into account variables at more than one level (Choi, 2006), as considering contextual variables as moderators helps shedding light on relationships that might otherwise be overlooked (Johns, 2006). In this way, a study on individual helping behavior found that group trust moderates the relationship between affective commitment and interpersonal helping behavior (Choi, 2006), such that employees are more likely to help others when interpersonal trust was high. Arthaud-Day, Rode, and Turnley (2012) argued that the environment in which a group of people has similar values, is deemed to reinforce or weaken the individual level relationship; specifically, team-level power and team-level self-direction either weakened or strengthened the relationship between individual power and individual self-direction and $O C B$, respectively. 
To continue on this new multilevel road, the goal of the present study is to go beyond the individual level and to shed light on team-level conditions that channel the relationship between prosocial motivation and inclusive behavior. Specifically, we introduce the concept of "inclusive climate" and investigate its role as a contextual variable on the relationship of prosocial motivation with inclusive behavior. In general, climate refers to the overall perceptions of the work environment at an aggregated or team level that represents the shared psychological meanings of a group (L. James et al., 2008; Benjamin Schneider \& Reichers, 1983). Colella and Bruyère (2011) defined workplace inclusion as the degree to which "people with disabilities are accepted, helped, and treated as others by their coworkers"[5, p. 492-493]. We look at inclusion at the team level of analysis and consequently define inclusive climate as team members' norms and perceptions of the way people with disabilities are accepted, helped, and treated in their team. We build on literature on collectivistic norms (Ehrhart \& Naumann, 2004) in arguing that inclusive climate has both a direct and an indirect influence on the amount of displayed inclusive behavior by individual team members.

\section{Inclusive Climate and Individual Inclusive Behavior}

When people form groups, norms are created to guide behavior (Ehrhart \& Naumann, 2004). As group norms are used as guidelines for employees to act within their social work setting, they will govern behavior according to the procedures set by the work group (Ehrhart \& Naumann, 2004). When being inclusive becomes the standard way to act in a group, employees will thus try to adhere to that norm in order to behave in a socially consistent way. In addition, specific group norms such as the norm to behave socially responsible might contribute to inclusive behavior because people attempt to preserve a positive view on themselves (Penner et al., 2005). Furthermore, people who are focused on the collective, place high value on belonging to a group, and will therefore easily adhere to group norms to foster group well-being (Moorman \& Blakely, 1995). Even merely the prevalence of collectivistic norms may engage employees to express more prosocial motivation because norms dictate that group well-being is important (Grant \& Berg, 2010). Similarly, workers who adhere to collectivistic norms have been found to be related to within group helping behavior (M. A. Finkelstein, 2012). In all, collectivistic group norms, such as prevalent in a positive inclusive climate, might be positively related to inclusive behavior.

Hypothesis 2: There is a positive relationship between inclusive climate and individual inclusive behavior. 
The Moderating Role of Inclusive Climate on the Prosocial Motivation-Inclusive Behavior Link

In the preceding sections we proposed that both, individual prosocial motivation and team inclusive climate are positively related to individual inclusive behavior. Here we argue that they also interact in predicting individual inclusive behavior.

Team climate refers to the shared perceptions of the work environment in a group that make up the implicit rules which team members follow (Benjamin Schneider \& Reichers, 1983). Accordingly, inclusive climate refers to the implicit rules team members adhere to about the way people with disabilities are accepted, helped and treated within the work team. Thus when inclusive climate for work groups is high, there will be a shared vision and set of rules on positive behavior that is acceptable and valued within the group, such as inclusive behavior. Both employees high and low in prosocial motivation, influenced by a high inclusive climate are consequently more likely to adhere to group norms and display more inclusive behavior. Therefore, inclusive climate might shape the expression of individual dispositions like prosocial motivation. Moreover, climates in general that aim to create positive environments have been argued to augment employees' views on displaying citizenship behaviors (Walumbwa, Hartnell, \& Oke, 2010).

In contrast, in work groups that rate the inclusive climate to be low, employees are likely to perceive that inclusive norms are less valued. In such a situation there is a reduced emphasis on inclusion toward people with disabilities and no external need to display inclusive behavior. However, as suggested earlier, based on the functional approach (Penner et al., 1997; Rioux \& Penner, 2001; Snyder, 1993), one would expect those employees who are high in prosocial motivation to display inclusive behavior regardless of the external climate whereas this is less likely for employees with low prosocial motivation. We therefore hypothesize that inclusive climate interacts with prosocial motivation in predicting inclusive behavior.

Hypothesis 3: Inclusive climate moderates the relationship between individual prosocial motivation and individual inclusive behavior, such that the relationship is stronger when inclusive climate is low and weaker when inclusive climate is high.

\section{Method}

\section{Participants and Procedure}

Respondents were 372 team members of 103 work teams from seven organizations, located throughout the Netherlands (response rate $=35 \%$ ). The organizations were active in e.g. the healthcare sector, super market industry, and the disability employment sector. The 
data used in this study was collected as part of a larger 4-year research project on inclusive organizations. Another publication that resulted from this project is Nelissen et al. (2015) on how and when stereotypes relate to inclusive behavior toward people with disabilities.

Team members worked in teams with a minimum of three colleagues with the addition of one coworker with a disability (including various physical, cognitive, mental, sensory, and developmental impairments). All employees who work in teams with people with disabilities were provided with a personalized envelope containing two sets of questionnaires, one self-report questionnaire and one for their peers. All team members (except for the team member with a disability) filled in the inclusive team climate measure and provided selfratings on prosocial motivation.

Individual inclusive behavior was assessed by peer-ratings, provided by 313 work colleagues (response rate $29.4 \%$ ). These peers were selected by the target participant, who was instructed to pair up with a colleague who knew him/her well, and regularly observed their daily work practices. Independently choosing a peer is common procedure to obtain reliable multiple source data (Rioux \& Penner, 2001).

The final sample consisted of data for 282 team members, distributed over 84 teams: Data for 35 participants was omitted because they worked in teams in which less than 3 members had responded; data for 55 participants could not be included in analyses because no peer-ratings of inclusive behavior were available. The average team size was 4.30 (SD $=1.41$, ranging from 3-9 members/team). Jobs of team members entailed e.g. shelf restockers $(42 \%)$, nurses $(10 \%)$, or cashiers $(8 \%)$. Team members were $46 \%$ male, with a total average tenure of 12.6 years $(S D=10.53)$, and 38 years of age $(S D=13.84)$.

\section{Measures}

All measures, apart from the inclusive climate measure, were adopted from English and translated into Dutch with a translation and back-translation process, whilst taking into account the guidelines for test translation and adaptation (Hambleton, 2001). All scales were assessed on a 5-point Likert scale ranging from 1 (strongly disagree) to 5 (strongly agree).

Individual team members provided ratings on prosocial motivation, and inclusive climate.

Prosocial motivation. Participants completed the 5 items of the prosocial motivation measure put forward by Grant and Sumanth (2009). Sample items are "I prefer to work on tasks that allow me to have a positive impact on others", "It is important to me to have the opportunity to use my abilities to benefit others". Cronbach's Alpha was $a=.86$.

Inclusive climate. Since, to our knowledge, a measure of inclusive climate has not yet been proposed in the literature, we developed an inclusive climate measure. It consisted of 5 items, mirroring the definition of inclusive climate presented above: "In my team people with disabilities are accepted," "In my team people with disabilities are helped," 
"In my team people with disabilities are treated as other colleagues," "In my team we are attentive to the needs of people with disabilities", and "In my team we are attentive to the opportunities of people with disabilities" $(a=.90)$. We calculated both within-group agreement $(r w g(j))$ and intra class coefficients (ICC) to provide empirical justification for aggregating data to the team level (LeBreton \& Senter, 2007). The mean rwg(j) of inclusive climate was .85. Following LeBreton and Senter (LeBreton \& Senter, 2007) values lying between .71 and .90 indicate strong agreement among raters. Furthermore, analyses revealed an ICC1 value of .18, and ICC2 value of .43. ICC1 values lying between .10 and .25 indicate a medium to strong effect, justifying aggregation to the team level (LeBreton \& Senter, 2007).

Peers (work colleagues) provided ratings on the target person's inclusive behavior.

Inclusive behavior. We assessed inclusive behavior with an 8-item scale adapted from the altruism and courtesy subscales of a measure of organizational citizenship behavior (Nelissen et al., 2016; P. M. Podsakoff et al., 1990). The scales were adapted to the viewpoint of the participant: peers' questionnaires referred to their colleague $(a=.89)$. The questions were; "My colleague does not abuse the right of people with disabilities", "My colleague tries to avoid creating problems with people with disabilities", "My colleague considers the impact of his/her actions on people with disabilities", "My colleague helps people with disabilities who have been absent", "My colleague helps people with disabilities who have heavy workloads", "My colleague helps orient new people with disabilities even though it is not required", "My colleague willingly helps people with disabilities who have work related problems", "My colleague is always ready to lend a helping hand to people with disabilities around him/her".

\section{Statistical Analysis}

We conducted multilevel random coefficient modeling following Bliese (2009), using the nlme package (linear and nonlinear mixed effect models; (Pinheiro, Bates, DebRoy, \& Sarkar, 2011) and the multilevel (Bliese, 2012) package in the R environment (R Core Team, 2012). Multilevel random coefficient modeling is a statistical procedure developed for testing hierarchically nested data structures, such as ours where employees (level 1) are nested in work teams (level 2). Predictor variables at both levels were grand mean centered following recommendations to base centering decisions on theoretical considerations (Aguinis, Gottfredson, \& Culpepper, 2013; Bliese, 2002). Our theoretical argumentation does not suggest a frog-pond model (in which researchers are interested in deviations from the team average), but rather suggests that absolute levels of prosocial motivation are related to inclusive behavior. Accordingly, we grand-mean-centered level 1 variables. 


\section{Results}

Means, standard deviations, and intercorrelations between study variables are displayed in Table 1.To test Hypotheses 1 and 2, we conducted a multilevel analysis predicting individual inclusive behavior from individual prosocial motivation and team inclusive climate (see Table 2, Model1). Results revealed that individual prosocial motivation was positively related to individual inclusive behavior (estimate $=.21, p<.001$ ), supporting Hypothesis 1 . Furthermore, in line with Hypothesis 2, inclusive team climate was significantly related to individual inclusive behavior (estimate $=.51, p<.001$ ).

Table 1. Means (M), Standard Deviations (SD), Reliability Estimates (a) and Intercorrelations of Study Variables

\begin{tabular}{lccccccc}
\hline \multicolumn{1}{c}{ Variable } & $n$ & $M$ & SD & a & 1 & 2 & 3 \\
\hline Individual Level & & & & & & & \\
$1 \quad$ Prosocial Motivation & 279 & 4.07 & .59 & .86 & - & & \\
$2 \quad$ Individual Inclusive Behavior & 282 & 4.06 & .61 & .89 & $.28^{* *}$ & - & \\
Team Level & & & & & & & \\
$3 \quad$ Inclusive Climate & 84 & 3.97 & .77 & .90 & $.43^{* *}$ & $.38^{* *}$ & - \\
\hline
\end{tabular}

Note. Means, standard deviations, and reliability estimates are individual level.

${ }^{* *} \mathrm{p}<.01$

To test the moderating role of team inclusive climate (Hypothesis 3), we followed the procedure described in Bliese (Bliese, 2009). Accordingly, we added a random slope for prosocial motivation in Model 2. We then investigated whether Model 2 provided a better fit to the data than Model 1. Model comparisons were conducted using the anova function provided in the nlme package which tests differences in model deviances (using -2log likelihood values) between both models based on a chi-square distribution (Bliese, 2009). Although -2 log likelihood values were slightly lower for Model 2 compared to Model 1 , the difference was not statistically significant $\left(x^{2}(2)=3.73, p>.05\right)$. However, due to the low power of such tests, researchers have strongly recommended testing theoretically hypothesized cross-level interactions regardless of significance of slope variance (as estimated with likelihood ratio tests (LaHuis \& Ferguson, 2007). We therefore proceeded to test whether team inclusive climate interacted with prosocial motivation in predicting inclusive behavior (Hypothesis 3). Accordingly, Model 3 revealed a significant interaction between prosocial motivation and team inclusive climate (estimate $=-0.27, p<.05$ ), supporting Hypothesis $3^{4}$. Simple slopes analyses revealed a significant relation between

\footnotetext{
${ }^{4}$ Since some authors have recommended group mean centering when testing cross-level interactions (Aguinis et al., 2013; Enders \& Tofighi, 2007), we ran the same set of analyses group-mean-centering prosocial motivation. The same pattern of results emerged, although the cross-level interaction was somewhat weaker $(p=.10)$.
} 
prosocial motivation and inclusive behavior when inclusive climate was low $(B=.49$, $p<.01)$, and no significant relationship when inclusive climate was high $(B=-.06$, n.s $)$. A graphical depiction of this interaction effect is shown in Figure 2.

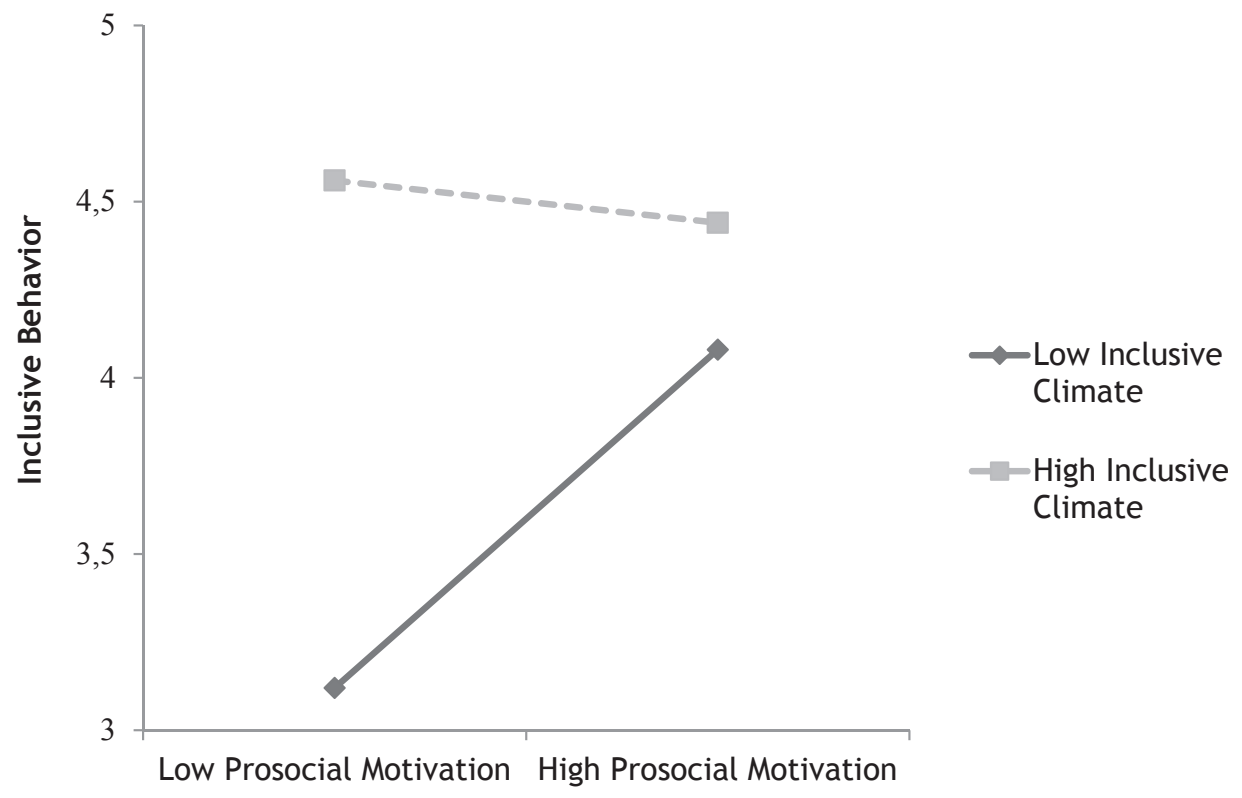

Figure 2. Interaction of inclusive climate and prosocial motivation on individual inclusive behavior 


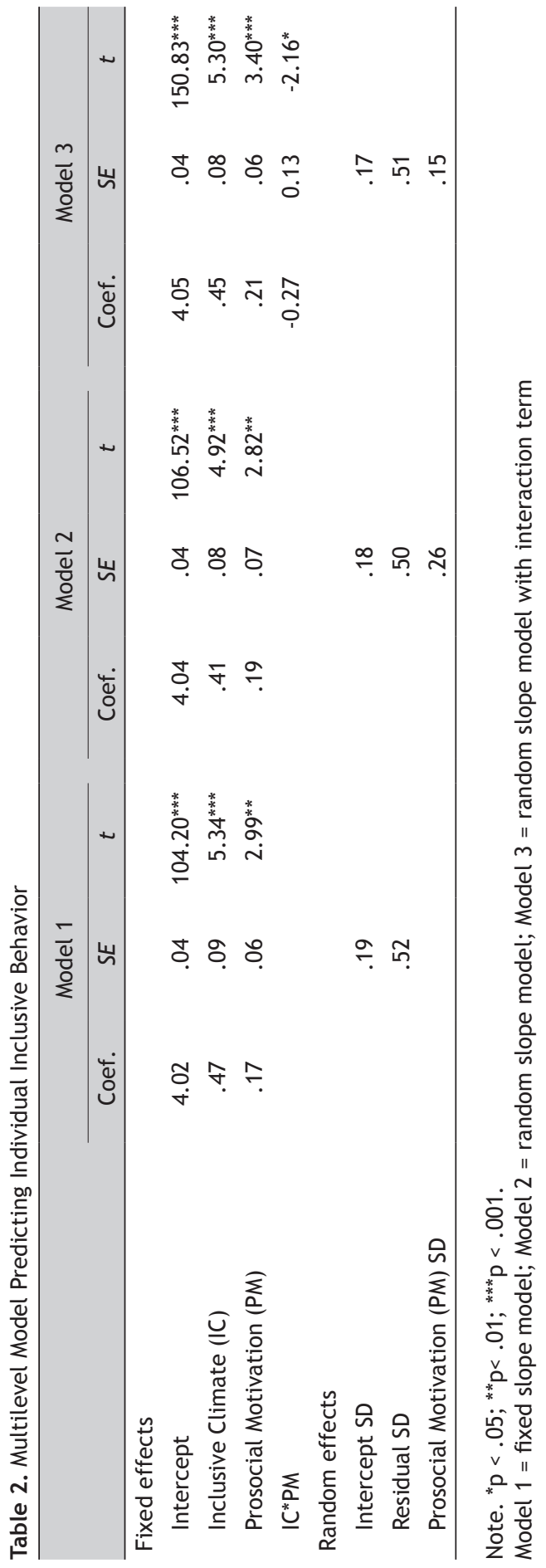




\section{Discussion}

In response to recent calls in the literature that prosocial motivation might have broader social implications with regards to corporate social responsibility (Grant \& Berg, 2010), this study set out to investigate the relationship of prosocial motivation and helping behavior directed at people with disabilities, referred to as inclusive behavior. We furthermore aimed to extend the multilevel literature on team level contextual variables that influence individual level relationships, by showing that the inclusive climate might be an important boundary condition for the display of inclusive behavior. Specifically, our study shows that prosocial motivation is positively related to individual inclusive behavior, as has been previously found in relation to helping behavior in general (Grant \& Mayer, 2009). The confirmation of Hypothesis 1 validates our premise that, from the perspective of the functional approach, people might try to satisfy their needs and goals by displaying inclusive behavior.

Furthermore, our study demonstrates that climate is an important contextual variable that has both direct and indirect effects on individual inclusive behavior. In particular when people with disabilities are concerned, colleagues showed more inclusive behavior when the group had an inclusive climate. More specifically, Hypotheses 2 and 3 were confirmed and we found that inclusive climate is not only directly related to individual inclusive behavior, but that it also moderates the relationship between prosocial motivation and individual inclusive behavior. This interaction reveals that a high inclusive climate as a team level variable seems to be strong enough to shape the individual's prosocial motivation. This shows that certain situations can be strong enough to restrain individual characteristics, because employees will adhere to the group settings as long as the norms are perceived in a collectivistic manner. These findings highlight the importance of a multilevel approach, because team level variables might show to have an overarching effect on individual inclusive behavior, which might not have been revealed using a single level approach.

From a theoretical point of view, our study aims to extend the understanding of contextual variables, such as inclusive climate, as multilevel occurrences, which have rarely been investigated in relation to helping behavior. Our research adds to current knowledge on helping behavior by showing that the relationship between prosocial motivation on the one hand, and helping behavior on the other hand, is not only confirmed, but also encompasses the specific kind of helping behavior towards people with disabilities. Furthermore, our results may contribute to previous qualitative studies in acknowledging the importance of the way people with disabilities are treated in the workplace (Schur et al., 2005) and may pertain to aid the organizational socialization process which has beneficial effects on performance, job satisfaction and even turnover intentions of people with disabilities (Colella, 1994). Additionally, in general terms, characteristics of the workplace at the 
departmental and individual level have been put forward as being important to the inclusion and participation level of people with disabilities (Wehman, 2003). Therefore, our findings on team inclusive climate and individual prosocial motivation can provide insight in factors that contribute to the workplace inclusion of people with disabilities, thereby serving the goal of this study.

Finally, our study contributes to the emerging field of corporate social responsibility; this research meets the call for new directions in 10 Psychology by Colella and Bruyère (2011) to address the gap in literature on what happens to people with disabilities once they enter the labor market. However, with a focus on factors that contribute to the inclusion of people with disabilities seen from a multilevel perspective. This new direction can be seen as an important issue to researchers, as the work-life journey of people with disabilities only begins when they find work.

\section{Limitations, Strengths, and Directions for Future Research}

Our study has some limitations that should be considered in future research. First, our results are based on cross-sectional data. We can therefore not draw any causal inferences based from our data and causal pathways may also be reversed or reciprocal. Although theory suggests, that causal pathways are such that prosocial motivation and inclusive climate precede inclusive behavior, we cannot rule out that, for instance, inclusive behavior also influences inclusive climate. In our situation, it is however not reasonable to assume that the ratings of peers would have an influence on the behavior of the employees. The displayed behavior of employees, on the other hand, should have an effect on the ratings of their peers. Future research may therefore benefit from investigating relationships, ideally with a cross-lagged panel design, allowing to investigate reverse and reciprocal causation.

Second, the relatively low response rate of $35 \%$ and $29.4 \%$ for employees and their peers, respectively, might give rise to a non-response bias. However, when examining the response rates in more detail, it shows that the low number of returned questionnaires is mainly due to one organization. This organization had the potential of providing many work teams but was still in a pilot project phase, a situation which could explain the lower response rate. The other 6 organizations provided a normal response rate of $58.9 \%$ and $53.8 \%$ respectively (Baruch \& Holtom, 2008).

Thirdly, employees worked with employees that have a large variety of disabilities, encompassing physical, cognitive, mental, sensory, and developmental disabilities. Since employees may react differently to people with different sorts of disabilities, effects of type of disability both as a predictor of inclusive behavior as well as a moderator, may also be investigated in future research. In addition, inclusive behavior was assessed, using a questionnaire, whereas observations of actual behavior at the workplace by independent observers rather than work colleagues would have obtained data that may be less susceptible 
to social desirable responding. However, a notable strength of this study is the multiple source data we used (predictors assessed by team members and inclusive behavior by work colleagues) allowing for independent assessments of inclusive behavior and subsequently the reduction of common method bias (Spector, 2001).

Our study provided valuable first insights into the factors that contribute to the inclusion of people with disabilities once they have entered the labor market. More empirical research is needed to address the aspects that might influence the work situation of people with disabilities. Moreover, with regard to inclusive behavior, relationships to performance, productivity, well-being, as well as the opinions of people with disabilities on these matters, need to be addressed in future research; in order to make sure that inclusive behavior does indeed lead to a better integration and more sustainable employment for people with disabilities.

\section{Practical Implications}

Inclusive behavior and inclusive climate are conceptualized as prerequisites for the boundary conditions of inclusion for people with disabilities, and are generally sought after in inclusive organizations that value a diverse workforce (Nijhuis et al., 2011; Zijlstra et al., 2012). Whereas previous studies have focused on the organizational socialization and the need for external and internal support for people with disabilities (Colella, 1994), we argue that the prevalence of inclusive behavior might help to attain inclusion for people with disabilities in inclusive organizations. Inclusion of people with disabilities in their team is deemed to be an important factor for success in the workplace (Colella \& Bruyère, 2011).

This study shows that inclusive organizations need to be aware of not only individual employee characteristics, but also team level climate to ensure the smooth integrations of people with disabilities into regular work teams. These findings may provide opportunities for organizations to become more inclusive, and attract a more diverse workforce. It is hard to change employees' individual mindset or motivation, but it is actually feasible to foster the inclusive climate. By expressing an inclusive mindset at an organizational level, but also through educating team leaders and supervisors to iterate the inclusive message, climates can be shaped. Supervisors have a strong hand in transforming their teams by leading by example in norms and values, which fit the general criteria of a climate.

Fostering sustainable employment for employees with disabilities might be a first step to address some of today's society major issues. Future employment levels are decreasing because the baby-boom generation has reached the age of retirement, whilst on the other hand, several groups, such as people with disabilities, are not considered to participate in the labor force (Zijlstra et al., 2012). Thus, seeking to integrate people with a broad range of disabilities more fully into the workforce might counter the unemployment rates, and signify a cut back on welfare payments, but especially allow people with disabilities to fully participate in our society. 
Lending a Helping Hand at Work 


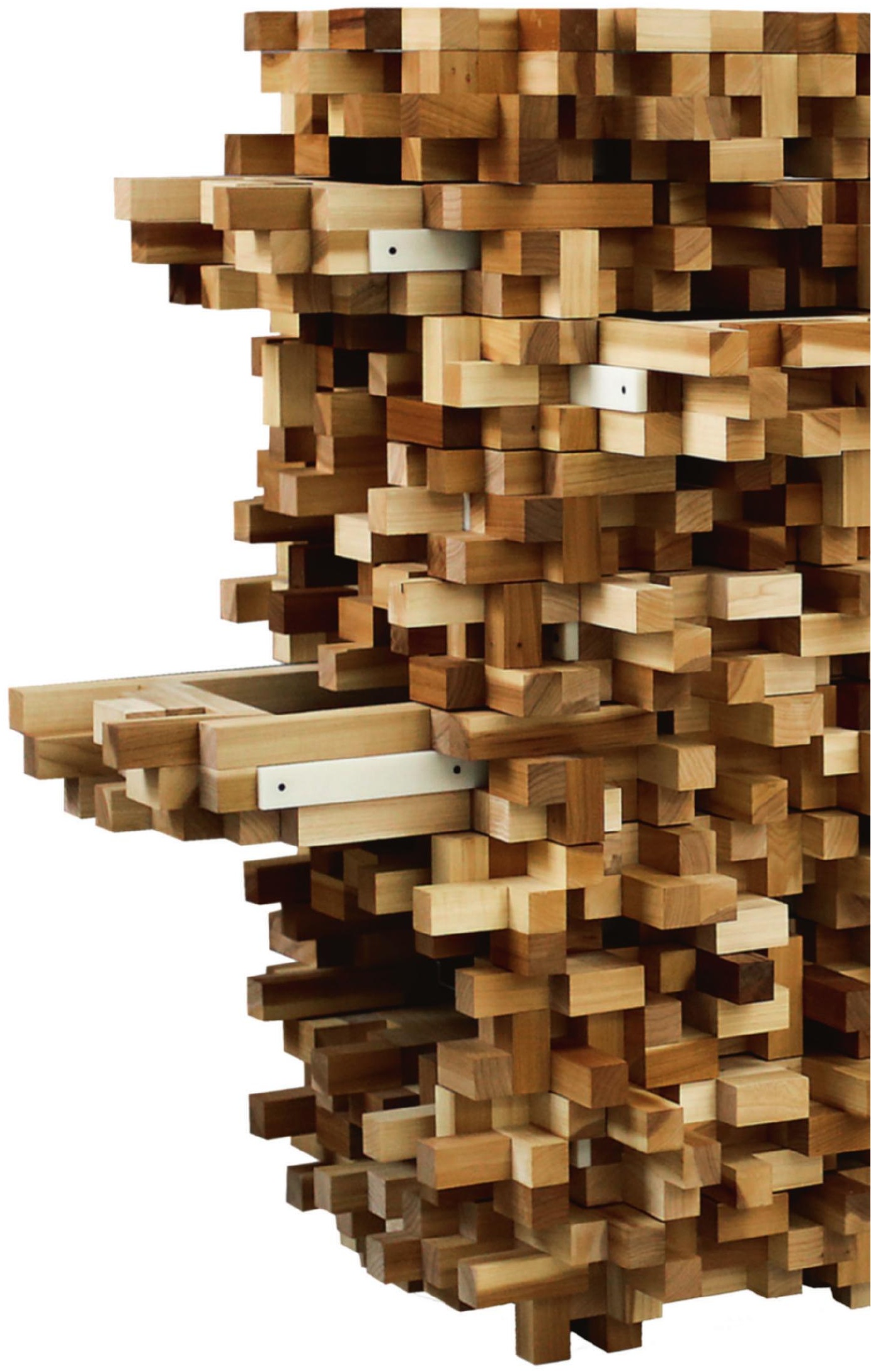




\title{
CHAPTER 4
}

\author{
With a Little Help from my Team: \\ Well-Being of People with Disabilities at Work
}

Nelissen, P. T. J. H., Hülsheger, U. R., van Ruitenbeek, G. M. C., \& Zijlstra, F. R. H. (submitted). With a little help from my team: Well-Being of people with disabilities at work. 


\begin{abstract}
Purpose - Future labor shortages are pushing organizations to consider the corporate social responsibility guidelines of the European Commission in employing people with disabilities. To facilitate the socialization and inclusion of people with disabilities, employees are required to go beyond the call of duty by providing a helping hand to their colleagues with disabilities. In this study we build upon social support theory and investigate whether team inclusive behavior positively affects the well-being of employees with disabilities.

Method - A survey was conducted in a sample of 167 employees and 55 people with disabilities, nested in 55 teams. Employees self-rated team inclusive behavior, positive and negative affect was self-rated by the team members with disabilities.

Results - Regression analysis at the team level showed that team inclusive behavior has a negative relationship with negative affect, but no effect on positive affect.

Conclusion - These findings show support for the link between helping behavior and well-being. More specifically, employees with disabilities experience less negative emotions when the team displays inclusive behavior. This indicates that team inclusive behavior might be vital to the workplace inclusion of people with disabilities in inclusive organizations.
\end{abstract}

Keywords: team inclusive behavior, positive affect, negative affect, people with disabilities, workplace inclusion 


\section{Introduction}

In a society that faces economic adversities and future labor shortages (European Union, 2012; van Duin \& Garssen, 2010; Zijlstra et al., 2012), organizations need to address all the potential that workers have to offer. Herein ensuing the European Commission's guidelines on the application of corporate social responsibility in organizations' strategic alignment (European Commission, 2011), organizations are encouraged to approach employees that would otherwise not be considered, such as people with disabilities. Practically implementing these views has implications for the current staff, as they are assumed to go "above and beyond the call of duty" to facilitate the inclusion and sustainable employment of these new employees by providing a helping hand (Nelissen et al., 2016). With the present study, we therefore aim to investigate whether team inclusive behavior (citizenship behavior specifically targeted at people with disabilities) (Nelissen et al., 2016) does indeed foster the inclusion of employees with disabilities. Specifically, we will investigate the role of team inclusive behavior on the well-being of employees with disabilities. This is grounded in the idea that health and well-being of employees is vital for their sustainable employment (Thornicroft \& Patel, 2014; van der Klink et al., 2016; Van Holland, De Boer, Brouwer, Soer, \& Reneman, 2012), and particularly essential for people with disabilities with regard to their inclusion in the workplace (Bosch et al., 2009; Lammerts \& Stavenuiter, 2010; Schur, 2003). In developing our hypotheses on the relationship between team inclusive behavior and well-being of employees with disabilities, we build on the social support theory (Cohen \& Wills, 1985).

Employee well-being is an important organizational outcome, not only because it sheds light on the extent to which employees with disabilities have been successfully integrated into a workplace, but also because it is an important outcome in and of itself: Employee well-being is at the top of organizations' agendas because it mitigates the direct and indirect costs for organizations in terms of productivity loss and absenteeism costs (Danna \& Griffin, 1999). Accordingly, the European Commission has put the prevention of work related diseases, such as stress, forward as one of their major challenges in the current health strategy (European Commission, 2014). Additionally, illustrating the added value of well-being for all employees, researchers have found evidence for the happy-productive worker hypothesis (Judge, Thoresen, Bono, \& Patton, 2001; Oswald, Proto, \& Sgroi, 2015; Taris \& Schreurs, 2009; Taris, 2006). This indicates that the higher employee well-being is, the more productive employees will be, as well as that lower well-being is related to lower performance outcomes. Thus, on top of the worth of employee well-being itself, the primary organizational goal of productivity is affected.

In the present study we aim to show the positive relationship between team inclusive behavior and the well-being of people with disabilities. In doing so we utilize the literature on 
helping behavior in which researchers have predominantly shown that citizenship behavior benefits employee performance and productivity at the individual, team, and organizational level (N. P. Podsakoff et al., 2009). Yet, despite the wealth of research on citizenship and other helping behaviors regarding performance outcomes, research on the significance of citizenship behavior for the well-being of the recipients of such acts of citizenship is scarce. This is especially surprising based on the distinction in citizenship behaviors that either intend to benefit the organization in general (OCB-O) (e.g. attendance at work is above the norm) or intend to directly benefit a colleague (OCB-I) (e.g. helping others with a heavy workload) (Williams \& Anderson, 1991), of which the latter should certainly be reflected in the recipient's well-being.

With the present study we thus aim to investigate the relationship between inclusive behavior and the recipient's well-being in terms of positive and negative affect. We will study team-level inclusive behavior as such collective efforts may have a stronger influence on the recipient's well-being than inclusive behavior from individual colleagues. Overall, we aim to make two contributions to the literature: First and foremost, this study adds to the emergent line of research on the inclusion of people with disabilities into the labor market. More empirical research is needed in order to focus on what happens to people with disabilities once they have entered the workplace, as well as to study the factors that influence their inclusion (Colella \& Bruyère, 2011). Secondly, our study will also inform the general citizenship literature by investigating the role of citizenship behavior for the wellbeing of the recipients of citizenship. Notably, we test hypotheses with a multi-source study design including data provided by team members and by employees with disabilities.

\section{Team Inclusive Behavior}

In our study we focus on a specific type of helping behavior, namely citizenship behavior towards people with disabilities, which we label team inclusive behavior (Nelissen et al., 2016). Inclusive behavior is defined as extra role behavior that is intended to benefit specifically people with disabilities at work. It is operationalized as the courtesy and altruism dimension of OCB (Organizational Citizenship Behavior), analogous to the concept of OCBI (OCB directed at individuals) (Lepine et al., 2002; N. P. Podsakoff et al., 2009; P. M. Podsakoff et al., 1990; Williams \& Anderson, 1991). The goal of inclusive behavior, as it is for $\mathrm{OCBI}$, is to benefit other individuals (people with disabilities) where an employee provides assistance to an individual with a particular problem to complete his or her task (altruism) or by preventing such work-related problems (courtesy) (Lepine et al., 2002).

Recently, research on organizational citizenship behavior has begun to focus on the unitlevel of analysis as "it is only in the aggregate and over time" (p.91) that these behaviors have beneficial consequences for the recipient and therefore the organization itself $(N$. P. Podsakoff et al., 2014). In accordance with this reasoning, we will study the effects of team inclusive behavior on the well-being of people with disabilities. 


\section{Team Inclusive Behavior and Well-Being}

Several reviews on the consequences of OCB have shown that scholars primarily focused on the individual and unit level outcomes with regard to organizational effectiveness, such as performance evaluations, productivity, service quality and profitability (Ehrhart \& Naumann, 2004; N. P. Podsakoff et al., 2014, 2009). However, some OCB-research also relates to aspects such as customer satisfaction and turnover intentions, which are important for the organizational effectiveness (N. P. Podsakoff et al., 2009), but at the same time also entail a more soft and 'affective' component, similar to employee well-being.

Considering the various conceptualizations of $O C B$ it seems that certain affective outcomes of OCB might have been overlooked. Podsakoff et al. (2014) categorized certain forms of $O C B$, such as altruism and courtesy, into a combination of helping behaviors that focus on the individual beneficiaries (Williams \& Anderson, 1991) and behaviors that are affiliation oriented (N. P. Podsakoff et al., 2014). With regard to the former, Williams and Anderson (1991) proposed, a distinction can be made towards the direction of the intended helping behavior. Behaviors that are intended to benefit specific individuals are termed $O C B I$, whereas those that target the organization are labeled OCBO. With regard to the latter, affiliation oriented behaviors typically refer to interpersonal helping that is focused on positive work relationships with others (AOCB) (N. P. Podsakoff et al., 2014). Moreover, Organ (1997) redefined OCB as behavior that "supports the social and psychological environment in which task performance takes place" (p.95). In all, these construct definitions target more then only an organizational effectiveness outcome, and pertain to an affective outcome of OCB on its recipients. However, despite the vast benefits in determining ways to ameliorate employees' well-being, there is hardly any empirical research that has looked into this relationship. One exception is research in Personality Psychology which suggests that helping behavior in general is positively associated with the well-being of the helper and the recipient (Weinstein \& Ryan, 2010). In their four-study paper, they posit that, based on self-determination theory, when helping behavior is accompanied by autonomous rather than controlled motivation, the recipient's well-being will be higher. The authors ascribed this effect to the warmness, effectiveness, sense of closeness to and effort of the autonomously motivated helpers.

In this study we build on social support theory (Cohen \& Wills, 1985) to demonstrate that helping behavior intended to benefit an individual's social and psychological environment is related to the recipient's well-being. More specifically that team inclusive behavior positively relates to the well-being of employees with disabilities. The main effect model of social support theory (Cohen \& Wills, 1985) claims that support is related to well-being because it provides "positive affect" as well as "integration in a social network which may also help one to avoid negative experiences" (p.311). According to Cohen and Wills (1985), this claim is especially relevant when the social support refers to the target's degree of 
inclusion, as is the case with inclusive behavior. More recent conceptualizations of social support theory such as the JD-R model (Bakker \& Demerouti, 2007; Demerouti, Bakker, Nachreiner, \& Schaufeli, 2001) are consistent with this line of reasoning: the JD-R model is based on the dyad of job demands and job resources, which may or may not lead to strain. Resources such as social support from colleagues are deemed to be "health protecting factors" (p.501) that help employees to attain goals, reduce stressors, and nourish the inner self (Demerouti et al., 2001). As social support refers to "actions of others that are either helpful or intended to be helpful” (Deelstra et al., 2003, p324), it has many commonalities with inclusive behavior. Inclusive behavior is therefore expected to be as beneficial to well-being as it has been shown for social support. Subsequently, as we expect inclusive behavior to have beneficial consequences for the well-being of people with disabilities, we hypothesize a positive relationship between team inclusive behavior and positive affect of people with disabilities, as well as a negative relationship between team inclusive behavior and negative affect of people with disabilities.

Hypothesis 1a: There is a positive relationship between team inclusive behavior and positive affect (PA) of people with disabilities.

Hypothesis 1b: There is a negative relationship between team inclusive behavior and negative affect (NA) of people with disabilities.

\section{Method}

\section{Participants and Procedure}

Respondents were 180 employees and 66 employees with disabilities of various organizations located throughout the Netherlands. Organizations were situated in the supermarket industry, hotel business, retail shops and health care centers. Employees worked in teams with a minimum of three coworkers, with the addition of one employee with a disability ${ }^{5}$. No distinction on disability type was made; various physical, cognitive, mental, sensory, and developmental impairments (e.g. deafness, learning disability, autism) were included. Employees were usually aware that certain team members had a disability; however specifics on their situation were not automatically communicated to the staff. As some teams did not meet our minimum size requirements, the final sample consisted of 167 employees and 55 employees with disabilities nested in a total of 55 teams. Team members rated the inclusive behavior of their team, and well-being was self-rated by the employees with disabilities. The average team size (coworkers) was 3.05 ( $S D=.21$, ranging from 3-4 members per team). Team members were $51.8 \%$ female and 39 years of age $(S D=12.57)$. The sample of people with disabilities were $42.4 \%$ female and 30 years of age $(S D=11.37)$.

\footnotetext{
${ }^{5}$ In the Netherlands, people with disabilities are examined and tested on their capability to work by governmental institutions and may receive wage dispensations for the work they perform.
} 


\section{Group Level Measures}

All measures were adopted from English and translated into Dutch via a translation and back-translation process, whilst taking into account the guidelines for test translation and adaptation (Hambleton, 2001). All scales were assessed on a 5-point Likert scale ranging from 1 (strongly disagree / not at all) to 5 (strongly agree / very much).

Team inclusive behavior. (Team members provided ratings of their team's inclusive behavior.) We assessed inclusive behavior with an 8-item scale adapted from the altruism and courtesy subscales as introduced for Organizational Citizenship Behavior (OCB) (Nelissen et al., 2016; P. M. Podsakoff et al., 1990). The scales were adapted to the viewpoint of the team, to utilize the referent shift consensus model (which refers to questions set to the level of analysis while still using a consensus among group members to assess the construct at hand) and truly represent the team inclusive behavior (L. James et al., 2008; N. P. Podsakoff et al., 2014) $(a=.86)$. The questions were; "My team does not abuse the right of people with disabilities", "My team tries to avoid creating problems with people with disabilities", "My team considers the impact of his/her actions on people with disabilities", "My team helps people with disabilities who have been absent", "My team helps people with disabilities who have heavy workloads", "My team helps orient new people with disabilities even though it is not required", "My team willingly helps people with disabilities who have work related problems", "My team is always ready to lend a helping hand to people with disabilities around him/her". We computed both within-group agreement (rwg) and intra class coefficients (ICC) to provide empirical justification for aggregating this construct to the team level (LeBreton \& Senter, 2007). The mean rwg of inclusive behavior was .89 which indicates strong agreement amongst raters. Subsequent analyses showed an ICC1 value of .23 and an ICC2 value of .47, indicative of a strong effect and therefore justification for aggregation to the team level (LeBreton \& Senter, 2007).

Well-being. (People with disabilities provided well-being ratings.) To conceptualize the concept of well-being, which should on the one hand relate to the beneficial effects of inclusive behavior, and on the other hand act as a valid scale that is suitable for a diverse population such as the one of people with disabilities, we opted for the PANAS (Positive and Negative Affect Schedule) (Watson, Clark, \& Tellegen, 1988). This scale encompasses both positive and negative emotions and the usage of key words requires a less complex interpretation of questions, which makes it perfectly suited for our target population. Participants completed all 20 items of the PANAS Scales (Watson et al., 1988). Participants were asked to indicate how they felt during the past few weeks. Cronbach's Alpha of the positive affect scale was $\alpha=.86$, the reliability of the negative affect scale was $\alpha=.83$. 


\section{Results}

Means, standard deviations, and intercorrelations between study variables are depicted in Table 1. Regression analyses at the group level revealed a marginally significant effect of inclusive behavior on negative affect $\left(b=-.231, t(54)=-1.74, p=.087, \mathrm{R}^{2}=.054\right)$, and no significant effect on positive affect $\left(b=.037, t(54)=.27, p=.788, \mathrm{R}^{2}=.001\right)$. As our hypothesis concerning positive and negative affect were directional in nature, it is appropriate to use a one-tailed test of significance. A value of $p<.10$ can therefore be considered to confirm Hypothesis $1 \mathrm{~b}$.

Table 1. Means, Standard Deviations, Reliability Estimates and Intercorrelations of Study Variables

\begin{tabular}{lllllllll}
\hline & Variable & $n$ & $M$ & SD & a & 1 & 2 & 3 \\
\hline 1 & Inclusive Behavior & 55 & 4.11 & .39 & .89 & & & \\
2 & Positive Affect (PANAS) & 55 & 3.91 & .68 & .86 & .04 & & \\
3 & Negative Affect (PANAS) & 55 & 1.70 & .61 & .85 & $-.23 \dagger$ & $-.31^{*}$ & \\
\hline
\end{tabular}

Note. ${ }^{*} \mathrm{p}<.05 . \dagger \mathrm{p}<.10$.

\section{Discussion}

In response to the call for research on factors that influence what happens once people with disabilities finally enter the labor market (Colella \& Bruyère, 2011) our study focused on well-being of people with disabilities at the workplace. Our premise was that team inclusive behavior by work colleagues would facilitate well-being. The results presented in our study are consistent with the social support theory (Cohen \& Wills, 1985): inclusive behavior has a positive influence on well-being for people with disabilities. More specifically, the results indicate that as far as negative affect is concerned our hypothesis is confirmed. Team inclusive behavior is negatively related to negative affect, indicating less negative emotions of people with disabilities when the team displays inclusive behavior. No effect of team inclusive behavior on positive affect was found.

Although we expected team inclusive behavior to have a positive direct effect on well-being, it might not be surprising that we have found a stronger effect for negative affect compared to positive affect. Previous research has shown that negative affect has a stronger impact on individuals than the experience of a positive emotion (Baumeister, Bratslavsky, Finkenauer, \& Vohs, 2001; Smith et al., 2006). Furthermore, as has been previously established in the buffering model of the social support theory (Cohen \& Wills, 1985), and in accordance with the JD-R model (Bakker \& Demerouti, 2007), social support, and thus helping behavior, have been primarily found to compensate for strain and work related stress factors. 
The findings for our study are not only important to show that team inclusive behavior is related to the well-being of people with disabilities, but these also open a new paradigm on the positive consequences of helping behavior at the workplace. Helping behavior is concerned with providing aid to others, however research rarely concentrates on the wellbeing of the recipients of such helping behavior. There is no reason to assume that the consequences of helping behavior need to be limited to the scope performance related variables. Especially with the goal of sustainable employment at heart, the well-being of employees should be equally as important as the level of performance. Particularly for demographic groups with a large distance to the labor market who experience high work pressure and turnover, and have low tenure, well-being might be a prominent reason for success or failure at the workplace.

\section{Limitations, Strengths, and Directions for Future Research}

There are potential limitations to our study, such as that our study is based on cross-sectional data in which no causal inferences can be made. However, our pathway that team inclusive behavior influences the subjective well-being of a person with a disability seems more plausible than the other way around. It does not seem reasonable that the subjective wellbeing of one person will affect an entire team's helping behavior. Moreover, our research is consistent with findings of Weinstein and Ryan (2010) who found experimental support for the direction of the relationship between helping and well-being. Another limitation is the relatively small sample size of 55 teams which may limit the generalizability of our findings. The low statistical power might explain why our findings have not reached the desired level of significance.

The use of multiple source data in our study is one of our major strengths. Well-being was assessed by the people with disabilities, and team inclusive behavior by the work colleagues of the person with a disability. Another strength is the usage of the reference shift consensus model (L. James et al., 2008; N. P. Podsakoff et al., 2014) that allows us to truly grasp the team level construct of inclusive behavior, combined and aggregated from the original individual input.

Very little is known about the link between helping behaviors and its consequences outside the realm of performance. Particularly research with regard to well-being of the recipients of such helping behavior needs to be further addressed in future research. Also, our results are confined to the specific situation of people with disabilities. Future research should investigate whether our findings extrapolate to other work settings. 


\section{Practical Implications}

Due to societal developments, organizations are required to employ people with disabilities. For humanitarian as well as cost-effectivity reasons it is best that these new employees are durably employed. Sustainable employment can be facilitated by integrating people with disabilities in the workforce. Inclusion functions as a barrier to negative stereotypes and other biases that often impede people with disabilities to fully participate in working life. Qualitative research has shown that well-being of people with disabilities is an important factor to facilitate inclusion in the workplace (Bosch et al., 2009; Lammerts \& Stavenuiter, 2010; Schur, 2003). Therefore, inclusive organizations -that wish to sustainably employ people with disabilities- should pay attention to the level of well-being of their employees, and particularly people with disabilities as it is vital for their sustainable employment (Thornicroft \& Patel, 2014; Van Holland et al., 2012). This research now demonstrates that a negative emotional state might be countered by the display of team inclusive behavior. Therefore inclusive organizations should encourage inclusive behavior towards people with disabilities. Although this behavior is in sense volitional and discretionary, teams can be boosted by their team leaders or organizational mission to display more inclusive behavior. Furthermore, as there also have been found numerous positive relationships between helping behavior organizational performance, it might be beneficial for organizations as a whole to directly and indirectly stimulate inclusive behavior to achieve a higher degree of sustainable employment. This way corporate social responsibility can go hand in hand with organizations that are set-up to maximize profit. 
With a Little Help from my Team: Well-Being of People with Disabilities at Work 


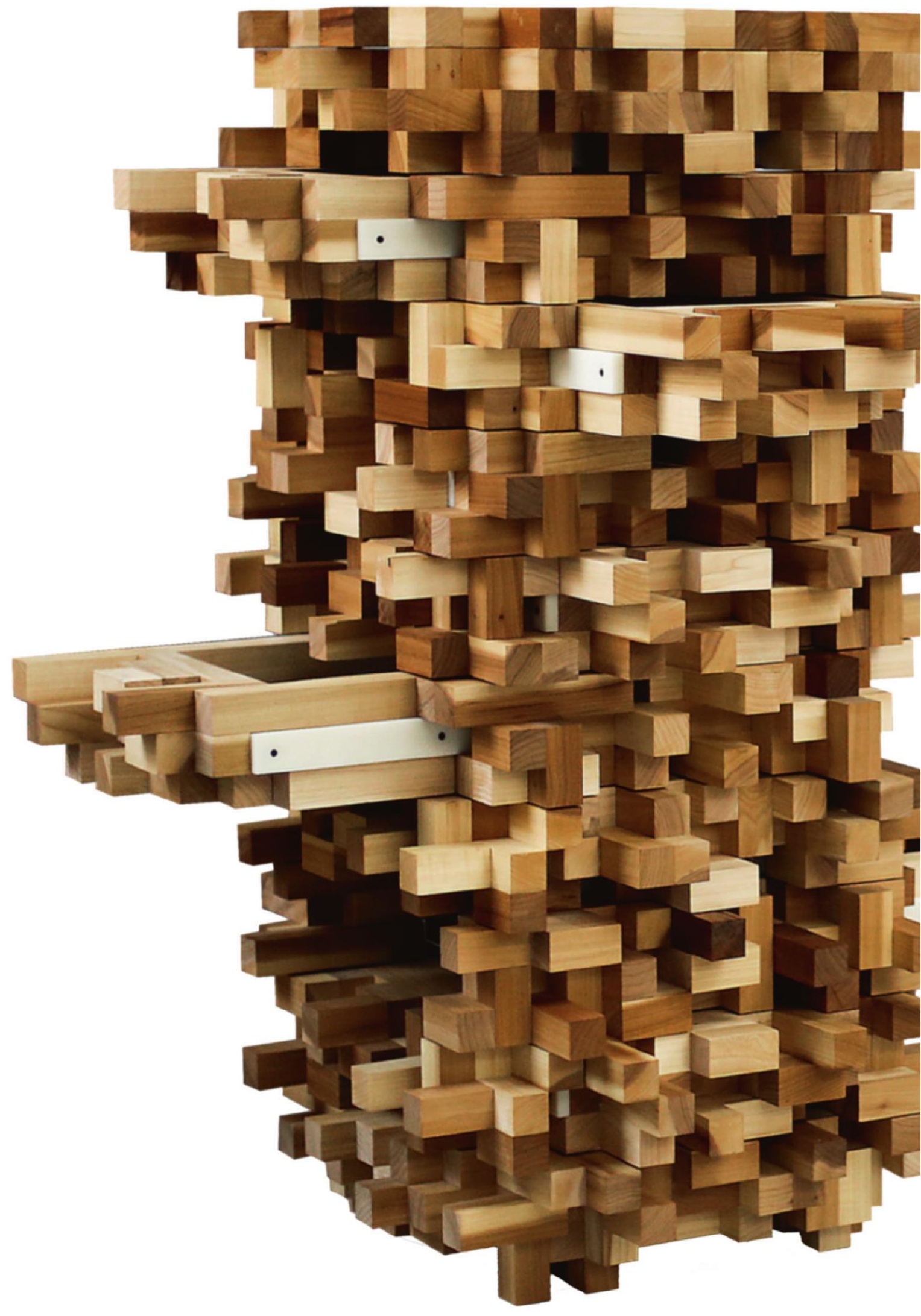




\section{CHAPTER 5}

\section{Disclosure or non-disclosure - is this the question?}

\section{Published as;}

Nelissen, P. T. J. H., Vornholt, K., Van Ruitenbeek, G. M. C., Hülsheger, U. R., \& Uitdewilligen, S. (2014). Disclosure or Nondisclosure-Is This the Question? Industrial and Organizational Psychology, 7(2), 231-235. http://doi.org/10.1111/iops.12138 
Chapter 5 


\section{Introduction}

In their focal article "Invisible disabilities: unique challenges for employees and organizations" Santuzzi, Waltz, Rupp \& Finkelstein (2013) argue that people with invisible disabilities are insufficiently protected by legislation and policies at their workplaces. Accordingly, they suggest that existing acts such as the ADA and ADAAA (ADA, 1990; ADA Amendments Act, 2008) need to be substantially adapted. We concur with their argumentation and agree that legislation and policies, in their current form, rather impede the process of disclosing a disability instead of contributing to an improved situation of people with invisible disabilities at work.

In our commentary we extend Santuzzi and colleagues' work by highlighting the role of the employing organization itself, particularly the organizational culture and climate, in facilitating disclosure of invisible disabilities, an aspect that the focal article only slightly touches upon. Furthermore, we argue for taking a more international perspective on factors that may help or hinder the process of disclosing disabilities at work.

\section{Looking beyond legislation}

Santuzzi and colleagues discuss factors that inhibit employees with invisible disabilities to disclose. In doing so, they focus on legislative issues as well as on factors such as expected stigma and unfairness perceptions. We aim to contribute to this discussion by emphasizing organizational aspects that may facilitate disclosure. By taking this perspective, disability research can build more strongly on the existing knowledge base in $1 / 0$ research on organizational factors that affect employees' attitudes, behaviors, and eventually wellbeing. There is a need to stimulate knowledge on how the integration of individuals with disabilities into the work context can be facilitated on the individual, team, and organizational level of analysis.

First, on the individual level stereotypes, attitudes, empathy and knowledge can have a profound impact on the disclosure decisions of employees with disabilities. Those who expect to be judged by their peers may experience stigma by being perceived as different and devaluated, which will consequently negatively affect their well-being (Bos, Pryor, Reeder, \& Stutterheim, 2013). In I/O literature there is a large number of studies demonstrating the impact the organization and its leaders can have on employee attitudes. One of the possibilities is to implement interventions to influence employees' stereotypes, attitudes, and general awareness on disabilities. Previous research suggests that feelings of empathy work as a catalyst to improve attitudes towards a stigmatized group (Batson et al., 1997). When individuals come into contact with and receive information about people with disabilities, their attitudes will change in a favorable manner (Anthony, 1972). For instance, Hunt and Hunt (2004) devised an educational intervention which increased knowledge 
on and subsequently yielded positive attitudes towards people with disabilities in the workplace. Notably, there is also evidence that suggests that acknowledging a disability will lead to more liking by their peers (Hastorf, Wildfogel, \& Cassman, 1979), which stresses the positive consequences of disclosure.

Second, on the team level, there is initial evidence that climate perceptions on justice and inclusion are important for the well-being of people with disabilities. Studies on the consequences of a justice climate highlight the relationship with citizenship behavior, wellbeing and team performance. A recent study shows that work environments that are fair and responsive are specifically beneficial for people with disabilities (Schur et al., 2009). Literature on employees with disabilities stresses the importance of a climate that fosters inclusion in work teams. Inclusion refers to the "extent to which people with disabilities are accepted, helped, and treated as others by their coworkers" (Colella \& Bruyère, 2011, p. 492-493). An inclusive climate will therefore be vital to the well-being of people with disabilities at the workplace. Existing literature emphasizes the role of leaders and supervisors in structuring the daily practices and procedures that constitute a climate. Therefore, supervisors need to be made aware of their facilitating role in creating a climate that fosters inclusion and thereby mitigates the negative outcomes of disclosing.

Third, on the organizational level corporate culture can have a profound effect on the beliefs, attitudes, and behaviors towards people with disabilities. Research shows that the adoption of corporate social responsibility as part of an organizational identity leads to favorable evaluations by the organization's stakeholders (Martínez, Pérez, \& Rodríguez del Bosque, 2013). An alignment of goals throughout the organization is likely to facilitate the inclusion of people with disabilities, as employees will act according to the values set by the organization (Aguilera \& Rupp, 2007). Thus when organization culture and team climate promote positive attitudes towards people with disabilities as coworkers, the negative consequences of disclosure can be mitigated.

\section{An international perspective}

A second point we want to address is that the focal article is strongly based on the specific US labor market situation and US legislation. This is regrettable for at least two reasons. First, because the labor market situation may differ from country to country; a single US solution may not be generalizable to other countries. Second, given the heterogeneity of legislation regarding employment of people with disabilities among countries, it should be worthwhile to study and compare these different types of legislation in order to come to more informed decisions.

From a European perspective we can add experiences showing the ineffectiveness of interventions that are aimed at fostering the integration of people with disabilities, but are exclusively based on legislation. Due to demographic changes, such as the retirement of the 
baby-boom generation and an ageing workforce, a number of European countries anticipate a considerable decline in the working-age population by 2020. As a result, governments have implemented legislation to motivate organizations to employ people with disabilities. However, despite these policies, hardly any country was able to boost the inclusion of people with disabilities into regular organizations (European Commission, 2008). The overall level of work participation of people with disabilities is still very low (45\% compared to $75 \%$ employment in non-disabled people).

An approach that has been implemented, for instance in Germany, France and Poland, is a disability quota system which forces companies to employ a minimum amount (five percent or more of the workforce) of people with disabilities. With this form of legislation it is favorable for a company when employees disclose their disability as this helps them to attain their quota. Unfortunately, even in countries that have installed quota systems, the employment rate of people with disabilities is still considerably lower compared to the employment rate of non-disabled people (Shima, Zólyomi \& Zaidi, 2008). Moreover, a quota system can have the negative side effect of stimulating negative attitudes toward people with disabilities by both employers and co-workers. Companies faced with quota systems often experience people with disabilities as a burden instead of a valuable contribution to their workforce and non-disabled workers may perceive the quota job placements as creating an unfair division in the labor market.

Due to the expected decline in the working-age population in several European countries, there is an increasing recognition visible, both in governmental policies and in organizations, that people with disabilities can provide added value to an organization. Demographic changes are expected to negatively influence the competitiveness of one third of the European regions and the extent to which these developments will affect economic growth depends considerably on labor participation. From this perspective, people with disabilities do not only constitute a valuable contribution to the workforce of a company, they are also indispensable.

An important challenge to the successful inclusion of people with disabilities arises from a mismatch in the labor market due to the rapid shift of primary sector industries towards a service oriented and knowledge-intensive economy (European Commission, 2008). The consequence of this shift is an increase in the complexity of work and job demands. As a result, employers search for people with high levels of education and competences; requirements, which especially people with disabilities are often not able to meet. Interventions at the organizational level, such as the redesign of work and work processes, can help to overcome these difficulties (Van Ruitenbeek, Mulder, Zijlstra, Nijhuis, \& Mulders, 2013). Merely adapting legislation will not establish a sound base for disability disclosure. 


\section{Final thoughts}

As a last point, we would like to draw attention to a broader perspective of research on people with disabilities at work. We concur with the authors that it is a challenge for researchers and practitioners to understand the experiences of and accommodate individuals with invisible disabilities. However, knowing more about the challenges of having disabilities in general in organizations, how these individuals are treated, and what helps or hinders their functioning in organizations is needed before addressing the unique challenges of individuals with invisible disabilities. The decision to disclose a disability is likely to depend on the general treatment of people with disabilities within organizations as disclosing is eventually a decision to become part of the recognized group of people with disabilities. It is therefore necessary to look behind the scenes and understand the complex network of social relationships within organizations and most prominently we need to understand why people with disabilities are often excluded from these networks and what we can do about this. Given the overall paucity of research on disability and employment in I/O psychology, we should not focus too narrowly on the issue of disclosure of invisible disabilities but also find out more about integration processes in general, such as acceptance, socialization etc. considering various levels of analysis. A sound base of knowledge on factors related to the integration of people with disabilities in general can set the stage for addressing the challenges faced by people with invisible disabilities more in particular.

In their focal article, the authors take the perspective that the adjustment of legislation and policies facilitates the decision of people with invisible disabilities to disclose their disability. In our comment we add, on the one hand, the important role of the organization itself in the process of disclosure and on the other hand we express our doubts about the success of exclusively legislation based interventions when comparing different European countries. Therefore, we certainly agree with Santuzzi et al. (2013) that legislation does not yet sufficiently protect people with invisible disabilities and that more research is needed on this topic, but we would advocate a greater focus on multiple perspectives on barriers and enablers of disclosure and to go beyond the question of disclosure, taking into account and putting greater emphasize on the social aspects of the integration process of people with disabilities within an organization. 
Disclosure or non-disclosure - is this the question? 


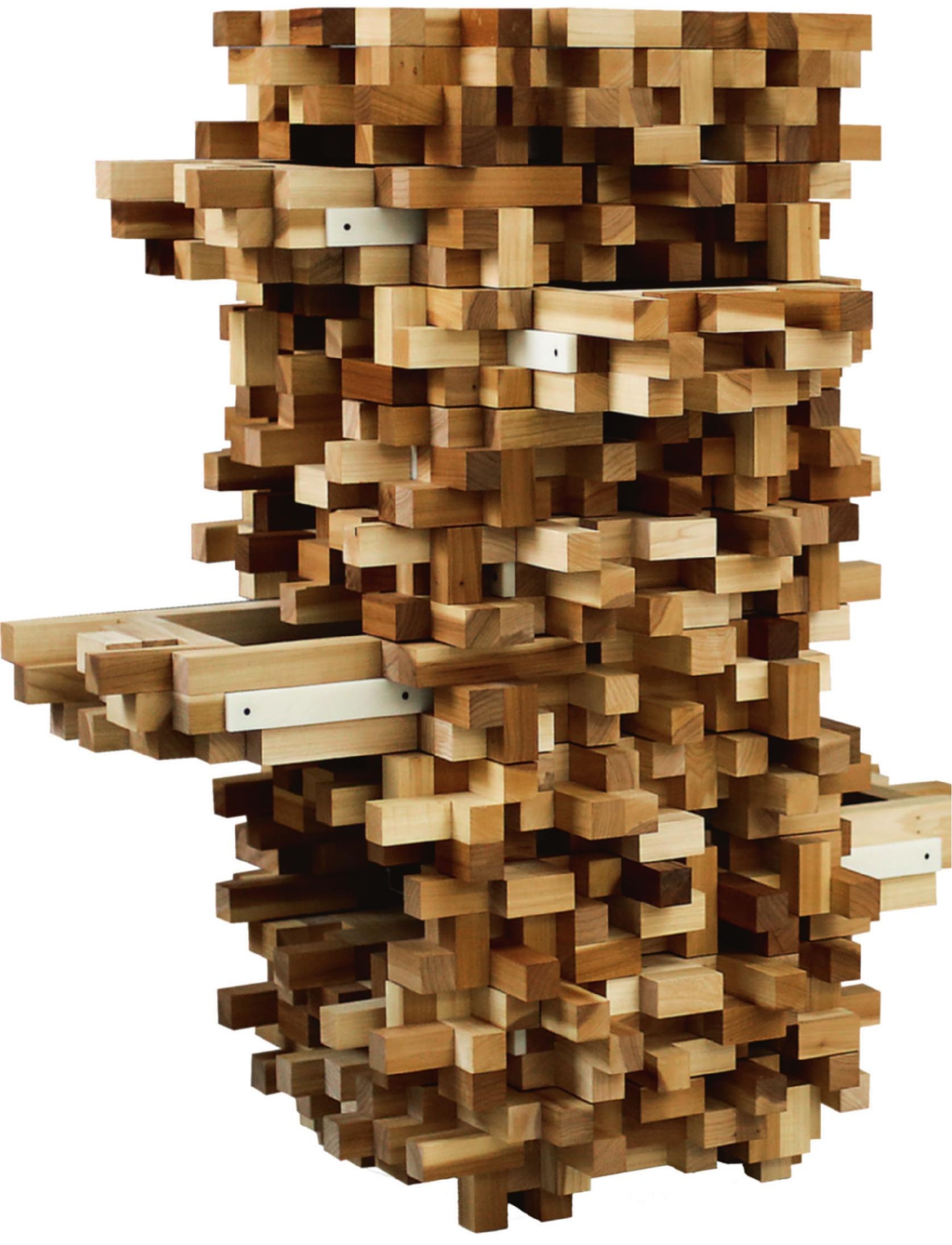


CHAPTER 6

General Discussion 
Chapter 6 


\section{Introduction}

People with disabilities have a hard time to attain and retain employment. Not only has a lot of low-skilled work moved to 'low-wage' countries, local work has grown to become more complex. In turn, this has led to a high increase of job demands, which are often too high for the limited skill set of people with disabilities. Traditional organizations are furthermore too often in search for the ultimate 'jack of all trades' employee. This high threshold leads to a further decline in employment opportunities and a larger distance to the labor market for people with disabilities. However, current societal changes are forcing governments and organizations to change their views on the working society. Demographic developments such as the ageing of the population will lead to a shortage of manpower, but also the costs of welfare payments to people with disabilities weigh on our society. By employing more people with disabilities and adhering to corporate social responsibility guidelines, both problems can be tackled at the same time.

Legislators are now addressing the issue of creating new employment opportunities for people with disabilities by developing new regulations such as the Dutch Participation Act (2015). In response, inclusive organizations are committing to create job openings for people with disabilities at large scale. However, what happens once people with disabilities enter the labor market and whether workplace inclusion can be reached, has hardly been studied. In an effort to contribute to this topic, we have addressed this issue by developing our research question: What are the building blocks that facilitate the workplace inclusion of people with disabilities? Our goal was to contribute to the field of employment issues of people with disabilities, to identify factors that contribute to workplace inclusion, as well as to further knowledge on what happens to people with disabilities once they enter the workplace. In doing so this dissertation offers three main contributions to theory and scientific research literature, in the domain of research on people with disabilities at work, within the literature of organizational citizenship behavior, and by adopting a multilevel approach in team climate research.

In this conclusion, I will first give an overview of the main findings concerning the empirical chapters, to continue with a discussion on the implications for theory. Next, I will illustrate some relevant practical implications, and finally I will discuss the limitations of the present studies as well as present ideas for future research.

\section{Main Findings}

In the empirical chapters 2, 3, and 4 the building blocks that facilitate inclusion, as presented in our overall schematic model (p. 27), are addressed. It was argued that the inclusive behavior displayed by the coworkers of people with disabilities is pivotal to workplace inclusion. Inclusive behavior is therefore utilized as the central concept in our model. In 
both chapters 2 and 3 we set out to empirically investigate the antecedents of inclusive behavior, whereas in chapter 4 we researched one of its possible outcomes. In this way we were able to verify the beneficial consequences of inclusive behavior as deemed necessary to reach workplace inclusion, as well as variables that may evoke inclusive behavior.

In chapter 2 we applied the Reasoned Action Approach (Fishbein \& Ajzen, 2010) to show that positive stereotypes lead to positive attitudes and consequently to more inclusive behavior. Not only did we highlight the theoretical differences between stereotypes and attitudes, and how they affect the amount of inclusive behavior, but we added to the literature on the behavioral consequences of stereotypes on the group to which the stereotypes refer. That is, we found that the more positive stereotypes are towards people with disabilities, the more employees will be inclined to display inclusive behavior. This process is guided by the cognitive appraisal of stereotypes which lead to an attitude, which consequently affects the amount of inclusive behavior. Now that we identified how stereotypes work, it is vital to check for boundary conditions to see when they relate to inclusive behavior. Our research showed that the amount of work pressure influences the opportunities coworkers of people with disabilities have to display inclusive behavior. The results show that under conditions of low work pressure employees (with positive stereotypes) are more likely to display inclusive behavior, compared to those who are under high work pressure. As inclusive behavior is noncompulsory, high work pressure might prevent employees' inclusive behavior in order to manage their regular work related activities.

In chapter 3, the positive relationship between prosocial motivation and inclusive behavior provides evidence for the theoretical perspective of the functional approach (Penner et al., 1997; Rioux \& Penner, 2001; Snyder, 1993). People will try to satisfy their needs and goals by displaying helping behavior. Those employees who are prosocially motivated, aim to satisfy this motivation by actively including people with disabilities in their work team. This multilevel study furthermore contributes to a better understanding of contextual variables and as multilevel occurrences which have rarely been investigated in relation to helping behavior. Contextual variables can help shed light on individual level relationships that might otherwise be overlooked. Accordingly, in this study, team inclusive climate influenced individual helping behavior over and above individual level factors. In conditions of a high inclusive climate, employees are driven to display inclusive behavior, whereas in conditions of a low inclusive climate, only highly prosocially motivated employees would act in such a way.

Chapter 4 leads our research to the next level as it concerns the consequences of team inclusive behavior. Based on the social support theory (Cohen \& Wills, 1985) we were able to show that team inclusive behavior has a (marginally) positive relationship to well-being. More specifically, in such a way that team inclusive behavior reduces the negative emotions for people with disabilities at work. Activities that display support are found to alleviate 
the adverse consequences of strains that accompany work. Since qualitative studies have demonstrated that especially the well-being of people with disabilities is important for their inclusion at work, we might infer that inclusive behavior will contribute to the workplace inclusion.

Chapter 5 concerns a discussion paper on disclosure challenges for people with disabilities, and reminds us that difficulties concerning their employment are a universal issue. To fully tackle these difficulties, we need to look beyond legislation and address all three levels within the organization. On the individual level interventions can create awareness and knowledge about people with disabilities, on team level the work environment and supervisors have a hand facilitating inclusion. Finally, organizational values play an important role in developing a positive mindset within its constituents and will thus pave the road to sustainable employment.

\section{Theoretical Implications}

This dissertation offered three main contributions to theory and scientific literature; in the domain of research on people with disabilities within Industrial and Organizational Psychology (IO Psychology), within the literature on organizational citizenship behavior, and by adopting a multilevel approach in climate research.

Firstly, the research presented in this dissertation has helped to build a bridge between research on people with disabilities and the field of 10 Psychology. This research is among the first to empirically investigate people with disabilities at work in inclusive organizations (rather than sheltered employment) and addresses factors that may contribute to their organizational career success. In doing so we have advanced this line of research by addressing the research call by Colella and Bruyère (2011) to focus on factors that facilitate the inclusion of people with disabilities.

Whereas a great deal of research on people with disabilities has focused on health related issues (Krahn, Hammond, \& Turner, 2006; Rimmer \& Rowland, 2008), characteristics of people with disabilities (Colella \& Varma, 1999; Colella \& Bruyère, 2011), or a societal view of their employment (Milner \& Kelly, 2009), we applied core concepts of IO Psychology (e.g. motivation, climate, and $\mathrm{OCB}$ ) to gain insight in the employment situation of people with disabilities. More specifically, a focus was set on what happens to people with disabilities once they are employed (versus the hiring process), and the factors that give rise to workplace inclusion in work teams. Since workplace inclusion has been defined as the degree to which "people with disabilities are accepted, helped, and treated as others by their coworkers"(Colella \& Bruyère, 2011, p. 492-493), it seems that the behavior displayed by colleagues has a central role in achieving workplace inclusion. We consequently explored whether features such as stereotypes, prosocial motivation or an inclusive climate function as precursors of inclusive behavior, and if well-being would function as its consequence. 
Thus, having identified antecedents and outcomes of the pivotal inclusive behavior, the studies in this dissertation have shown that these facets constitute essential building blocks of workplace inclusion for people with disabilities.

Attaining workplace inclusion and reaching a higher level of well-being for employees and people with disabilities in particular, may give rise to sustainable employment (Vornholt, Uitdewilligen, \& Nijhuis, 2013). That is, sustainable employability refers to "employees having the opportunity to perform work with preservation of health and wellbeing during their working life, now and in the future" (van Holland, de Boer, Brouwer, Soer, \& Reneman, 2012, p2). Therefore, reaching sustainable employment for people with disabilities in inclusive organizations can be considered as the overall goal. This therefore implies that our studies add to the research on people with disabilities by identifying 10 variables that induce inclusive behavior, by demonstrating that inclusive behavior facilitates higher levels of well-being, and consequently by showing how workplace inclusion can be achieved.

Secondly, this dissertation added to the broad field of research on organizational citizenship behavior. One of the main research contributions was introducing the new concept of inclusive behavior. Inclusive behavior is very similar to organizational citizenship behavior $(O C B)$, as both are volitional, discretionary and intended to benefit others. However, whereas OCB focuses on all work colleagues, inclusive behavior targets employees with disabilities in particular. OCB has been shown to be beneficial for both employees and organizations as a whole (N. P. Podsakoff et al., 2014). Therefore, inclusive behavior might be seen as equally valuable for inclusive organizations that wish to facilitate workplace inclusion for people with disabilities. This might therefore imply that the display of inclusive behavior will not only facilitate workplace inclusion but will also have a positive effect on the productivity, efficiency, absenteeism, job satisfaction and turnover intentions $(N$. P. Podsakoff et al., 2014, 2009) of employees with disabilities.

In chapter 4 we have furthermore conceptualized inclusive behavior at the team level, in accordance with more recent research that has addressed OCB at the unit-level (Ehrhart \& Naumann, 2004; N. P. Podsakoff et al., 2014, 2009). This conceptualization is in line with the theoretical reasoning presented in Ehrhart and Naumann (2004) who state that OCB in groups will be displayed because of group norms, especially when this behavior is deemed to be important to the survival of the group. In inclusive organizations it is consequently more likely that group members will help their colleagues with disabilities when group norms have an inclusive character. Particularly in settings where people with disabilities are thought of to function in regular teams in inclusive organizations, the perspective of team inclusive behavior can bring additional insight to complex situations (Johns, 2006).

Moreover, most research on the outcomes of OCB has focused on performance or performance related constructs such as turnover or absenteeism (N. P. Podsakoff et al., 2014, 2009), however in this dissertation social support theory (Cohen \& Wills, 1985) is used 
to show that helping behavior also affects employees' well-being, analogous to social support facilitating positive affect (Cohen \& Wills, 1985). More specifically, inclusive behavior is argued and found to be positively related to the well-being of people with disabilities. In this way we address a research gap on the positive consequences of citizenship behaviors. A focus on the well-being of recipients of citizenship behavior seems obvious since they are primarily intended to benefit others as it is the case for the more general OCBI $(O C B$ targeted to benefit the individual) (Williams \& Anderson, 1991). Besides providing evidence for this novel relationship, this intuitive, yet astounding finding opens the door to a new broad research area within the positive outcomes of helping behaviors.

Citizenship behaviors that are found to not only have positive effects on performance related aspects but also on employee well-being, can provide a new perspective on the definition of OCB provided by Organ (1997, p.95): "performance that supports the social and psychological environment in which task performance takes place". Instead of allowing for an environment in which employees are 'merely' able to perform better or be more productive, citizenship behaviors can help to build an environment that facilitates employee well-being. This finding could once again underline the great importance that citizenship behaviors have within IO Psychology literature (N. P. Podsakoff et al., 2014), as well as at the same time urge scholars to research this relationship into more detail.

Thirdly, in this dissertation we added to the climate research literature. Climate is a well-used classic research tool that should reflect employees' opinions and shows the perceptions of a team on the daily policies, practices and procedures, such as they are specific per team, that are rewarded, supported, and expected (Schneider, 2000) on a certain topic. We conceptualized a new climate "for something" (Schneider \& Reichers, 1983) on the topic of inclusion; an inclusive climate. In developing this inclusive climate we adhered to general climate recommendations; it refers to the team level and it utilizes the referent shift model in which survey items refer to the group level (James et al., 2008; Schneider, Ehrhart, \& Macey, 2013). In this way climate can truly assess the collective perceptions of the team on the way people with disabilities are treated in the workplace.

Inclusive climate is tailored towards employees' observations of inclusion and refers to the perceptions of a team on the way people with disabilities are accepted, helped, and treated as others by their coworkers. Both (team) inclusive behavior and inclusive climate can therefore be very useful as specific measures to further investigate the work situation of people with disabilities. Especially because variables at a higher than the individual level tend to explain more variance and give more insight in the social context at work (Johns, 2006; Schneider, González-Romá, Ostroff, \& West, 2016). Further research could explore the workings of an inclusive climate even further by looking at climate strength and climate uniformity (González-Romá \& Hernández, 2014; Benjamin Schneider et al., 2013). Whereas climate strength represents the within unit agreement of team members 
on climate perceptions, the climate uniformity concerns the pattern if climate perceptions within the group. In this way the distribution of the climate perceptions can be clarified and provide more insight in the overall perception of the climate and in relationship to its outcomes (González-Romá \& Hernández, 2014).

To conclude the theoretical implication section, we return to the research question: What are the building blocks of workplace inclusion? Within this dissertation various building blocks have been put forward at the individual as well as the team level (see figure p. 27). The variables brought forward in the empirical chapters all seemed to be of importance to achieve workplace inclusion. Nonetheless, this dissertation does not (aim to) offer an exhaustive list of all variables that may influence workplace inclusion. Other variables such as personal characteristics (e.g. prosocial personality, job satisfaction, justice sensitivity), job characteristics (e.g. autonomy, communication, feedback) or organizational characteristics (e.g. justice climate, leadership, group cohesion, psychological safety, organizational support) may play an additional role in creating workplace inclusion for people with disabilities. It is within this way of thinking that one can imagine the metaphor of a Jenga puzzle that represents workplace inclusion. All the blocks represent the different variables that may contribute to achieve workplace inclusion. The most solid foundation is present when all blocks are placed firmly on top of one another, however, the more blocks that are missing, the shakier the tower will be. Thus the more building blocks are present, the more workplace inclusion can be achieved. Nonetheless, I do believe that in the absence of particularly the building blocks of inclusive behavior and inclusive climate, the tower of workplace inclusion is destined to collapse.

\section{Limitations, Strengths and Suggestions for Further Research}

Despite the important knowledge gained from the empirical chapters, there are several limitations which might restrict the conclusions that can be drawn from the studies presented in this dissertation. I will discuss these limitations and consequently suggest areas of future research.

One limitation refers to the set-up of our studies, which were all cross-sectional. Therefore the relationships found are correlational and do not allow for causal conclusions. However, as the presented relationships are formulated based on various theories, the set-up of variables as presented in the overall scheme (p. 27) seems to be the most reasonable. Future research may therefore benefit from investigating the relationships in this dissertation as part of a longitudinal study, ideally with a cross-lagged panel design, allowing to investigate reverse and reciprocal causation (Spector, 2001). Ideally the first measurements would take place prior to the employment of people with disabilities. This would allow researchers to compare the base rate of several building blocks of workplace inclusion to the level after employment. Especially when using an intervention method to 
change or increase the amount of inclusive behavior in (inclusive) organizations where this might be needed, a pre- and posttest are crucial to measure any effects of the intervention (Bartholomew Eldredge et al., 2016).

Another limitation concerns the relatively low response rates upon which the data is based. The response rate in chapter 2 and 3 concerns 35\% and $29.4 \%$ for employees and their peers, respectively, might give rise to a non-response bias. However, looking at the response data there is a probable explanation at hand. Our sample includes 7 organizations, the largest one being a hospital that accounts for $50 \%$ of our target sample. This organization had a response rate of $15.8 \%$ and $9.8 \%$ for employees and their peers respectively. For the other 6 organizations combined, the response rate was $58.9 \%$ and $53.8 \%$, providing a normal response rate (Baruch \& Holtom, 2008). In chapter 4 the response rate for participating teams was comparably low at $18.3 \%$. This rate was mostly due to the timing of the data collection; the Participation Act had recently gone into effect which most likely lead to an overburdening of employers in terms of administration and research requests. Future research will thus have to take into account that high response rates will be difficult to achieve because 1. there are fewer teams to be found which are composed of minimum 3 employees and an employee with a disability in inclusive organizations, compared to 'regular' teams, 2. such teams are usually scattered over many organizations, and 3 . it concerns a delicate topic upon which many employers and people with disabilities will decline to participate.

A third limitation refers to the large variety of disabilities of the participants in our studies. These encompass physical, cognitive, mental, sensory, and developmental disabilities. Since employees may react differently to people with different sorts of disabilities, the effects of type of disability might have an influence on the displayed amount of inclusive behavior. Therefore these variations might be taken into account into future research. However, within the scope of this dissertation, we purposefully have not distinguished between types of disabilities. Within the Participation Act, people with disabilities are encouraged to attain and retain work, without differentiation in disability type. Therefore, to mirror the situation in our society, we opted to study variables with regard to workplace inclusion for all people with disabilities.

A considerable strength within the studies in this dissertation is the use of a multisource and multilevel design. We used different raters (people with disabilities, employees and their peers, and supervisors) which allowed for greater objectivity independent assessments of inclusive behavior and consequently the reduction of common method bias (Spector, 2001). Furthermore, variables were assessed at both the individual and team level which permitted to take into account the teams in which employees and people with disabilities work. This provides a greater insight in the actual work situation and shows the effect of team level variables on the individual. 
In terms of future research, to concretely create interventions to change actual behavior, Intervention Mapping can be used (Bartholomew Eldredge et al., 2016; Kok, Schaalma, Ruiter, van Empelen, \& Brug, 2004). Intervention Mapping is a theory and evidence based, six step protocol developed to guide professionals in changing behavior of target groups. These targets can be found at various levels (individual, interpersonal, organizational, community, and society). Thus, all recommendations which relate to changing behavior of people with disabilities, their peers, their teams, their supervisors, as well as the inclusive organizations they work at, can be put into practice using a systematic Intervention Mapping approach. Based on theory, empirical evidence, and population data, Intervention Mapping allows professionals to set-up change interventions which aim to change behavior and thus ameliorate the quality of life of the target group (Bartholomew Eldredge et al., 2016; Kok et al., 2004).

To conclude this section, I wish to recap the possibilities for potential future research that were suggested throughout the discussion. First we posited to validate our research model using a longitudinal set-up. Then, having identified some of the building blocks that lead to workplace inclusion, there are more to be found within personal, job, and organizational characteristics. Additionally, with regard to $\mathrm{OCB}$, we have opened the door to a nonperformance related outcome such as well-being. Furthermore, within the climate literature we suggest to have a closer look at climate strength and climate uniformity to create a deeper understanding in the inclusive climate within organizations. Lastly, a suggestion is made to utilize Intervention Mapping as a tool to change the behavior of all stakeholders within an inclusive organization, and consequently achieve a higher level of workplace inclusion.

\section{Practical Implications}

Within the scope of corporate social responsibility, it seems that a lot of ground has been covered in setting up the prerequisites to obtain work for people with disabilities. However, what happens to people with disabilities once they enter an organization or what building blocks are necessary to achieve workplace inclusion, has hardly been researched. Therefore, the practical implications of our research aim to transfer the newly gained knowledge presented in this dissertation to tools and guidelines which may be used to ameliorate the workplace inclusion of people with disabilities. The practical implications are similar across the studies presented in this dissertation, as they are carried out with one similar goal; to improve the working conditions and consequently stimulate the workplace inclusion of people with disabilities at inclusive organizations.

Inclusive behavior fosters workplace inclusion, which represents the way people with disabilities are accepted, helped and treated as others within the workplace. Therefore, our foremost practical implication is the need for inclusive behavior at the workplace. 
Accordingly, it is important for employers to find ways to stimulate such behavior as it will ameliorate the chance of success with regard to sustainable employment. There are several factors at the individual as well as the team level that we have been able to show to have a positive relationship with inclusive behavior. At the individual level we discovered that prosocially motivated employees and those that hold positive stereotypes are more likely to display inclusive behavior. Therefore inclusive organizations need to take these individual characteristics in mind when aiming to employ people with disabilities. Recruiting a workforce that has such features is one option, however it is much more feasible to provide interventions and matching trainings that are aimed at educating, motivating and changing the behavior of employees (Bartholomew Eldredge et al., 2016). Stereotypes are usually based on a lack of knowledge, therefore educational interventions focused on the correctness of stereotypes, norms of daily interactions and decreasing feelings of anxiety that might accompany working with people with disabilities, will stimulate positive attitudes. Hunt and Hunt (2004) found that even a one hour educational intervention proved to be adequate in increasing knowledge and attitudes toward people with disabilities. Positive attitudes, in turn, lead to more inclusive behavior (chapter 3).

At the team level we have seen that inclusive climate is a direct and indirect predictor of inclusive behavior. Climate is built from the aggregate of perceptions of an entire team or department but is also malleable by the team supervisor. It is therefore important for inclusive organizations to have transformational leaders that fully embody the "inclusive message". Supervisors have a strong hand in transforming their teams by leading by example in norms and values that go along with an inclusive climate (Ehrhart \& Naumann, 2004; Grojean, Resick, Dickson, \& Smith, 2004). Therefore, in inclusive organizations leaders should be able to display inclusive behavior and thus inspire their employees to follow suit which might, in turn, create new norms and values that are in line with in an inclusive climate. That is, since the climate is built from the perceptions on "the way we do things around here" of the employees, a leader can aim to change these perceptions by modeling and leading by example. Furthermore, it has become apparent that work pressure is a factor that might inhibit the display of inclusive behavior. Supervisors aware of this situation may take into account the amount of work that employees have to fulfill to create room for opportunities of inclusive behavior.

Finally, organizations that wish to be inclusive should adopt the culture of corporate social responsibility as part of their organizational identity. This can be achieved by including corporate social responsibility as one of the main mission statements of the organization, and creating a human resources policy which aims to put these values into practice. This will evoke similar feelings with the company's stakeholders and encourage them to act similarly. In total, inclusion starts as a top down process in which the highest level needs to lead by example and empower teams, departments and their leaders to manage employees 
in a way that allows and encourages inclusion. This way, employees will be most likely to display inclusive behavior, which is the highway towards workplace inclusion for people with disabilities.

In conclusion, organizations that wish to accommodate the building blocks of workplace inclusion for people with disabilities would do right by measuring factors such as inclusive climate and inclusive behavior. Together with the measurement of the individual characteristics presented above, organizations will have tools and matching guidelines on the aspects that are best ameliorated to accommodate the socialization and inclusion of people with disabilities at the workplace. 
General Discussion 

References 
References 


\section{References}

Americans With Disabilities Act of 1990, Pub. L. No. 101-336, 104 Stat. 328 (1990). Retrieved from http: / /www.ada.gov/pubs/ada.htm.

Americans With Disabilities Act Amendments Act of 2008, Pub. L. No. 110-325, (S. 3406). Retrieved from http://www.eeoc.gov/laws/statutes/ adaaa.cfm.

Aguilera, R., \& Rupp, D. (2007). Putting the $S$ back in corporate social responsibility: A multilevel theory of social change in organizations. Academy of Management Review, 32(3), 836-863. http://doi. org/http://dx.doi.org/10.5465/AMR.2007.25275678

Aguinis, H., Gottfredson, R. K., \& Culpepper, S. A. (2013). Best-Practice recommendations for estimating cross-level interaction effects using multilevel modeling. Journal of Management, 39(6), 14901528. http://doi.org/10.1177/0149206313478188

Akrami, N., Ekehammar, B., Claesson, M., \& Sonnander, K. (2006). Classical and modern prejudice: Attitudes toward people with intellectual disabilities. Research in Developmental Disabilities, 27(6), 605-617. http://doi.org/10.1016/j.ridd.2005.07.003

Amodio, D. M., \& Devine, P. G. (2006). Stereotyping and evaluation in implicit race bias: Evidence for independent constructs and unique effects on behavior. Journal of Personality and Social Psychology, 91(4), 652-61. http://doi.org/10.1037/0022-3514.91.4.652

Anthony, W. A. (1972). Societal rehabilitation: Changing society's attitudes toward the physically and mentally disabled. Rehabilitation Psychology, 19(3), 117-126. http://doi.org/10.1037/h0090877

Arthaud-Day, M. L., Rode, J. C., \& Turnley, W. H. (2012). Direct and contextual effects of individual values on organizational citizenship behavior in teams. Journal of Applied Psychology, 97(4), 792-807. http://doi.org/10.1037/a0027352

Bakker, A. B., \& Demerouti, E. (2007). The Job Demands-Resources model: State of the art. Journal of Managerial Psychology, 22(3), 309-328. http://doi.org/10.1108/02683940710733115

Bartholomew Eldredge, L. K. B., Markham, C. M., Ruiter, R. A. C., Fernández, M. E., Kok, G., \& Parcel, G. S. (2016). Planning health promotion programs: an Intervention Mapping approach (4th ed.). San Francisco: John Wiley \& Sons.

Baruch, Y., \& Holtom, B. C. (2008). Survey response rate levels and trends in organizational research. Human Relations, 61(8), 1139-1160. http://doi.org/10.1177/0018726708094863

Batson, C. D. (1987). Prosocial motivation: Is it ever truly altruistic? In L. Berkowitz (Ed.), Advances in experimental social psychology (pp. 65-122). New York, NY: Academic Press.

Batson, C. D., Polycarpou, M. P., Harmon-Jones, E., Imhoff, H. J., Mitchener, E. C., Bednar, L. L., ... Highberger, L. (1997). Empathy and attitudes: Can feeling for a member of a stigmatized group improve feelings toward the group? Journal of Personality and Social Psychology, 72(1), 105-18. http://doi.org/http://dx.doi.org/10.1037//0022-3514.72.1.105

Baumeister, R. F., Bratslavsky, E., Finkenauer, C., \& Vohs, K. D. (2001). Bad is stronger than good. Review of General Psychology, 5(4), 323-370. http://doi.org/10.1037//1089-2680.5.4.323

Bliese, P. (2002). Multilevel random coefficient modeling in organizational research: Examples using SAS and S-PLUS. In F. Drasgow \& N. Schmitt (Eds.), Measuring and analyzing behavior in organizations: Advances in measurement and data analysis (pp. 401-445). San Francisco: Jossey-Bass.

Bliese, P. (2009). Multilevel Modelling in R (2.3), A Brief Introduction to $R$, the multilevel package and the nlme package. Retrieved from http://cran.r-project.org/doc/contrib/Bliese_Multilevel.pdf

Bliese, P. (2012). Package "Multilevel" (2.4). Retrieved from http://cran.r-project.org/web/packages/ multilevel/multilevel.pdf

Borman, W. C. (2004). The concept of organizational citizenship. Current Directions in Psychological Science, 13(6), 238-241. 
Borman, W. C., Penner, L. A., Allen, T. D., \& Motowidlo, S. J. (2001). Personality predictors of citizenship performance. International Journal of Selection and Assessment, 9(1\&2), 52-69. http://doi. org/10.1111/1468-2389.00163

Bos, A. E. R., Pryor, J. B., Reeder, G. D., \& Stutterheim, S. E. (2013). Stigma: Advances in theory and research. Basic and Applied Social Psychology, 35(1), 1-9. http://doi.org/10.1080/01973533.20 12.746147

Bosch, L., Overmars-Marx, T., Ooms, D., \& Zwinkels, W. (2009). Wajongers en werkgevers: over omvang en omgang. Utrecht.

Bradbury, M. D., \& Jacobson, W. S. (2013). A new era of protection against disability discrimination? The ADA Amendments Act of 2008 and "regarded as" disabled. Review of Public Personnel Administration, 33(4), 320-339. http://doi.org/10.1177/0734371X12472683

Bruyère, S. M., Erickson, W. A., \& Ferrentino, J. T. (2002). Identity and disability in the workplace. William and Mary Law Review, 44, 1173-1196.

Bureau of Labor Statistics. (2015). Bureau of Labor Statistics. Retrieved from http://www.bls.gov/bls/ unemployment.htm

CBS. (2015). Sociale Zekerheid. Retrieved from http://www.cbs.nl/nl-NL/menu/themas/arbeidsociale-zekerheid/cijfers/default.htm

Choi, J. N. (2006). Multilevel and cross-level effects of workplace attitudes and group member relations on interpersonal helping behavior. Human Performance, 19(4), 383-402. http://doi.org/10.1207/ s15327043hup1904_4

Cohen, S., \& Wills, T. A. (1985). Stress, social support, and the buffering hypothesis. Psychological Bulletin, 98(2), 310-357. http://doi.org/10.1037/0033-2909.98.2.310

Cole, M. (2007). Re-Thinking Unemployment: A Challenge to the Legacy of Jahoda et al. Sociology, 41(6), 1133-1149. http://doi.org/10.1177/0038038507082319

Colella, A. J. (1994). Organizational socialization of employees with disabilities: Critical issues and implications for workplace interventions. Journal of Occupational Rehabilitation, 4(2), 87-106. http://doi.org/10.1007/BF02110048

Colella, A. J., \& Bruyère, S. M. (2011). Disability and employment: New directions for industrial and organizational psychology. In APA Handbook of Industrial and Organizational Psychology, Vol 1: Building and Developing the Organization (Vol. 1, pp. 473-503). http://doi.org/10.1037/12169015

Colella, A. J., DeNisi, A. S., \& Varma, A. (1997). Appraising the performance of employees with disabilities: A review and model. Human Resource Management Review, 7(1), 27-53. http://doi. org/10.1016/S1053-4822(97)90004-8

Colella, A. J., \& Varma, A. (1999). Disability-job fit stereotypes and the evaluation of persons with disabilities at work. Journal of Occupational Rehabilitation, 9(2), 79-95. http://doi. org/10.1023/A:1021362019948

Coles, S., \& Scior, K. (2012). Public attitudes towards people with intellectual disabilities: A qualitative comparison of white British \& South Asian people. Journal of Applied Research in Intellectual Disabilities, 25(2), 177-188. http://doi.org/10.1111/j.1468-3148.2011.00655.x

Danna, K., \& Griffin, R. (1999). Health and well-Being in the workplace: A review and synthesis of the literature. Journal of Management, 25(3), 357-384. http://doi.org/10.1177/014920639902500305

Deelstra, J., \& Peeters, M. (2003). Receiving instrumental support at work: When help is not welcome. Journal of Applied Psychology, 88(2), 324-331. http://doi.org/10.1037/0021-9010.88.2.324

Demerouti, E., Bakker, A. B., Nachreiner, F., \& Schaufeli, W. B. (2001). The Job DemandsResources model of burnout. Journal of Applied Psychology, 86(3), 499-512. http://doi. org/10.1108/02683940710733115

Ehrhart, M. G., Bliese, P., \& Thomas, J. (2006). Unit-level OCB and unit effectiveness: Examining the incremental effect of helping behavior. Human Performance, 19(2), 159-173. http://doi. org/10.1207/s15327043hup1902_4 
Ehrhart, M. G., \& Naumann, S. E. (2004). Organizational citizenship behavior in work groups: A group norms approach. Journal of Applied Psychology, 89(6), 960-74. http://doi.org/10.1037/00219010.89.6.960

Enders, C. K., \& Tofighi, D. (2007). Centering predictor variables in cross-sectional multilevel models: A new look at an old issue. Psychological Methods, 12(2), 121-38. http://doi.org/10.1037/1082989X.12.2.121

Eurofound. (2012). Fifth European Working Conditions Survey: Overview Report. http://doi. org/10.2806/34660

European Commission. (2007). Europe's demographic future: Facts and figures on challenges and opportunities. Luxemburg. Retrieved from http://ec.europa.eu/social/ BlobServlet?docld=1540\&langld=en

European Commission. (2011). Communication from the commission to the European Parliament, the Council, the European Economic and Social Committee and the Committee of the Regions; A renewed EU strategy 2011-14 for corporate social responsibility. Brussels. Retrieved from http: / / eur-lex.europa.eu/LexUriServ/LexUriServ.do?uri=COM:2011:0681:FIN:EN:PDF

European Commission. (2014). EU occupational safety and health (OSH) strategic framework 2014-2020. Brussels. Retrieved from http://eur-lex.europa.eu/legal-content/EN/TXT/ PDF/?uri=CELEX:52014DC0332

European Union. (2012). EU response to the crisis. Retrieved from http://ec.europa.eu/economy finance/crisis/index_en.htm

Eurostat. (2001). Disability and social participation in Europe. Brussels. Retrieved from http:// ec.europa.eu/eurostat/en/web/products-pocketbooks/-/KS-AW-01-001

Finkelstein, L. M., Ryan, K. M., \& King, E. B. (2013). What do the young (old) people think of me? Content and accuracy of age-based metastereotypes. European Journal of Work and Organizational Psychology, 22(6), 633-657. http://doi.org/10.1080/1359432X.2012.673279

Finkelstein, M. A. (2012). Individualism/collectivism and organizational citizenship behavior: An integrative framework. Social Behavior and Personality, 40(10), 1633-1644. http://doi. org/10.1037/12169-015

Finkelstein, M. A., Penner, L. A., \& Brannick, M. T. (2005). Motive, role identity, and prosocial personality as predictors of volunteer activity. Social Behavior and Personality: An International Journal, 33(4), 403-418. http://doi.org/10.2224/sbp.2005.33.4.403

Fishbein, M., \& Ajzen, I. (2010). Predicting and changing behavior: The reasoned action approach. New York, NY: Taylor \& Francis.

Fisher, C. D. (1985). Social support and adjustment to work: A longitudinal study. Journal of Management, 11, 39-53. http://doi.org/10.1177/014920638501100304

Fiske, S. T., Cuddy, A. J. C., Glick, P., \& Xu, J. (2002). A model of (often mixed) stereotype content: Competence and warmth respectively follow from perceived status and competition. Journal of Personality and Social Psychology, 82(6), 878-902. http://doi.org/10.1037//0022-3514.82.6.878

Fogarty, G. J., \& Shaw, A. (2010). Safety climate and the theory of planned behavior: Towards the prediction of unsafe behavior. Accident; Analysis and Prevention, 42(5), 1455-9. http://doi. org/10.1016/j.aap.2009.08.008

Fraser, R., Ajzen, I., Johnson, K., Hebert, J., \& Chan, F. (2011). Understanding employers' hiring intention in relation to qualified workers with disabilities. Journal of Vocational Rehabilitation, 35(1), 1-11. http://doi.org/10.3233/JVR-2011-0548

Gilbride, D., Stensrud, R., Ehlers, C., Evans, E., \& Peterson, C. (2000). Employers' attitudes toward hiring persons with disabilities and vocational rehabilitation services. Journal of Rehabilitation.

Glasman, L. R., \& Albarracín, D. (2006). Forming attitudes that predict future behavior: A metaanalysis of the attitude-behavior relation. Psychological Bulletin, 132(5), 778-822. http://doi. org/10.1037/0033-2909.132.5.778 
González-Romá, V., \& Hernández, A. (2014). Climate uniformity: Its influence on team communication quality, task conflict, and team performance. Journal of Applied Psychology, 99(6), 1042-1058. http://doi.org/10.1037/a0037868

Grant, A. M. (2007). Relational job design and the motivation to make a prosocial difference. Academy of Management Review, 32(2), 393-417. http://doi.org/10.5465/AMR.2007.24351328

Grant, A. M. (2008). Does intrinsic motivation fuel the prosocial fire? Motivational synergy in predicting persistence, performance, and productivity. Journal of Applied Psychology, 93(1), 48-58. http:// doi.org/10.1037/0021-9010.93.1.48

Grant, A. M., \& Berg, J. M. (2010). Prosocial motivation at work: When, why, and how making a difference makes a difference. In The Oxford handbook of positive organizational scholarship (pp. 28-44).

Grant, A. M., Campbell, E. M., Chen, G., Cottone, K., Lapedis, D., \& Lee, K. (2007). Impact and the art of motivation maintenance: The effects of contact with beneficiaries on persistence behavior. Organizational Behavior and Human Decision Processes, 103(1), 53-67. http://doi.org/10.1016/j. obhdp.2006.05.004

Grant, A. M., \& Gino, F. (2010). A little thanks goes a long way: Explaining why gratitude expressions motivate prosocial behavior. Journal of Personality and Social Psychology, 98(6), 946-55. http:// doi.org/10.1037/a0017935

Grant, A. M., \& Mayer, D. M. (2009). Good soldiers and good actors: prosocial and impression management motives as interactive predictors of affiliative citizenship behaviors. Journal of Applied Psychology, 94(4), 900-12. http://doi.org/10.1037/a0013770

Grant, A. M., \& Sumanth, J. J. (2009). Mission possible? The performance of prosocially motivated employees depends on manager trustworthiness. Journal of Applied Psychology, 94(4), 927-44. http://doi.org/10.1037/a0014391

Grojean, M. W., Resick, C. J., Dickson, M. W., \& Smith, D. B. (2004). Leaders, values, and organizational climate: Examining leadership strategies for establishing an organizational climate regarding ethics. Journal of Business Ethics, 55(3), 223-241. http://doi.org/10.1007/s10551-004-1275-5

Hagen, B., Zwinkels, W., Mulder, A., Berkouwer, L., Overmars-Marx, T., Ooms, D., ... Sanders, J. (2008). Trainen voor een baan: Onderzoek naar de werkwijze Stam BV: vergelijking en resultaten. Utrecht.

Hambleton, R. K. (2001). The next generation of the ITC test translation and adaptation guidelines. European Journal of Psychological Assessment, 17(3), 164-172. http://doi.org/10.1027//10155759.17.3.164

Hastorf, A. H., Wildfogel, J., \& Cassman, T. (1979). Acknowledgment of handicap as a tactic in social interaction. Journal of Personality and Social Psychology, 37(10), 1790-7. http://doi.org/http:// dx.doi.org/10.1037//0022-3514.37.10.1790

Hayes, A. (2013). Introduction to mediation, moderation, and conditional process analysis: A regressionbased approach. New York, NY: Guilford Press.

Hayes, A. F. (2009). Beyond Baron and Kenny: Statistical mediation analysis in the new millennium. Communication Monographs, 76(4), 408-420. http://doi.org/10.1080/03637750903310360

Hilton, J. L., \& von Hippel, W. (1996). Stereotypes. Annual Review of Psychology, 47(1), 237-271. http://doi.org/10.1146/annurev.psych.47.1.237

Hirst, G., Van Knippenberg, D., \& Zhou, J. (2009). A cross-level perspective on employee creativity: Goal orientation, team learning behavior, and individual creativity. Academy of Management Journal, 52(2), 280-293. http://doi.org/10.5465/AMJ.2009.37308035

Hoffman, B. J., Blair, C. a, Meriac, J. P., \& Woehr, D. J. (2007). Expanding the criterion domain? A quantitative review of the OCB literature. Journal of Applied Psychology, 92(2), 555-66. http:// doi.org/10.1037/0021-9010.92.2.555 
Hu, L., \& Bentler, P. M. (1999). Cutoff criteria for fit indexes in covariance structure analysis: Conventional criteria versus new alternatives. Structural Equation Modeling: A Multidisciplinary Journal, 6(1), 1-55. http://doi.org/10.1080/10705519909540118

Hunt, C. S., \& Hunt, B. (2004). Changing attitudes toward people with disabilities: Experimenting with an educational intervention. Journal of Management Issues, 16(2), 266-280.

Ilies, R., Scott, B. A., \& Judge, T. A. (2006). The interactive effects of personal traits and experienced states on intraindividual patterns of citizenship behavior. Academy of Management Journal, 49(3), 561-575. http://doi.org/10.5465/AMJ.2006.21794672

Jahoda, M. (1981). Work, employment, and unemployment: Values, theories, and approaches in social research. American Psychologist, 36(2), 184-191. http://doi.org/10.1037//0003-066X.36.2.184

James, L. A., \& James, L. R. (1989). Integrating work environment perceptions: Explorations into the measurement of meaning. Journal of Applied Psychology, 74(5), 739-751. http://doi. org/10.1037/0021-9010.74.5.739

James, L., Choi, C., Ko, C.-H. E., McNeil, P., Minton, M., Wright, M. A., \& Kim, K. (2008). Organizational and psychological climate: A review of theory and research. European Journal of Work and Organizational Psychology, 17(1), 5-32. http://doi.org/10.1080/13594320701662550

Johns, G. (2006). The essential impact of context on organizational behavior. Academy of Management Review, 31(2), 386-408. http://doi.org/10.5465/AMR.2006.20208687

Johnson, R. W., Mermin, G. B. T., \& Resseger, M. (2007). Employment at older ages and the changing nature of work. The AARP Public Policy Institute. Retrieved from http://www.urban.org/ research/publication/employment-older-ages-and-changing-nature-work

Judge, T. A., Thoresen, C. J., Bono, J. E., \& Patton, G. K. (2001). The job satisfaction-job performance relationship: A qualitative and quantitative review. Psychological Bulletin, 127(3), 376-407. http://doi.org/10.1037/0033-2909.127.3.376

Kaye, H. S., Jans, L. H., \& Jones, E. C. (2011). Why don't employers hire and retain workers with disabilities? Journal of Occupational Rehabilitation, 21(4), 526-36. http://doi.org/10.1007/ s10926-011-9302-8

Kok, G., Schaalma, H., Ruiter, R. A. C., van Empelen, P., \& Brug, J. (2004). Intervention Mapping: A protocol for applying health psychology theory to prevention programmes. Journal of Health Psychology, 9(1), 85-98. http://doi.org/10.1177/1359105304038379

Krahn, G., Hammond, L., \& Turner, A. (2006). A cascade of disparities: Health and health care acces for people with intellectual disabilities. Mental Retardation and Developmental Disabilities Research Reviews, 12(2), 70-82. http://doi.org/10.1002/mrdd.20098

Kraus, S. J. (1995). Attitudes and the prediction of behavior: A meta-analysis of the empirical literature. Personality and Social Psychology Bulletin, 21(1), 58-75. http://doi. org $/ 10.1177 / 0146167295211007$

Kruse, D., \& Schur, L. (2003). Employment of people with disabilities following the ADA. Industrial Relations, 42(1), 31-64. http://doi.org/10.1111/1468-232X.00275

LaHuis, D. M., \& Ferguson, M. W. (2007). The accuracy of significance tests for slope variance components in multilevel random coefficient models. Organizational Research Methods, 12(3), 418-435. http: //doi.org/10.1177/1094428107308984

Lammerts, R., \& Stavenuiter, M. (2010). Wajongers op de werkvloer: Inpassing en acceptatie van jonggehandicapten in bedrijven. Retrieved from http://www.kcco.nl/doc/kennisbank/ Wajongers_op_de_werkvloer.pdf

LeBreton, J. M., \& Senter, J. L. (2007). Answers to 20 questions about interrater reliability and interrater agreement. Organizational Research Methods, 11(4), 815-852. http://doi. org/10.1177/1094428106296642

Lepine, J. a, Erez, A., \& Johnson, D. E. (2002). The nature and dimensionality of organizational citizenship behavior: A critical review and meta-analysis. Journal of Applied Psychology, 87(1), 52-65. http://doi.org/10.1037//0021-9010.87.1.52 
Leyens, J.-P., Yzerbyt, V., \& Schadron, G. (1994). Stereotypes and Social Cognition. London: Sage Publications Ltd.

Lindgreen, A., \& Swaen, V. (2010). Corporate Social Responsibility. International Journal of Management Reviews, 12(1), 1-7. http://doi.org/10.1111/j.1468-2370.2009.00277.x

Lopes, H. (2011). Why do people work? Individual wants versus common goods. Journal of Economic Issues, 45(1), 57-74. http://doi.org/10.2753/JEI0021-3624450104

Mackelprang, R. W., \& Salsgiver, R. O. (1996). People with disabilities and social work: Historical and contemporary issues. Social Work, 41(1), 7-14.

Maner, J. K., \& Gailliot, M. T. (2007). Altruism and egoism: Prosocial motivations for helping depend on relationship context. European Journal of Social Psychology, 37(2), 347-358. http://doi. org/10.1002/ejsp.364

Martínez, P., Pérez, A., \& Rodríguez del Bosque, I. (2013). Exploring the role of CSR in the organizational identity of hospitality companies: A case from the Spanish tourism industry. Journal of Business Ethics, 124(1), 47-66. http://doi.org/10.1007/s10551-013-1857-1

McNeely, B. L., \& Meglino, B. M. (1994). The role of dispositional and situational antecedents in prosocial organizational behavior: An examination of the intended beneficiaries of prosocial behavior. Journal of Applied Psychology, 79(6), 836-844. http://doi.org/10.1037//0021-9010.79.6.836

Milner, P., \& Kelly, B. (2009). Community participation and inclusion: People with disabilities defining their place. Disability \& Society, 24(1), 47-62. http://doi.org/10.1080/09687590802535410

Moorman, R. H., \& Blakely, G. L. (1995). Individualism-collectivism as an individual difference predictor of organizational citizenship behavior. Journal of Organizational Behavior, 16(2), 127-142. http:// doi.org/10.1002/job.4030160204

Morgeson, F. P., Reider, M. H., \& Campion, M. a. (2005). Selecting individuals in team settings: The importance of social skills, personality characteristics, and teamwork knowledge. Personnel Psychology, 58(3), 583-611. http://doi.org/10.1111/j.1744-6570.2005.655.x

Nelissen, P. T. J. H., Hülsheger, U. R., van Ruitenbeek, G. M. C., \& Zijlstra, F. R. H. (2016). How and when stereotypes relate to inclusive behavior toward people with disabilities. The International Journal of Human Resource Management, 27(14), 1610-1625. http://doi.org/10.1080/09585192 .2015.1072105

Nelissen, P. T. J. H., Vornholt, K., Van Ruitenbeek, G. M. C., Hülsheger, U. R., \& Uitdewilligen, S. (2014). Disclosure or nondisclosure-Is this the question? Industrial and Organizational Psychology, 7(2), 231-235. http://doi.org/10.1111/iops. 12138

Nijhuis, F. J. N., Mulders, H. P. G., \& Zijlstra, F. R. H. (2011). Inclusief herontwerp van werkprocessen. Aan de Slag, 20-23. Retrieved from http://www.uwv.nl/overuwv/images/aan_de_slag.pdf

NOS. (2015). DNB: de zeven magere jaren zijn voorbij. NOS.nl. Retrieved from http://nos.nl/ artikel/2040185-dnb-de-zeven-magere-jaren-zijn-voorbij.html

Nota, L., Santilli, S., Ginevra, M. C., \& Soresi, S. (2014). Employer attitudes towards the work inclusion of people with disability. Journal of Applied Research in Intellectual Disabilities, 27(6), 511-520. http://doi.org/10.1111/jar.12081

Organ, D. (1988). Organizational citizenship behavior: The good soldier syndrome. Lexington, MA: Lexington Books.

Organ, D. W. (1997). Organizational Citizenship Behavior: It's construct clean-up time. Human Performance, 10(2), 85-97. http://doi.org/10.1207/s15327043hup1002

Oswald, A. J., Proto, E., \& Sgroi, D. (2015). Happiness and productivity. Journal of Labor Economics, 33(4), 789-822. http://doi.org/10.1086/681096

Paling, F. (2013). De uitvoering van het Participatiebeleid. In Congres Inclusieve Arbeidsmarkt. Amersfoort.

Peck, B., \& Kirkbride, L. (2001). Why businesses don't employ people with disabilities. Journal of Vocational Rehabilitation, 16, 71-75. 
Penner, L. A., Dovidio, J. F., Piliavin, J. A., \& Schroeder, D. A. (2005). Prosocial behavior: Multilevel perspectives. Annual Review of Psychology, 56, 365-92. http://doi.org/10.1146/annurev. psych.56.091103.070141

Penner, L. A., \& Finkelstein, M. A. (1998). Dispositional and structural determinants of volunteerism. Journal of Personality and Social Psychology, 74(2), 525-537. http://doi.org/10.1037//00223514.74.2.525

Penner, L. A., Midili, A. R., \& Kegelmeyer, J. (1997). Beyond job attitudes: A personality and social psychology perspective on the causes of organizational citizenship behavior. Human Performance, 10(2), 111-131. http://doi.org/10.1207/s15327043hup1002_4

Pinder, C. (1984). Work motivation: Theory, issues, and applications. Glenview, IL: Scott, Foresman.

Pinheiro, J., Bates, D., DebRoy, S., \& Sarkar, D. (2011). Nlme: Linear and Nonlinear Mixed Effects Models. $\mathrm{R}$ foundation for statistical computing. R package version 3.1-97.

Podsakoff, N. P., Podsakoff, P. M., Mackenzie, S. B., Maynes, T. D., \& Spoelma, T. M. (2014). Consequences of unit-level organizational citizenship behaviors: A review and recommendations for future research. Journal of Organizational Behavior, 35(SUPPL.1), 87-119. http://doi.org/10.1002/ job.1911

Podsakoff, N. P., Whiting, S. W., Podsakoff, P. M., \& Blume, B. D. (2009). Individual- and organizationallevel consequences of organizational citizenship behaviors: A meta-analysis. Journal of Applied Psychology, 94(1), 122-41. http://doi.org/10.1037/a0013079

Podsakoff, P. M., Mackenzie, S. B., \& Moorman, H. (1990). Leader behaviors and their effects on followers' trust in leader, satisfaction, and citizenship behaviors. Leadership, (2), 107-142. http: / /doi.org/10.1016/1048-9843(90)90009-7

Podsakoff, P. M., MacKenzie, S. B., Paine, J. B., \& Bachrach, D. G. (2000). Organizational citizenship behaviors: A critical review of the theoretical and empirical literature and suggestions for future research. Journal of Management, 26(3), 513-563. http://doi.org/10.1177/014920630002600307

Preacher, K. J., \& Kelley, K. (2011). Effect size measures for mediation models: quantitative strategies for communicating indirect effects. Psychological Methods, 16(2), 93-115. http://doi. org $/ 10.1037 / \mathrm{a} 0022658$

Reyna, C., Dobria, O., \& Wetherell, G. (2013). The complexity and ambivalence of immigration attitudes: Ambivalent stereotypes predict conflicting attitudes toward immigration policies. Cultural Diversity \& Ethnic Minority Psychology, 19(3), 342-56. http: / /doi.org/10.1037/a0032942

Rijksoverheid. (2015). Jetta Klijnsma, Staatssecretaris van Sociale Zaken en Werkgelegenheid. Retrieved from http://www.rijksoverheid.nl/regering/bewindspersonen/jetta-klijnsma

Rijksoverheid. (2016). Participatiewet.

Rimmer, J. H., \& Rowland, J. L. (2008). Health promotion for people with disabilities: Implications for empowering the person and promoting disability-friendly environments. American Journal of Lifestyle Medicine, 2(5), 409-420. http://doi.org/10.1177/1559827608317397

Rioux, S. M., \& Penner, L. A. (2001). The causes of organizational citizenship behavior: A motivational analysis. Journal of Applied Psychology, 86(6), 1306-1314. http://doi.org/10.1037//00219010.86.6.1306

Roe, R. A., \& Zijlstra, F. R. H. (2000). Work Pressure. Results of Conceptual and Empirical Analysis. In M. Vartiainen, F. Avallone, \& N. Anderson (Eds.), Innovative theories, tools, and practices in work and organizational psychology. (viii, pp. 29-45). Ashland, OH, US: Hogrefe \& Huber Publishers.

Rosseel, Y. (2012). lavaan: An R package for structural equation modeling. Journal of Statistical Software, 48(2), 1-36. Retrieved from http://www.jstatsoft.org/v48/i02/.

Ruiter, R. A. C., Massar, K., van Vugt, M., \& Kok, G. (2013). Applying Social Psychology to Understanding Social Problems. In A. Golec De Zaala \& A. Cichocka (Eds.), Social Psychology of Social Problems (pp. 337-362). Palgrave Macmillan. 
Santuzzi, A. M., Waltz, P. R., Finkelstein, L. M., \& Rupp, D. E. (2014). Invisible disabilities: Unique challenges for employees and organizations. Industrial and Organizational Psychology, 7(2), 204219. http://doi.org/10.1111/iops. 12134

Schneider, B. (2000). The psychology of organizations. In Handbook of Organizational Culture and Climate.

Schneider, B., Ehrhart, M. G., \& Macey, W. H. (2013). Organizational climate and culture. Annual Review of Psychology, 1(12), 361-88. http://doi.org/10.1146/annurev-psych-113011-143809

Schneider, B., González-Romá, V., Ostroff, C., \& West, M. (2016). Organizational climate and culture: Reflections on the history of constructs in JAP. Journal of Applied Psychology, (303), 1-55.

Schneider, B., \& Reichers, A. (1983). On the etiology of climates. Personnel Psychology, 36(1), 19-39. http://doi.org/10.1111/j.1744-6570.1983.tb00500.x

Schneider, J. (2008). Supported-employment practice in the UK: evidence about an emerging occupational group. Disability and Rehabilitation, 30(23), 1819-28. http://doi.org/10.1080/09638280701661257

Schur, L. (2003). Barriers or opportunities? The causes of contingent and part-time work among people with disabilities. Industrial Relations, 42(4), 589-622. http://doi.org/10.1111/1468-232X.00308

Schur, L., Kruse, D., \& Blanck, P. (2005). Corporate culture and the employment of persons with disabilities. Behavioral Sciences \& the Law, 23(1), 3-20. http://doi.org/10.1002/bsl.624

Schur, L., Kruse, D., Blasi, J., \& Blanck, P. (2009). Is disability disabling in all workplaces? Workplace disparities and corporate culture. Industrial Relations: A Journal of Economy and Society, 48(3), 381-410. http://doi.org/10.1111/j.1468-232X.2009.00565.x

Schuring, M., Mackenbach, J., Voorham, T., \& Burdorf, A. (2011). The effect of re-employment on perceived health. Journal of Epidemiology and Community Health, 65(7), 639-44. http://doi. org/10.1136/jech.2009.103838

Schwartz, S. H., \& Bilsky, W. (1987). Toward a universal psychological structure of human values. Journal of Personality and Social Psychology, 53(3), 550-562. http://doi.org/10.1037//00223514.53.3.550

Scior, K. (2011). Public awareness, attitudes and beliefs regarding intellectual disability: A systematic review. Research in Developmental Disabilities, 32(6), 2164-82. http://doi.org/10.1016/j. ridd.2011.07.005

Selenko, E., \& Batinic, B. (2013). Job insecurity and the benefits of work. European Journal of Work and Organizational Psychology, 22(6), 725-736. http://doi.org/10.1080/1359432X.2012.703376

Shima, I., Zólyomi, E., \& Zaidi, A. (2008). The Labour Market Situation of People with Disabilities in EU25. European Centre, Policy Bri(1), 1-18. Retrieved from http://www.euro.centre.org/ data/1201610451_25081.pdf

Smith, N. K., Larsen, J. T., Chartrand, T. L., Cacioppo, J. T., Katafiasz, H. a, \& Moran, K. E. (2006). Being bad isn't always good: affective context moderates the attention bias toward negative information. Journal of Personality and Social Psychology, 90(2), 210-20. http://doi. org/10.1037/0022-3514.90.2.210

Snyder, M. (1993). Basic research and practical problems: The promise of a "functional" personality and social psychology. Personality and Social Psychology Bulletin, 19(3), 251-264. http://doi. org $/ 10.1177 / 0146167293193001$

Sonnentag, S., \& Zijlstra, F. R. H. (2006). Job characteristics and off-job activities as predictors of need for recovery, well-being, and fatigue. The Journal of Applied Psychology, 91(2), 330-50. http:// doi.org/10.1037/0021-9010.91.2.330

Spector, P. E. (2001). Research methods in industrial and organizational psychology: Data collection and data analysis with special consideration to international issues. In N. Anderson (Ed.), Handbook of industrial, work and organizational psychology (Vol. 1, pp. 10-26). London: Sage Publications Ltd.

Stone, D., \& Colella, A. (1996). A model of factors affecting the treatment of disabled individuals in organizations. Academy of Management Review, 21(2), 352-401. 
Taris, T. W. (2006). Is there a relationship between burnout and objective performance? A critical review of 16 studies. Work \& Stress, 20(4), 316-334. http://doi.org/10.1080/02678370601065893

Taris, T. W., \& Schreurs, P. J. G. (2009). Well-being and organizational performance: An organizationallevel test of the happy-productive worker hypothesis. Work \& Stress, 23(2), 120-136. http://doi. org/10.1080/02678370903072555

Thornicroft, G., \& Patel, V. (2014). Including mental health among the new sustainable development goals. The British Medical Journal, 349, 1-2. http://doi.org/10.1136/bmj.g5189

Unger, D. D. (2002). Employers' attitudes toward persons with disabilities in the workforce: Myths or realities? Focus on Autism and Other Developmental Disabilities, 17(1), 2-10. http://doi. org/10.1177/108835760201700101

United Nations. (2013). World Population Ageing 2013. United Nations. New York, NY. http://doi.org/ ST/ESA/SER.A/348

UWV. (2013). Kerngegevens Wajong, Feiten en Cijfers. Retrieved from http://www.uwv.nl/zakelijk/ Images/kerngegevens-wajong.pdf

UWV. (2015). UWV Kennisverslag. Retrieved from http://www.uwv.nl/overuwv/kennis-cijfers-enonderzoek/kennis-onderzoeken/uwv-kennisverslag-2015-1.aspx

UWV. (2016). Ik ben arbeidsbeperkt. Retrieved from http://www.uwv.nl/particulieren/arbeidsbeperkt/

van der Klink, J. J. L., Bültmann, U., Burdorf, A., Schaufeli, W. B., Zijlstra, F. R. H., Abma, F. I., ... Van der wilt, G. J. (2016). Sustainable employability - definition, conceptualization, and implications: A perspective based on the capability approach. Scandinavian Journal of Work, Environment and Health, 42(1), 71-79. http://doi.org/10.5271/sjweh.3531

van der Laan, S. (2015). Minister Dijsselbloem: economische crisis is voorbij. Elsevier. Retrieved from http://www.elsevier.nl/Economie/nieuws/2014/5/Minister-Dijsselbloem-economische-crisis-isvoorbij-1516975W/

Van der Pijl, N., Waasdorp, G.-J., \& Oonk, V. (2014). War for Wajong. Rotterdam. Retrieved from http://www. intelligence-group.nl/media/files/Downloads/War for Wajong_def.pdf

van Duin, C., \& Garssen, J. (2010). Bevolkingsprognose 2010- 2060: sterke vergrijzing, langere levensduur. Publicatie CBS.

Van Holland, B. J., De Boer, M. R., Brouwer, S., Soer, R., \& Reneman, M. F. (2012). Sustained employability of workers in a production environment: design of a stepped wedge trial to evaluate effectiveness and cost-benefit of the POSE program. BMC Public Health, 12(1), 1003. http://doi. org /10.1186/1471-2458-12-1003

van Ruitenbeek, G. M. C., Mulder, M. J. G. P., Zijlstra, F. R. H., Nijhuis, F. J., \& Mulders, H. P. G. (2013). Een alternatieve benadering voor herontwerp van werk: Ervaring met de methode Inclusief Herontwerp Werkprocessen. Gedrag En Organisatie, 26(1), 104-122.

Vornholt, K., Uitdewilligen, S., \& Nijhuis, F. J. N. (2013). Factors affecting the acceptance of people with disabilities at work: A literature review. Journal of Occupational Rehabilitation, 23(4), 463475. http://doi.org/10.1007/s10926-013-9426-0

Walumbwa, F. O., Hartnell, C. A., \& Oke, A. (2010). Servant leadership, procedural justice climate, service climate, employee attitudes, and organizational citizenship behavior: a cross-level investigation. Journal of Applied Psychology, 95(3), 517-29. http://doi.org/10.1037/a0018867

Watson, D., Clark, L. A., \& Tellegen, A. (1988). Development and validation of brief measures of positive and negative affect: The PANAS scales. Journal of Personality and Social Psychology, 54(6), 1063-70. http://doi.org/10.1037/0022-3514.54.6.1063

Wehman, P. (2003). Workplace inclusion: Persons with disabilities and coworkers working together. Journal of Vocational Rehabilitation, 18, 131-141.

Weinstein, N., \& Ryan, R. M. (2010). When helping helps: autonomous motivation for prosocial behavior and its influence on well-being for the helper and recipient. Journal of Personality and Social Psychology, 98(2), 222-44. http://doi.org/10.1037/a0016984 
Williams, L., \& Anderson, S. (1991). Job satisfaction and organizational commitment as predictors of organizational citizenship and in-role behaviors. Journal of Management, 17(3), 601-617. http:// doi.org/10.1177/014920639101700305

Wright, C., Wright, C. W., \& Sablynski, C. J. (2008). Procedural justice, mood, and prosocial personality influence on organizational citizenship behavior. North American Journal of Psychology, 10(2), 397-412.

Zijlstra, F. R. H. (2009). Taken voor laag-gekwalificeerden: op weg naar een parallelle arbeidsmarkt? In UWV (Ed.), Innovatieve voorstellen voor Sociaal-Medische Beoordeling van Arbeidsvermogen (pp. 177-191). UWV.

Zijlstra, F. R. H., Mulders, H. P. G., \& Nijhuis, F. J. (2012). Inclusieve Organisaties: Op weg naar duurzame arbeidsparticipatie. Tijdschrift Voor Arbeidsvraagstukken, 28(1), 21-29. 
Appendix 
Appendix 


\section{Appendix}

Table 1. Correlation Table Between Study Variables of Chapter 2 and 3

\begin{tabular}{|c|c|c|c|c|c|c|c|c|c|}
\hline Variable & M & SD & 1 & 2 & 3 & 4 & 5 & 6 & 7 \\
\hline 1 Prosocial Motivation & 4.11 & .58 & $(.86)$ & & & & & & \\
\hline 2 Stereotype Warmth & 3.32 & .63 & $.18^{* *}$ & $(.67)$ & & & & & \\
\hline 3 Stereotype Competence & 2.65 & .66 & .07 & $.39^{* *}$ & $(.80)$ & & & & \\
\hline $\begin{array}{l}\text { Attitudes towards the } \\
4 \text { employment of people } \\
\text { with disabilities }\end{array}$ & 3.85 & .63 & $.37^{* *}$ & $.32^{* *}$ & $.24^{* *}$ & (.61) & & & \\
\hline 5 Work Pressure & 2.58 & .80 & .02 & .02 & -.06 & .02 & $(.86)$ & & \\
\hline 6 Inclusive Behavior & 4.09 & .62 & $.26^{* *}$ & .07 & .04 & $.19^{* *}$ & -.01 & $(.89)$ & \\
\hline 7 Inclusive Climate & 3.97 & .77 & $.42^{* *}$ & $.26^{* *}$ & $.15^{*}$ & $.30^{* *}$ & -.03 & $.36^{* *}$ & $(.90)$ \\
\hline
\end{tabular}

Note. All correlations are at the individual level $(N=313)$, with the group-level variable (inclusive climate) assigned down to individual employees. Reliability coefficients are reported in parentheses on the diagonal.

${ }^{*} p<.05 .{ }^{* *} p<.01$. 

Valorization 
Valorization 


\section{Valorization}

The valorization concerns the social value creation based on the research results presented in this dissertation. Therefore in this valorization an overview is provided on the societal and legislative setting in which this research is situated, target groups are identified, and it is described to what extent the presented tools and guidelines can be utilized to accommodate beneficiaries of the target group.

\section{Societal and legislative setting}

The European Commission advocates to apply the vision of Corporate Social Responsibility in all organizations (European Commission, 2011). Socially responsible organizations aim to integrate social concerns in their business agenda and thus contribute to a better society. Nowadays, corporate social responsibility is a hot issue for many employers (Lindgreen \& Swaen, 2010; Martínez et al., 2013). It is recognized as an important ethical topic in our current society and is a way for organizations to display their organizational identity to its stakeholders (Martínez et al., 2013).

In the Netherlands, corporate social responsibility and legislation recently seem to go hand in hand. First, in 1998, the first Act 'Wajong' (Wet Werk en Arbeidsondersteuning Jonggehandicapten) was introduced, to be renewed in 2010 (nieuwe Wet Wajong). Since 2010, the focus of the Dutch government lies with what people with disabilities are capable to do, instead of what their limitations are. More recently it has evolved to 'de Wet Werken naar Vermogen', and as of the first of January 2015, the Participation Act (Participatiewet) has gone into effect. This has led to a social plan upon which the government and the employers' organization have agreed to create 125.000 jobs for people with disabilities over a period of 10 years. 25.000 of these jobs will be created by the government, whereas the other 100.000 jobs will be provided by all organizations in the Netherlands. Such an agreement shows the effort, concern and social base of the employers. This way, organizations are furthermore able to postpone the $5 \%$ employment quota that is imbedded in the Participation Act, which would give rise to a set minimum of $5 \%$ people with disabilities in every organization (Rijksoverheid, 2016) ${ }^{6}$.

\footnotetext{
${ }^{6}$ In other countries, such as Germany, France, and Poland, the disability quota system of $5 \%$ has not been the ultimate solution to activating and employing people with disabilities in regular organizations. The employment level of people with disabilities in these countries has not risen to the equivalent of those without disabilities (Shima, Zólyomi, \& Zaidi, 2008). Even in the U.S., legislation such as the ADA and the ADAAA (ADA, 1990; ADAAA, 2008) has not been able to resolve employment issues for people with disabilities. Additionally, enforcing organizations to hire people with disabilities as part of a quota or law might be perceived as an extra regulatory load.
} 


\section{Target group}

As a consequence of the given the current societal and legislative setting, people with disabilities need to be employed in large numbers. The employment process will be arranged by the municipalities in order to be more effective and efficient in directing employment opportunities. Every person with a disability will be evaluated on their capacity to work. Everyone who is deemed capable to work will be entered into a register that will allow them to be eligible for support and guidance, but this is also a way to be found by potential employers. Those who are found unfit to work will continue to receive welfare payments (UWV, 2016). However, once the hiring process is completed and people with disabilities start to work, many organizations discover that the socialization of this particular group may not run as smoothly as with others (Lammerts \& Stavenuiter, 2010; Vornholt et al., 2013). Hence, the groups targeted in this dissertation are the people with disabilities, their colleagues, as well as the employers they work for. The findings presented in this dissertation can therefore be very useful for employers to ameliorate the opportunities for workplace inclusion in order to reach the desired level of employment of people with disabilities as agreed upon in the Participation Act. As it has become apparent within this dissertation that employee individual characteristics, behavior, and team climate are required building blocks, these findings are crucial to the way the peers of employees with disabilities need to conduct to achieve workplace inclusion.

\section{Innovation, products, and implementation}

This research is innovating as it answers the call for research by Collela and Bruyère (2011) to focus on what happens to people with disabilities when they enter the workplace and what factors would facilitate their inclusion. This research is among the first to apply the Work and Organizational perspective on the work setting of people with disabilities to study what factors might contribute to their workplace inclusion and in the long run sustainable employment. Furthermore, new concepts such as inclusive behavior and inclusive climate were developed in this dissertation, and tailored to the specific work setting of people with disabilities in inclusive organizations. Both inclusive behavior and inclusive climate have been argued and found to be pivotal towards achieving workplace inclusion. These concepts can be seen as tools, guidelines, and critical knowledge which will facilitate organizations and their employees in achieving workplace inclusion for people with disabilities. Taken together these could be formed into a product that serves as an instrument that measures relevant personality characteristics, as well as inclusive behavior, or even gauge the perceptions of employees towards the practices, procedures, and policies that make up the (inclusive) climate.

By measuring these building blocks employers are able to further their understanding on the way people with disabilities are accepted, helped, and treated as others within 
the workplace. Preferably these measurements are taken prior to (and again after) the intake of people with disabilities into the workplace, but also in existing situations the insights provided will be able to contribute to workplace inclusion. Additionally, based on the outcomes of this measurement, Work and Organizational psychologists will be able to provide suggestions to improve the working conditions and consequently enhance the workplace inclusion. Examples of such suggestions might entail: providing educational information (individual level), leadership modelling (team level), and aligning corporate social responsibility goals throughout the organization (organizational level). It is within this frame of mind that it was suggested to use theory based Intervention Mapping as a possible implementation protocol, on all three organizational levels. In this way the behavior of employees within inclusive organizations can be changed or adapted to fit the organizational values of corporate social responsibility. Taken together, inclusive organizations are advised to measure and stimulate the building blocks of workplace inclusion. 

Summary 
Summary 


\section{Summary}

Corporate social responsibility and current legislation encourage the employment of people with disabilities in inclusive organizations. However, people with disabilities encounter difficulties in the workplace such as exclusion or unfair treatment. As the conditions at the workplace might have a large influence on the level of inclusion, this dissertation concerns the building blocks of workplace inclusion for people with disabilities. Specifically, this dissertation offers three main contributions to theory and scientific research literature, in the domain of research on people with disabilities at work, within the literature on Organizational Citizenship Behavior, and by adopting a multilevel approach in team climate research. In chapter 2 we build upon the Reasoned Action Approach to illuminate how and when stereotypes of employees relate to inclusive behavior at work. Results show that the relationship between stereotypes and inclusive behavior is mediated by attitudes toward the employment of people with disabilities. Furthermore, work pressure is a boundary condition of this relationship in such a way that the relationship is stronger when work pressure is low. Chapter 3 focuses on the relationship between prosocial motivation, team inclusive climate, and employee inclusive behavior. Based on the functional approach, this study shows that prosocial motivation is positively related to inclusive behavior. Furthermore, this relationship is moderated by team inclusive climate, in such a way that a high inclusive climate seems to be strong enough to guide the individual's inclusive behavior, regardless of their prosocial motivation. In chapter 4 the social support theory is used to show that team inclusive behavior has an effect on the well-being of people with disabilities within the work team. More precisely, inclusive behavior reduces the negative emotions for people with disabilities at work. In chapter 5 it is discussed how legislation might influence the disclosure decisions of people with disabilities, but at the same time the need for looking beyond legislation is addressed, particularly by adopting a Work and Organizational (and multilevel) perspective. In conclusion, the studies in this dissertation contribute to a greater understanding of what happens when people with disabilities enter the workplace. After all, the more building blocks are present, the more workplace inclusion can be achieved. 

Samenvatting 
Samenvatting 


\section{Samenvatting}

Maatschappelijk verantwoord ondernemen en de huidige wetgeving moedigen de tewerkstelling van mensen met beperkingen in inclusieve organisaties aan. Desondanks ervaren mensen met beperkingen moeilijkheden op de werkplek zoals buitensluiting of onrechtvaardig gedrag. Omdat de omstandigheden op de werkplek een grote invloed hebben op de inclusie, houdt het onderzoek in dit proefschrift zich bezig met de bouwstenen van inclusie op de werkplek voor mensen met beperkingen. Meer specifiek biedt dit proefschrift drie grote bijdrages aan de theorie en wetenschappelijke onderzoeksliteratuur, in het domein van onderzoek naar mensen met beperkingen op de werkplek, binnen de literatuur van werk gerelateerd hulpgedrag $(\mathrm{OCB})$, en door het bekijken van klimaat onderzoek op verschillende niveaus. In hoofdstuk 2 bouwen we op de Reasoned Action Approach om te verhelderen hoe en wanneer stereotypen van werknemers met inclusief gedrag op het werk samenhangen. De resultaten laten zien dat de relatie tussen stereotypen en inclusief gedrag gemedieerd wordt door de attitudes ten aanzien van de tewerkstelling van mensen met beperkingen. Deze relatie hangt af van de hoogte van de werkdruk waardoor deze relatie sterker is wanneer de werkdruk laag is. Hoofdstuk 3 concentreert zich op de relatie tussen prosociale motivatie, inclusief klimaat en inclusief gedrag van de werknemers. Gebaseerd op de functional approach laat deze studie zien dat prosociale motivatie positief samenhangt met inclusief gedrag. Daarnaast wordt deze relatie gemodereerd door het inclusieve klimaat, een hoog inclusief klimaat blijkt sterk genoeg te zijn om het inclusief gedrag te leiden, ongeacht de individuele prosociale motivatie. In hoofdstuk 4 wordt de social support theory gebruikt om te laten zien dat het inclusief gedrag van een team effect heeft op het welbevinden van mensen met beperkingen. De resultaten tonen dat het inclusief gedrag van het team de negatieve emoties van mensen met beperkingen op het werk reduceert. In hoofdstuk 5 wordt besproken hoe de wetgeving de onthulling van een beperking kan beïnvloeden. Tegelijkertijd wordt de noodzaak geduid om vanuit een arbeids- en organisatie psychologisch perspectief verder dan wetgeving te kijken. Samengevat, de studies in dit proefschrift dragen bij tot een groter begrip wanneer mensen met beperkingen gaan werken. Immers, hoe meer bouwstenen aanwezig zijn, hoe meer inclusie op de werkplek er zal zijn. 

Dankwoord 
Dankwoord 


\section{Dankwoord}

Na een promotietraject van “ongeveer 4 jaar” mag ik eindelijk beginnen aan het dankwoord. Groot is dan ook mijn waardering naar iedereen die op zijn manier een steentje bijgedragen heeft aan mijn tijd als promovendus en docent bij WSP in Maastricht.

Beste promotoren, dank dat ik van jullie de kans heb gekregen om over zo een belangrijk onderwerp mijn proefschrift te mogen schrijven. Beste Fred, jij kon altijd onze besprekingen in de juiste banen leiden en ervoor zorgen dat iedereen met de neus in dezelfde richting naar buiten kwam. Beste Ute, ook al waren we het niet altijd eens, van jou heb ik geleerd wat het betekent om een echte wetenschapper te zijn. Dank voor al het academisch advies dat het niveau van het proefschrift en mezelf ten goede is gekomen. Beste Gemma, jouw inzicht in de doelgroep en rol als mediator heeft er voor gezorgd dat dit project is kunnen slagen, dank voor je feedback op alle niveaus.

Alicia en Bram, mijn paranimfen, fantastisch om twee zo hulpvaardige collega's aan mijn zijde te hebben staan. Alicia, na jaren kamergenoot te zijn, kennen we elkaars ins en outs. Gelukkig zijn we het altijd eens, nou ja over de belangrijke zaken dan toch... Super om bevriend te zijn met zo een waardevolle collega!! Bram, altijd goedgezind, bereid om te helpen en klaar met vinnige opmerking als je het niet verwacht. Fijn om met jou te kunnen samenwerken (en kebab te eten).

Abbas, aangezien je al heel wat Nederlands hebt geleerd, vertaal ik het niet in het Engels. Je was een fijne kamergenoot en hebt mij een goede dosis cultureel perspectief gegeven.

Robert en Sjir, de laatste kamer op de gang, maar de eerste plek waar ik terecht kon met al mijn vragen over onderzoek en onderwijs. Bedankt voor al jullie advies.

SarKasme, niemand die deze sport beoefent zoals jij Karlijn. We hebben veel gelachen, maar ook voor een iets serieuzer gesprek kon ik altijd bij je terecht.

Stefan, hier sta je dan, in mijn proefschrift! Zoals gewoonlijk begroet ik je met een grapje, maar het zijn vooral de vele gezellige momenten van vriendschap die ik me graag zal herinneren.

Beste Mariëlla en Trudy, dank voor alle goede zorgen, aangename gesprekken en onmisbare momenten van perspectief. 
Verder wil ik al mijn collega's van Work \& Social (Gerda, Loes, Vincent, Katharina, Marie, Fleurie, Katharina, Sarah, Fraukje, Suzanne, Phil, Martin, Joachim, Mart, Annet, Irma, Tobias, Louk, Sylvia, Annika, Arie, Margje, Herco, Rob, Kai, en Gerjo) bedanken voor de aangename tijd op kantoor, stimulerende lunches, verhelderende praatjes en verfrissende koffiepauzes.

Uiteraard vergeet ik mijn oud-collega's niet (Inge, Birthe, Maarten, Henna, Sanne, Pia, en Dilana). Jullie hebben een onuitwisbare indruk op me achtergelaten in de tijd die we hier samen werkten en daar denk ik graag aan terug.

Beste Henny, als ambassadeur van de inclusieve organisatie binnen UWV, wil ik jou bedanken om aan dit vooraanstaande project te mogen deelnemen, alsook voor de motiverende tips en gesprekken tijdens talloze vergaderingen. Verder bedank ik graag het Slotervaart ziekenhuis en Albert Heijn om mij toegang te geven tot jullie organisaties om er data te kunnen verzamelen.

Beste Jo, het is al van 2005 geleden dat ik onder jouw begeleiding als stagiair mocht aanvatten. $\mathrm{Na}$ afloop ben jij één van de drijvende krachten geweest in mijn beslissing om verder te gaan als student Psychologie. Daar ben ik je nog steeds dankbaar voor. Fijn dat we nog steeds contact hebben, die heerlijke lunches moeten we zeker in ere houden.

Beste Kris, Stefan, Dirk, Joeri, Jan, Rik, Joachim, Wouter, John en Job, ik ben trots dat ik jullie mijn vrienden mag noemen. Bedankt voor alle leuke momenten waarbij het werk even vergeten mag worden.

Marleen en Dirk, dankjewel voor de gezellige weekendjes in Zaandam, maar in dit geval vooral voor die prachtige cover.

Wim en Marianne, bij jullie heb ik vanaf het begin gevoeld dat ik bij de familie hoor, dank voor alle steun en goede zorgen voor ons gezinnetje.

Mama, het is dankzij jouw steun en overtuiging dat ik de mogelijkheid heb gehad om (lang) te studeren, zelfs tot in Santa Cruz (California). Alleen daarom ben ik als promovendus kunnen beginnen. Bedankt voor je liefde, vertrouwen en dat je altijd voor mij (ons) klaar staat. 
Lieve Dorine, tijdens mijn tijd als promovendus in Maastricht hebben we samen een huis gekocht, twee prachtige kinderen gekregen en zijn we getrouwd. Dankjewel voor alle steun in deze drukke periode. Ik kan me niemand anders voorstellen om elke dag naar huis te komen. 

Curriculum Vitae 
Curriculum Vitae 


\section{Curriculum Vitae}

Philippe Nelissen was born on January 9, 1982 in Riemst, Belgium. He attended the SintLambertuscollege in Bilzen, where he graduated in 2000. He graduated with distinction at the University of Applied Sciences XIOS Hasselt in 2005, studying Social Work. Later that year he enrolled at Maastricht University to continue his studies in the field of Psychology. During the first two years of his bachelor in Psychology he concurrently obtained a Teaching Qualification degree at PCVO in Diepenbeek. After having spent most of his third bachelor year abroad at the University of Santa Cruz California (UCSC), he graduated and received his master's degree in Work and Organizational Psychology in Maastricht in 2009. In 2010 Philippe started to work on his dissertation as a PhD-candidate on inclusive organizations in the department of Work and Social Psychology at the Faculty of Psychology and Neuroscience of Maastricht University. Currently, he works as a lecturer within the same department. 



\section{Publications}


Publications 


\section{Publications}

Nelissen, P. T. J. H., Hülsheger, U. R., van Ruitenbeek, G. M. C., \& Zijlstra, F. R. H. (submitted). With a little help from my team: Well-Being of people with disabilities at work.

Nelissen, P. T. J. H., Hülsheger, U. R., van Ruitenbeek, G. M. C., \& Zijlstra, F. R. H. (2016). Lending a helping hand at work: A multilevel investigation of prosocial motivation, inclusive climate and inclusive behavior. Journal of Occupational Rehabilitation, 1-10. http: / / doi.org/10.1007/s10926-016-9680-z

Nelissen, P. T. J. H., Hülsheger, U. R., van Ruitenbeek, G. M. C., \& Zijlstra, F. R. H. (2016). How and when stereotypes relate to inclusive behavior toward people with disabilities. The International Journal of Human Resource Management, 27(14), 1610-1625. http: / / doi.org/10.1080/09585192.2015.1072105

Nelissen, P. T. J. H., Vornholt, K., Van Ruitenbeek, G. M. C., Hülsheger, U. R., \& Uitdewilligen, S. (2014). Disclosure or nondisclosure - Is this the question? Industrial and Organizational Psychology, 7(2), 231-235. http://doi.org/10.1111/iops.12138

Nijhuis, F. J. N., Zijlstra, F. R. H., van Ruitenbeek, G. M. C., Mulder, M. J. G. P., \& Nelissen, P. T. J. H. (2014). Eindrapportage Wajongproject "Een passende baan bij het Slotervaartziekenhuis." Universiteit Maastricht 


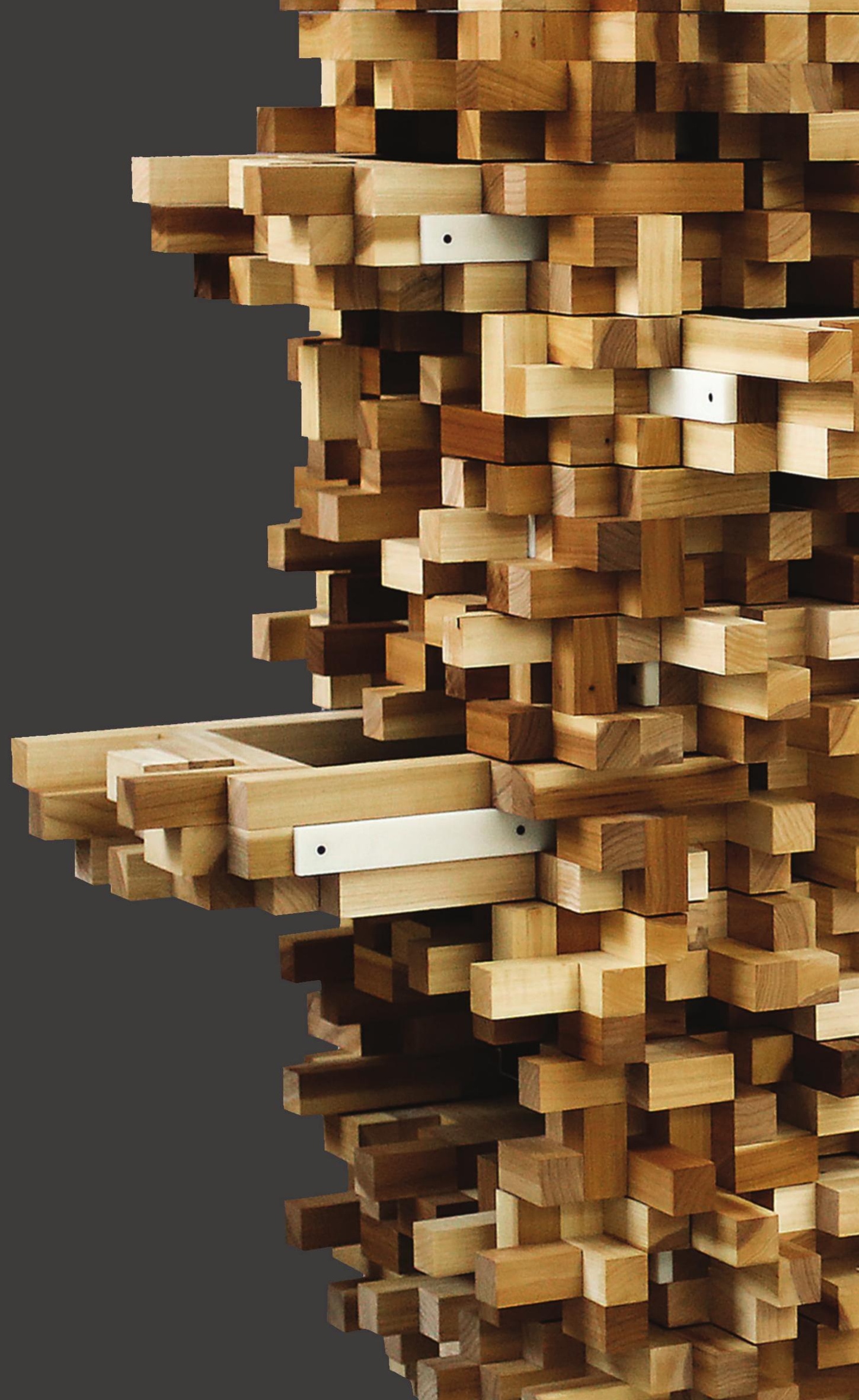

